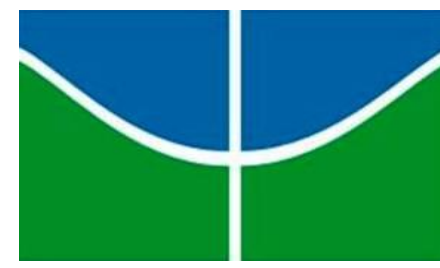

UNIVERSIDADE DE BRASÍLIA INSTITUTO DE CIÊNCIAS BIOLÓGICAS DEPARTAMENTO DE BOTÂNICA PROGRAMA DE PÓS-GRADUAÇÃO EM BOTÂNICA

Leandro Carvalho Ribeiro

Fatores ambientais e a germinação de espécies arbóreas do Brasil Central e de áreas disjuntas da Amazônia no bioma Cerrado

\author{
Brasília - DF \\ 2014
}


Leandro Carvalho Ribeiro

Fatores ambientais e a germinação de espécies arbóreas do Brasil Central e de áreas disjuntas da Amazônia no bioma Cerrado

Tese apresentada ao Programa de Pós-Graduação em Botânica da Universidade de Brasília, como parte dos requisitos necessários à obtenção do título de Doutor em Botânica.

Orientador: Prof. Dr. Fabian Borghetti

Brasília - DF

2014 


\title{
Fatores ambientais e a germinação de espécies arbóreas do Brasil Central e de áreas disjuntas da Amazônia no bioma Cerrado
}

\author{
Banca Examinadora
}

Prof. Dr. Fabian Borghetti

Orientador

Prof. Augusto César Franco, $\mathrm{PhD}$
Examinador interno

Prof. José Felipe Ribeiro, PhD

Examinador externo

\section{Dulce Alves da Silva, PhD}

Examinador externo

Eduardo Rogério Moribe Barbosa, $\mathrm{PhD}$

Examinador externo

Profa. Dra. Cristiane da Silva Ferreira

Suplente 
Dedico este trabalho aos meus pais, irmãos, amigos e a todos aqueles que contribuíram de alguma forma para a realização e o sucesso do mesmo. 
"Procure ser uma pessoa de valor, em vez de procurar ser uma pessoa de sucesso. O sucesso é consequência."

\section{Albert Einsten}




\section{AGRADECIMENTOS}

Agradeço, primeiramente, ao meu orientador, Prof. Fabian Borghetti, pelas conversas, pelos ensinamentos, pela franqueza e, especialmente, por seguir confiando em mim, no meu potencial e no sucesso da continuidade de nossa parceria.

À Coodenação de Aperfeiçoamento de Pessoal de Nivel Superior (CAPES), pelo apoio financeiro concedido, nos âmbitos nacional (PNADB - 451/2010) e internacional (CAPES/NUFFIC, Processo 3931-13-7), sem o qual partes consideráveis deste trabalho não seriam possíveis de serem apresentados da forma em que estão.

Ao Prof. Augusto César Franco, por sua dedicação para comigo nos momentos oportunos, para que fosse possível a realização do meu trabalho de campo na Amazônia; pelas sérias e valiosas sugestões feitas nas defesas de projeto, dos resultados parciais e da tese.

Ao Dr. José Carlos S. Silva, pelas valiosas sugestões feitas na defesa de projeto.

Ao Prof. Paulo Câmara, pelas valiosas sugestões feitas na defesa de projeto.

À Profa. Dra. Cristiane Ferreira, pelas palavras sempre carinhosas e oportunas dirigidas a $\operatorname{mim}$.

À Dra. Dulce Alves da Silva, pelas ótimas conversas, pela satisfação da companhia durante minha jornada na Holanda e, sobretudo, pelas ótimas sugestões dadas para a melhoria deste trabalho, até sua versão final.

Às Professoras Veridiana Scudeller e Maria Tereza Piedade pelo empenho e por todo o apoio necessário à realização dos meus trabalhos de campo na Amazônia.

Ao Prof. Rodrigo de Oliveira, pela amizade, companheirismo e apoio durante minha estadia em Boa Vista, Roraima.

Ao Dr. Reinaldo Imbrózio, pelas valiosas conversas e por todo apoio logístico, profissional e pessoal durante a realização do meu trabalho de campo em Boa Vista. 
Aos colegas Hugo e Heleno, pela fundamental ajuda durante os trabalhos de campo em Roraima.

Ao colega Wando, pela fundamental ajuda durante os trabalhos de campo nos cerrados do Distrito Federal.

Ao amigo Edvar Alves, pela imprescindível ajuda durante os trabalhos de campo nos cerrados de Goiás.

Ao Prof. Dr. Frank van Langevelde, pela ótima receptividade em Wageningen University, na Holanda, pelas boas conversas e pelas sugestões dadas para a melhoria deste trabalho.

Ao amigo Dr. Eduardo Moribe, pelo apoio dado a mim durante minha passagem pela Holanda, pela ótima receptividade em sua casa, na cidade de Leiden, pelas conversas descontraídas sobre futebol, mas principalmente pelas valiosas discussões científicas, essenciais para a realização deste trabalho e de outros que virão.

Aos colegas Joost, Sintayehu e Zheng pelas ótimas conversas e pela excelente receptividade no Grupo de Pesquisas em Ecologia de Wageningen University.

Aos colegas "holandeses" do futebol pelas ótimas horas de diversão, pela parceria durante os jogos e por acreditarem no meu "potencial futebolístico".

Aos colegas do Laboratório de Termobiologia, Patrícia, Anabele, Desirée, Grazy, Bruno, Francisco, Manoel, Daniel e Antônio pelo excelente convívio, pelas ótimas conversas e principalmente, pelos momentos de descontração durante os famosos "Happy Hours da Termo".

À querida amiga, "mãezona", Dona Odete, pelas boas conversas, pelos ótimos conselhos, pelos almoços fantásticos, pelos mimos e, principalmente, pela acolhida.

Ao Dr. José Felipe Ribeiro, pelas sugestões dadas para a melhoria deste trabalho, até a sua versão final. 
Aos professores Paulo Câmara, Rosane Collevatti, Felipe Ribeiro e Micheline Carvalho, que contribuíram muito para o enriquecimento do meu conhecimento.

Por último, mas não menos importante, à minha família, por toda a dedicação, apoio, bons exemplos, conselhos e ensinamentos dedicados a mim, durante minha formação ética e moral. 


\section{RESUMO}

O Cerrado é o segundo maior bioma do Brasil e sua área nuclear ocorre no Planalto Central. Este bioma também ocorre em áreas disjuntas na região Norte do país, as quais são denominadas savanas amazônicas, destacando-se aquelas do estado de Roraima, que ocupam as maiores áreas de cerrado na Amazônia brasileira. Devido à ampla ocorrência geográfica do Cerrado, sua vegetação está exposta a diferentes gradientes de condições ambientais, e fatores como amplitude térmica elevada, déficit hídrico sazonal e ocorrência de fogo têm sido considerados os principais filtros ambientais que determinam a composição de espécies no bioma. Entretanto, os efeitos desses filtros sobre a capacidade de recrutamento, a partir de sementes, continuam pouco compreendidos. Em função das diferenças ambientais locais existentes entre os cerrados de Roraima e os do Planalto Central brasileiro, que sinalizam para uma maior tolerância a estresses ambientais para espécies de Roraima, o objetivo deste estudo foi investigar como a umidade reduzida, o déficit hídrico, choques térmicos e altas temperaturas afetam a estratégia de germinação de sementes de três espécies arbóreas (Bowdichia virgilioides, Curatella americana e Anadenanthera peregrina) que ocorrem em ambos os locais. De modo geral, sementes das populações ocorrentes nos cerrados de Roraima apresentaram maior tolerância à dessecação, ao déficit hídrico e aos choques térmicos do que sementes das populações dos cerrados do Brasil Central. Além disso, sementes das populações de Roraima também germinaram em faixa de temperatura mais ampla que aquelas do Brasil Central. Os tratamentos de choques térmicos e dessecação não alteraram de maneira significativa a velocidade de germinação de nenhuma espécie, independente do ambiente de origem da população. Por outro lado, o déficit hídrico crescente tornou a germinação das espécies significativamente mais lenta, independente do ambiente de origem da população. Modelos relacionados a mudanças climáticas prevêem a intensificação 
nos níveis de alguns estresses ambientais (aumento no déficit hídrico do solo, maiores temperaturas máximas e aumento na frequência de fogo) em diversas regiões onde o bioma Cerrado ocorre, os quais podem influenciar diretamente o processo germinativo. Considerando tais aspectos e de acordo com os resultados descritos para as três espécies deste estudo, mudanças ambientais serão, possivelmente, mais limitantes ao recrutamento de espécies, por sementes, às populações dos cerrados do Brasil Central.

Palavras-chave: Cerrado, Estresses Abióticos, Germinação, Planalto Central brasileiro, Savana Amazônica, Sementes. 


\section{ABSTRACT}

The Cerrado is the second largest Brazilian biome and its core area occurs in the Central Plateau. This biome also occurs in disjunct areas in the Northern region, which are named Amazonian savannas. In Roraima state are found the largest savanna areas of the Brazilian Amazon. Due to its wide geographical distribution in the Brazilian territory, the Cerrado occurs across a wide range of environmental conditions, and factors such as high temperatures, seasonal drought and fire have been considered filters determining species composition in the biome. However, the effects of these filters on the recruitment capability, from seeds, remain poorly understood. Due to the local environmental differences among Brazilian Central Plateau and Roraima cerrados, which point to a greater tolerance to environmental stress for Roraima species, the aim of this study was to investigate how the low moisture, drought, heat shocks and high temperatures affect the germination parameters of three woody species (Bowdichia virgilioides, Curatella americana e Anadenanthera peregrina) from both sites. Overall, seeds occurring in the Roraima populations showed higher tolerance to desiccation, drought and heat shocks than seeds occurring in the Brazilian Central Plateau. Furthermore, Roraima species also germinated in a wider temperature range. Heat shocks and desiccation did not consistently change germination rate for none species of this study, regardless of the population origin. On the other hand, increasing drought made seed germination consistently slower, for both Roraima and Centrau Plateau populations. Climate change models predict increases for some environmental stress (soil moisture redution, higher maximum temperatures and fire frequencies) within the geographical area of the Cerrado biome, which may have a direct effect on the seed germination. Considering these aspects and also according to the results presented for the three species of this study, 
environmental changes will be more limiting to the plant recruitment, from seeds, for Central Plateau populations.

Key words: Cerrado, Abiotic Stress, Germination, Brazilian Central Plateau, Amazon Savanna, Seeds. 


\section{LISTA DE TABELAS}

Tabela 1. Espécies estudadas, com suas respectivas informações fenológicas (fenologia foliar e dispersão) e fisionomias de ocorrência..

Tabela 2. Massa fresca, massa seca e conteúdo de água de sementes de pares conespecíficos ocorrentes nos cerrados do Brasil Central e de Roraima. (Dados expressos como média \pm desvio padrão)

Tabela A1. Efeitos do ambiente de origem da população (A), do conteúdo de água (C) e da massa da semente (M) sobre a resposta germinativa de sementes de pares conespecíficos dos cerrados de Roraima e do Brasil Central submetidas à dessecação. Os valores de significância estatística foram obtidos através do teste da razão de verossimilhança, em que os desvios com e sem cada termo do modelo foram comparados. O símbolo " - " representa as variáveis não incluídas no modelo 88

Tabela A2. Efeitos do ambiente de origem da população (A), do potencial osmótico (P) e da massa da semente (M) sobre a resposta germinativa de sementes de pares conespecíficos dos cerrados de Roraima e do Brasil Central submetidas ao déficit hídrico. Os valores de significância estatística foram obtidos através do teste da razão de verossimilhança, em que os desvios com e sem cada termo do modelo foram comparados. O símbolo " - " representa as variáveis não incluídas no modelo

Tabela A3. Efeitos do ambiente de origem da população (A), da temperatura (Tp), do tempo de exposição $(\mathrm{T})$ e da massa da semente $(\mathrm{M})$ sobre a resposta germinativa de sementes de pares conespecíficos dos cerrados de Roraima e do Brasil Central submetidas a choques térmicos. Os valores de significância estatística foram obtidos através do teste da razão de verossimilhança, em que os desvios com e sem cada termo do modelo foram comparados. $\mathrm{O}$ símbolo “ - " representa as variáveis não incluídas no modelo. 90

Tabela A4. Efeitos do ambiente de origem da população (A), da temperatura (Tp) e da massa da semente (M) sobre a resposta germinativa, em temperaturas crescentes, de sementes de pares conespecíficos dos cerrados de Roraima e do Brasil Central. Os valores de significância estatística foram obtidos através do teste da razão de verossimilhança, em que os desvios com 
e sem cada termo do modelo foram comparados. O símbolo " - " representa as variáveis não incluídas no modelo... 


\section{LISTA DE FIGURAS}

Figura 1. Distribuição geográfica do bioma Cerrado (Adaptado de Henriques 2005). 03

Figura 2. Visão geral da paisagem de uma savana do Planalto Central brasileiro, em Ipameri, Goiás (A) e de uma savana de Boa Vista, Roraima (B) Fonte: Elaborada pelo autor. 21

Figura 3. Precipitação média mensal ocorrente entre os anos 2004 e 2013 nas áreas de coleta de sementes, em Boa Vista/RR (A), Brasília/DF (B) e Ipameri/GO (C). Fonte: Instituto Nacional de Meteorologia, 2014.

Figura 4. Espécies selecionadas para o estudo, em fase reprodutiva. Bowdichia virgilioides (A), Curatella americana (B) e Anadenanthera peregrina (C) Fonte: Elaborada pelo autor. 24

Figura 5. Sementes de Bowdichia virgilioides (A e D), Curatella americana (B e E) e Anadenanthera peregrina (C e F) coletadas nos cerrados de Roraima (A, B e C) e do Planalto Central brasileiro (D, E e F). Fonte: Elaborada pelo autor.

Figura 6. Germinação (média \pm desvio padrão) de sementes de populações de Bowdichia virgilioides submetidas à dessecação. Valores representados pela mesma letra, sobre as barras, não diferem entre si pelo teste de Sidak $(\mathrm{P}<0,05)$ 34

Figura 7. Germinação (média \pm desvio padrão) de sementes de populações de Anadenanthera peregrina submetidas à dessecação. Valores representados pela mesma letra, sobre as barras, não diferem entre si pelo teste de Sidak $(\mathrm{P}<0,05)$.

Figura 8. Germinação (média \pm desvio padrão) de sementes de populações de Curatella americana submetidas à dessecação. Valores representados pela mesma letra, sobre as barras, não diferem entre si pelo teste de Sidak $(\mathrm{P}<0,05)$.

Figura 9. Tempo médio de germinação (média \pm desvio padrão) de sementes de Bowdichia virgilioides submetidas à dessecação. Valores representados pela mesma letra, sobre as barras, não diferem entre si pelo teste de Sidak $(\mathrm{P}<0,05)$. 
Figura 10. Tempo médio de germinação (média \pm desvio padrão) de sementes de Curatella americana submetidas à dessecação. Valores representados pela mesma letra, sobre as barras, não diferem entre si pelo teste de Sidak $(\mathrm{P}<0,05)$.

Figura 11. Tempo médio de germinação (média \pm desvio padrão) de sementes de Anadenanthera peregrina $(\mathrm{C})$ submetidas à dessecação. Valores representados pela mesma letra, sobre as barras, não diferem entre si pelo teste de Sidak $(\mathrm{P}<0,05)$ 37

Figura 12. Germinação (média \pm desvio padrão) de sementes de populações de Bowdichia virgilioides submetidas ao déficit hídrico. Valores representados pela mesma letra, sobre as barras, não diferem entre si pelo teste de Sidak $(\mathrm{P}<0,05)$.

Figura 13. Germinação (média \pm desvio padrão) de sementes de populações de Anadenanthera peregrina submetidas ao déficit hídrico. Valores representados pela mesma letra, sobre as barras, não diferem entre si pelo teste de Sidak $(\mathrm{P}<0,05)$

Figura 14. Germinação (média \pm desvio padrão) de sementes de populações de Curatella americana submetidas ao déficit hídrico. Valores representados pela mesma letra, sobre as barras, não diferem entre si pelo teste de Sidak $(\mathrm{P}<0,05)$.

Figura 15. Tempo médio de germinação (média \pm desvio padrão) de sementes de Bowdichia virgilioides submetidas ao déficit hídrico. Valores representados pela mesma letra, sobre as barras, não diferem entre si pelo teste de Sidak $(\mathrm{P}<0,05)$

Figura 16. Tempo médio de germinação (média \pm desvio padrão) de sementes de Curatella americana submetidas ao déficit hídrico. Valores representados pela mesma letra, sobre as barras, não diferem entre si pelo teste de Sidak $(\mathrm{P}<0,05)$.

Figura 17. Tempo médio de germinação (média \pm desvio padrão) de sementes de Anadenanthera peregrina submetidas ao déficit hídrico. Valores representados pela mesma letra, sobre as barras, não diferem entre si pelo teste de Sidak $(\mathrm{P}<0,05)$.

Figura 18. Germinação (média \pm desvio padrão) de sementes de populações de Bowdichia virgilioides submetidas a choques térmicos. Valores representados pela mesma letra, sobre as barras, não diferem entre si pelo teste de Sidak $(\mathrm{P}<0,05)$. 
Figura 19. Germinação (média \pm desvio padrão) de sementes de populações de Curatella americana submetidas a choques térmicos. Valores representados pela mesma letra, sobre as barras, não diferem entre si pelo teste de Sidak $(\mathrm{P}<0,05)$.

Figura 20. Germinação (média \pm desvio padrão) de sementes de populações de Anadenanthera peregrina submetidas a choques térmicos. Valores representados pela mesma letra, sobre as barras, não diferem entre si pelo teste de Sidak $(\mathrm{P}<0,05)$ 45

Figura 21. Tempo médio de germinação (média \pm desvio padrão) de sementes de Bowdichia virgilioides submetidas a choques térmicos. Valores representados pela mesma letra, sobre as barras, não diferem entre si pelo teste de Sidak $(\mathrm{P}<0,05)$.

Figura 22. Tempo médio de germinação (média \pm desvio padrão) de sementes de Curatella americana submetidas a choques térmicos. Valores representados pela mesma letra, sobre as barras, não diferem entre si pelo teste de Sidak $(\mathrm{P}<0,05)$.

Figura 23. Tempo médio de germinação (média \pm desvio padrão) de sementes de Anadenanthera peregrina submetidas a choques térmicos. Valores representados pela mesma letra, sobre as barras, não diferem entre si pelo teste de Sidak $(\mathrm{P}<0,05)$.

Figura 24. Germinação (média \pm desvio padrão), em temperaturas crescentes, de sementes de populações de Bowdichia virgilioides. Valores representados pela mesma letra, sobre as barras, não diferem entre si pelo teste de Sidak $(\mathrm{P}<0,05)$.

Figura 25. Germinação (média \pm desvio padrão), em temperaturas crescentes, de sementes de populações de Curatella americana. Valores representados pela mesma letra, sobre as barras, não diferem entre si pelo teste de Sidak $(\mathrm{P}<0,05)$.

Figura 26. Germinação (média \pm desvio padrão), em temperaturas crescentes, de sementes de populações de Anadenanthera peregrina. Valores representados pela mesma letra, sobre as barras, não diferem entre si pelo teste de $\operatorname{Sidak}(\mathrm{P}<0,05)$. 50

Figura 27. Tempo médio de germinação (média \pm desvio padrão), em temperaturas crescentes, de sementes de Bowdichia virgilioides. Valores representados pela mesma letra, sobre as barras, não diferem entre si pelo teste de Sidak $(\mathrm{P}<0,05)$. 
Figura 28. Tempo médio de germinação (média \pm desvio padrão), em temperaturas crescentes, de sementes de Curattela americana. Valores representados pela mesma letra, sobre as barras, não diferem entre si pelo teste de Sidak $(\mathrm{P}<0,05)$

Figura 29. Tempo médio de germinação (média \pm desvio padrão), em temperaturas crescentes, de sementes de Anadenanthera peregrina. Valores representados pela mesma letra, sobre as barras, não diferem entre si pelo teste de Sidak $(\mathrm{P}<0,05)$. 


\section{SUMÁRIO}

1. Introdução. 01

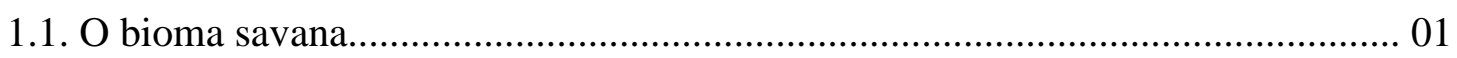

1.2. O bioma Cerrado: origem, evolução e distribuição atual da vegetação................ 02

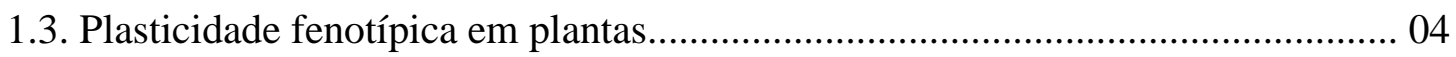

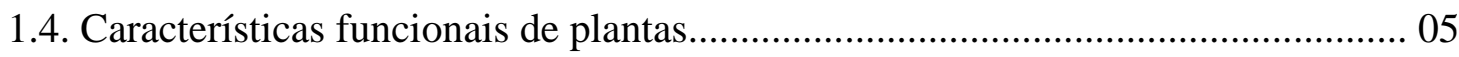

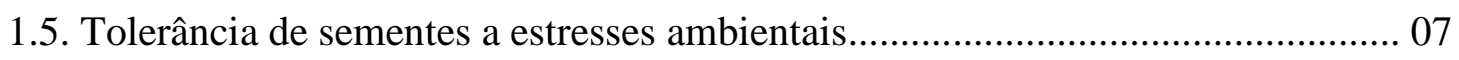

1.5.1. Tolerância à dessecação................................................................. 08

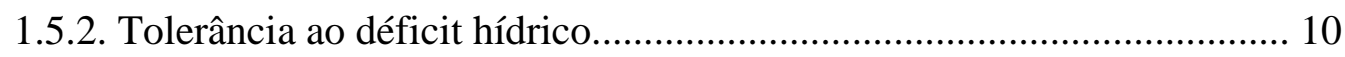

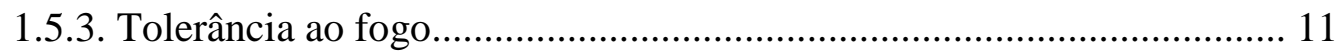

1.5.4. Germinação em temperaturas altas....................................................... 13

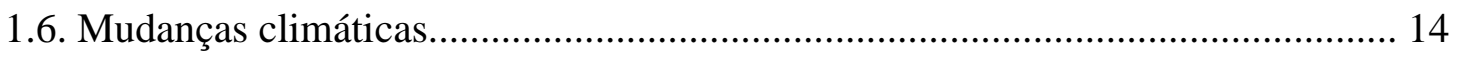

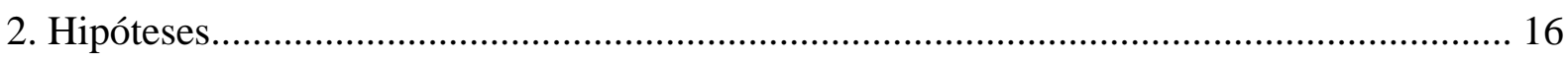

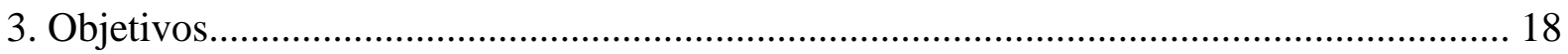

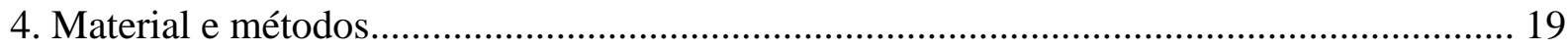

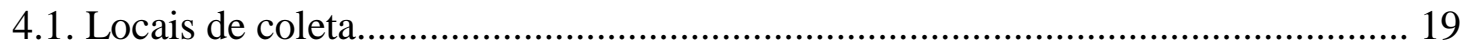

4.2. Seleção de espécies e coleta de sementes.......................................................... 23

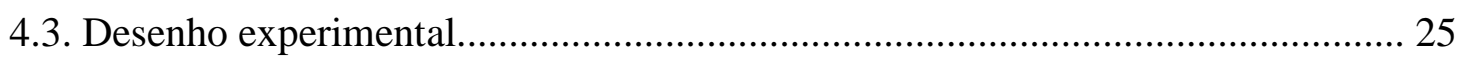

4.4. Massa fresca, massa seca e conteúdo de água inicial de sementes...................... 26

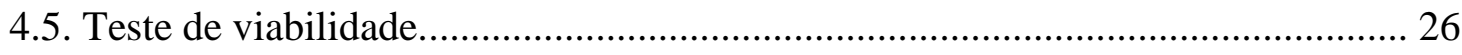

4.6. Germinação de sementes submetidas à dessecação............................................... 27

4.7. Germinação de sementes submetidas ao déficit hídrico..................................... 28

4.8. Germinação de sementes submetidas a choques térmicos.................................. 28

4.9. Germinação de sementes em temperaturas crescentes....................................... 29

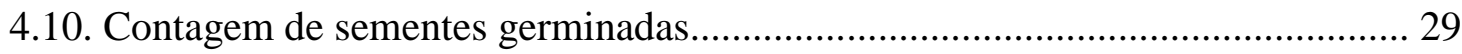


4.11. Medidas de Germinação..................................................................................... 30

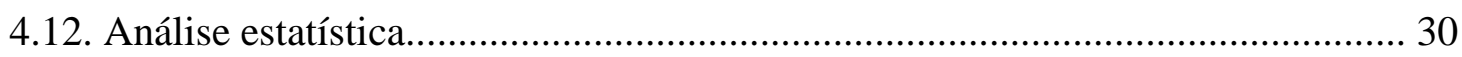

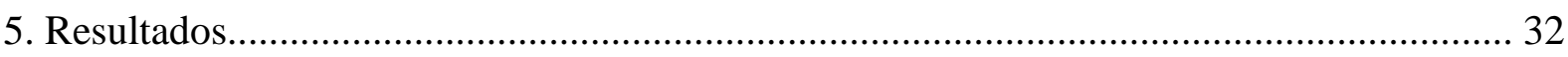

5.1. Massa fresca, massa seca e conteúdo de água inicial de sementes...................... 32

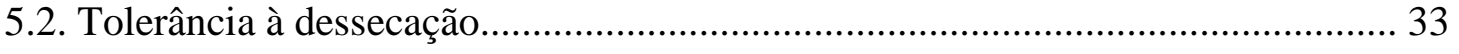

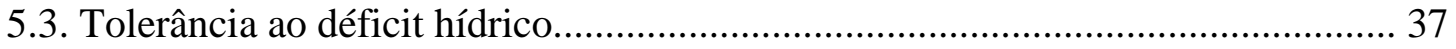

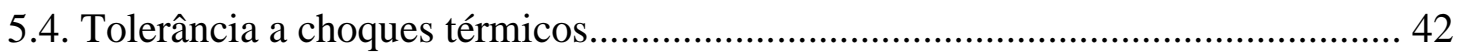

5.5. Germinação em temperaturas crescentes........................................................ 48

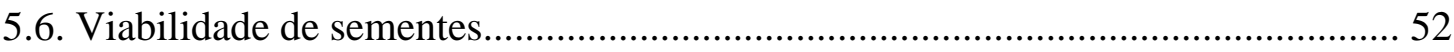

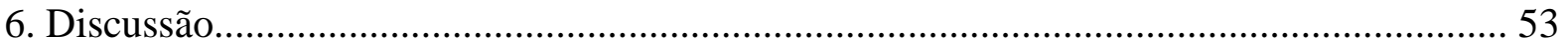

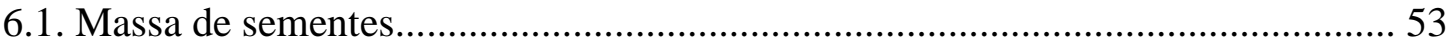

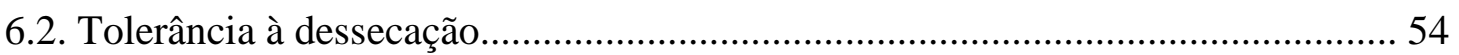

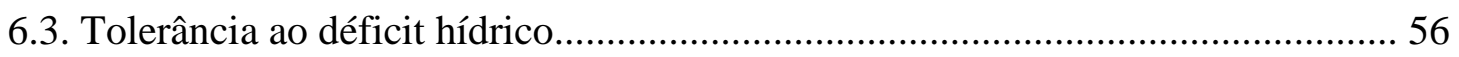

6.4. Tolerância a choques térmicos..................................................................... 57

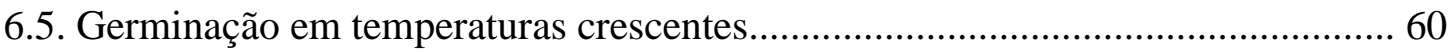

6.6. Estresses ambientais e tempo de germinação......................................................... 62

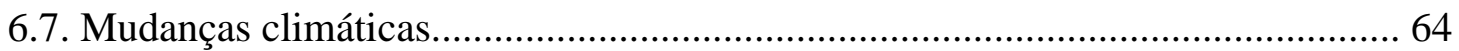

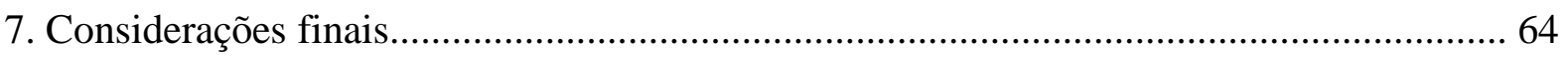

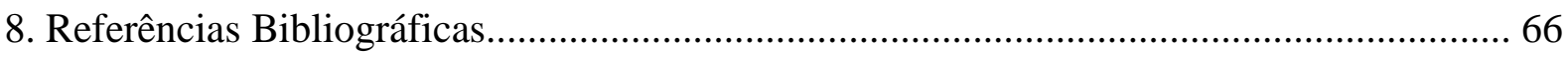

Apêndice 


\section{Introdução}

\subsection{O bioma savana}

As savanas são biomas amplamente distribuídos ao redor do mundo (Jeltsch et al. 2000) e ocorrem em um amplo gradiente de condições climáticas (Staver et al. 2011a). Estes biomas são usualmente descritos como mosaicos de paisagens nos quais, do ponto de vista fisionômico, observam-se a ocorrência de estrato herbáceo contínuo, com a presença de estrato arbóreo-arbustivo que pode variar em proporção, no espaço e no tempo (Scholes \& Archer 1997; Wiegand et al. 2005). Na maioria das savanas também podem ser encontrados fragmentos de formações florestais, onde há formação de dossel contínuo e pouca ou nenhuma ocorrência de espécies herbáceas (Sarmiento 1992).

Tem sido amplamente discutido que essa variação de paisagens ou fitofisionomias ocorrente em savanas está sob a influência de fatores ambientais (Ruggiero et al. 2002; Bond 2008; Staver et al. 2011a). Em escala macroclimática, tais fitofisionomias estão expostas a regimes de precipitação similares (Furley 1999; Hirota et al. 2011). Por outro lado, fitofisionomias mais abertas (savânicas e campestres) tendem a estar expostas a condições microambientais mais severas do que aquelas mais fechadas (florestais), tais como menor umidade relativa, amplitudes térmicas mais elevadas, maior déficit hídrico sazonal (OliveiraFilho \& Ratter 2002) e maior ocorrência de queimadas (Bond et al. 2005; Hoffmann et al. 2012). Assim, essa natureza conspícua das savanas, tanto em relação a fatores ambientais, quanto em relação às variadas formas de vida de suas plantas, torna estes biomas altamente interessantes sob uma perspectiva ecológica. 


\subsection{O bioma Cerrado: origem, evolução e distribuição atual da vegetação}

O Cerrado é o segundo maior bioma brasileiro em área, sendo superado apenas pela Floresta Amazônica e abriga, em seus limites, três grandes bacias hidrográficas da América do Sul: Araguaia-Tocantins, Prata e São Francisco (Ribeiro \& Walter 2008). A área nuclear do Cerrado ocorre essencialmente no Planalto Central brasileiro, que abrange todos os estados da região Centro-Oeste, e em parte de alguns estados das regiões Sudeste, Nordeste e Norte (Figura 1). Entretanto, sítios disjuntos de savanas também ocorrem nos estados do Pará, Amazonas, Amapá e Roraima (Figura 1), os quais se entrelaçam com florestas estacionais semidecíduas e são comumente denominadas "savanas amazônicas", cobrindo uma área de cerca de 7\% do total da Amazônia Brasileira (Ratter et al. 2003).

As savanas localizadas em Roraima (localmente denominadas de "lavrados") constituem-se como as maiores áreas de savanas da Amazônia brasileira (aproximadamente $41000 \mathrm{~km}^{2}$ ), representando parte de um grande complexo de savanas adjacentes situadas ao Norte da Amazônia, que também inclui parte dos Llanos venezuelanos e o complexo paisagístico Rupununi, na Guiana (Barbosa et al. 2007). Os lavrados de Roraima possuem alta similaridade florística com as formações savânicas dos Llanos e do complexo Rupununi, porém menor riqueza e diversidade de espécies do que os cerrados da área nuclear (Ratter et al. 2003). 


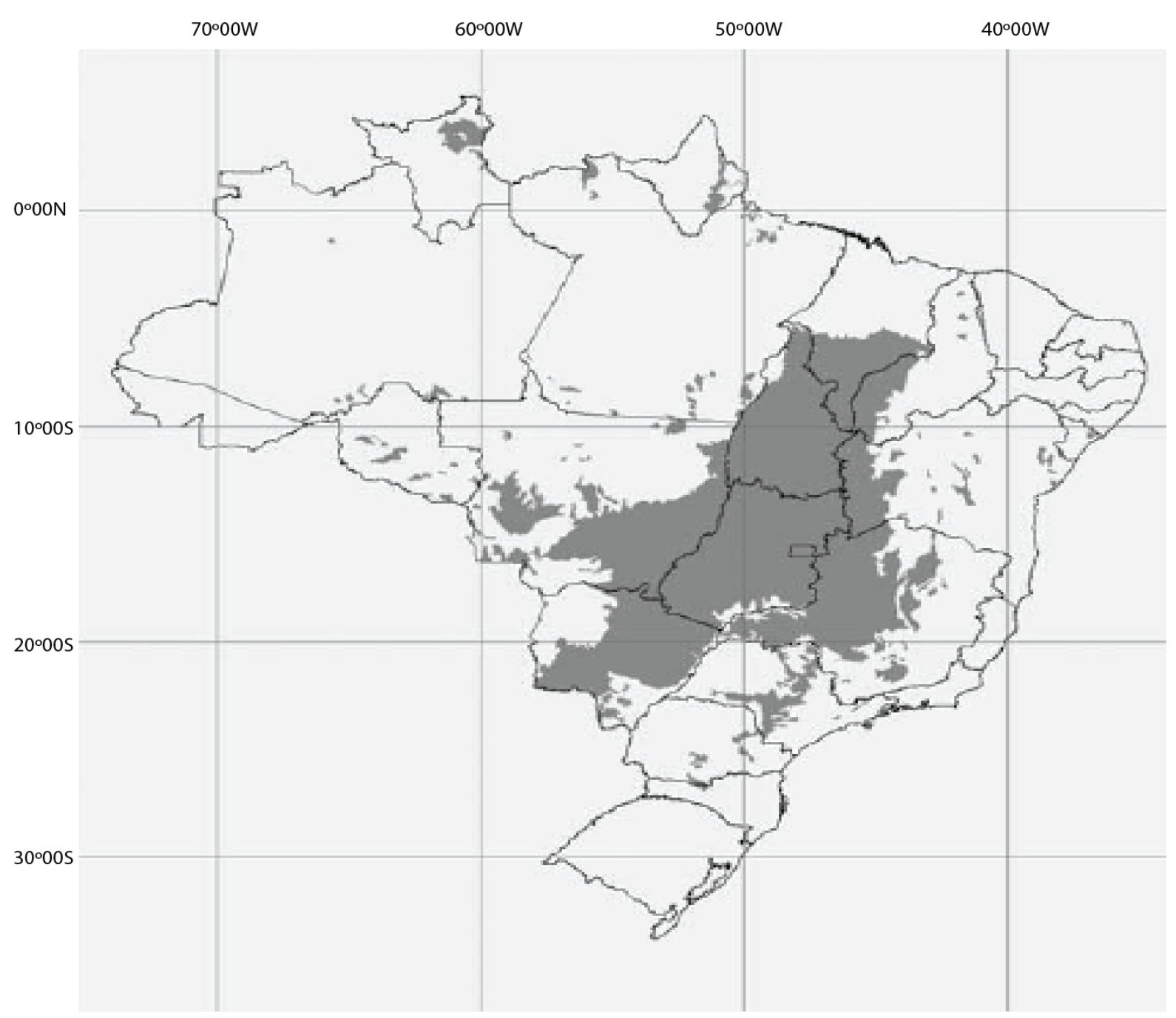

Figura 1. Distribuição geográfica do bioma Cerrado (Adaptado de Henriques 2005).

Considerando a origem e a distribuição atual das savanas brasileiras, estudos recentes indicam que a ocorrência do último período interglacial (120 mil anos AP), ligeiramente mais quente e seco ao norte da Amazônia, favoreceu a formação de savanas nesta região, as quais parecem ter sido isoladas pela expansão da floresta tropical entre este período e o início do último máximo glacial (21 mil anos AP) (Toledo \& Bush 2007; Werneck et al. 2012). Em relação ao Planalto Central brasileiro, estudos baseados em registros palinológicos apontam a existência de um período glacial seco que durou até aproximadamente 6000 mil anos AP, e que contribuiu para o predomínio de formações savânicas nesta região (Salgado-Labouriau et 
al. 1998; Behling 2003). Assim, mudanças nas características ambientais em escala regional, tais como redução nos níveis de umidade e aumento na frequência de queimadas, em função de períodos glaciais do Pleistoceno e do Holoceno, favoreceram a expansão de espécies adaptadas a climas mais secos (Salgado-Labouriau 1997; Behling \& Hooghiemstra 2000; Ledru 2002; Pinheiro \& Monteiro 2010).

\subsection{Plasticidade fenotípica em plantas}

De modo geral, uma espécie vegetal pode viver em ambientes heterogêneos e, dessa forma, apresentar ampla plasticidade de respostas morfo-funcionais em função das características do seu ambiente de ocorrência, denominada plasticidade fenotípica (Berg et al. 2005). A plasticidade fenotípica pode ser considerada o mecanismo de adaptação mais importante em espécies vegetais (De Jong 2005; Nicotra et al. 2010) e, quando combinada com a heterogeneidade de habitats, pode resultar em genótipos especializados e geneticamente distintos dentro de uma mesma espécie - os ecótipos - pela ação da seleção natural (Linhart \& Grant 1996; Hufford \& Mazer 2003). Uma vez formados, ecótipos podem aumentar suas diferenças genéticas em um processo que culminaria com eventos de especiação (Lortie \& Aarssen 1996; Black-Samuelsson \& Andersson 1997).

As diferenças entre espécies vegetais que ocupam ambientes contrastantes podem ser resultados de uma linhagem de espécies divergentes, da plasticidade de resposta a cada ambiente ou mesmo de uma pré-adaptação dos genótipos a um dado fator de seleção ou condição ambiental (Reich et al. 2003). Uma forma de distinguir como fatores ambientais estão envolvidos na variação natural encontrada em características funcionais é através do estudo de espécies filogeneticamente relacionadas e que ocupam ambientes contrastantes (Hoffmann \& Franco 2008; Barros et al. 2012). Sob tais aspectos, têm sido realizados muitos 
estudos ecofisiológicos utilizando-se espécies filogeneticamente similares, objetivando-se identificar e caracterizar as diferenças entre as mesmas, tanto em relação à utilização de recursos do meio quanto em relação à resposta funcional em diferentes condições de estresse (Hoffmann \& Franco 2003; Hoffmann et al. 2004; Lemos-Filho et al. 2008; Barros et al. 2012). De modo geral, tais estudos têm sido realizados utilizando-se espécies arbóreas congenéricas de ambientes florestais e savânicos, como forma de explicar a preferência de habitas e a dinâmica que governa o ecótono floresta-savana.

Por outro lado, diferenças encontradas nas respostas funcionais entre espécies do mesmo gênero podem ter evoluído em condições ambientais passadas e, neste caso, podem não ser facilmente relacionadas às condições ambientais atuais (Lemos-Filho et al. 2008). Neste sentido e a fim de se compreender as diferenças nas respostas funcionais associadas à adaptação a ambientes diferentes, também se torna interessante a comparação entre populações de uma mesma espécie (Lemos-Filho et al. 2008), havendo a vantagem adicional de que tais populações podem apresentar maior afinidade genética entre si e, neste caso, quaisquer diferenças encontradas nas respostas funcionais estarão, possivelmente, mais relacionadas às condições ambientais atuais (Bazzaz 1996; Lüttge \& Scarano 2004; Bradshaw 2006).

\subsection{Características funcionais de plantas}

O sucesso de uma espécie em um determinado ambiente depende, em parte, da energia utilizada na sua reprodução (Wulff 1995; Baskin \& Baskin 2001). Considerando que o valor adaptativo de um organismo é definido como a sua contribuição em número de indivíduos à geração seguinte na população, fatores que afetam o recrutamento de plantas estão entre os mais importantes a serem avaliados (Leishman et al. 2000; Coomes \& Grubb 2003). Neste 
sentido, a adaptação da espécie às condições locais e a plasticidade de resposta são qualidades necessárias para o seu estabelecimento efetivo dentro da população ou para a ocupação de novos ambientes (Galloway 2005).

Como é difícil avaliar a plasticidade de resposta para todas as espécies de plantas, é importante identificar características funcionais propensas a mostrar tal plasticidade em cenários de mudanças nas condições ambientais (Chevin et al. 2010; Barbosa et al. 2014). Em plantas, características funcionais são aquelas que ajudam a descrever a ecologia da espécie, utilizando variáveis facilmente identificáveis, tais como forma de vida, modo de dispersão, forma, massa da semente, entre muitas outras (Pérez-Harguindeguy et al. 2013).

Por sua vez, características funcionais da história de vida inicial de plantas estão entre as mais importantes do ponto de vista ecológico, pois elas podem influenciar fortemente os padrões de distribuição e abundância de espécies e populações (Rees \& Westoby 1997; Moles et al. 2007). Por exemplo, diferenças nas características funcionais de sementes podem influenciar a probabilidade de estabelecimento de plântulas, tanto por intermédio da distância de dispersão das sementes, como através da ocupação de habitats adequados para a sua germinação (Westoby et al. 1992; Westoby et al. 2002).

Embora a seleção estabilizadora consiga manter constante as características morfológicas de sementes (Jacquemyn et al. 2001), tem sido observada variação significativa em uma importante característica funcional de sementes - o tamanho, usualmente medido em função da massa (Leishman et al. 2000; Coomes \& Grubb 2003; Moles \& Westoby 2003) sendo tal variação frequentemente maior entre espécies do que dentro de uma espécie (Mooles et al. 2005; Rees \& Venable 2007). Neste sentido, fatores ambientais (temperatura, disponibilidade hídrica e nutricional do solo) e a própria plasticidade de resposta podem afetar a produção e a seleção para diferentes tamanhos de sementes, entre espécies e/ou populações, dentro de um ecossistema (Khurana \& Singh 2001; Baraloto et al. 2005). 
A partir de determinada quantidade de recursos, uma espécie vegetal pode investir na produção de muitas sementes pequenas ou de poucas sementes grandes (Leishman et al. 2000). Uma vez que o número de sementes produzidas se traduz diretamente em valor adaptativo, há pressão seletiva para a produção de maior quantidade de sementes, que serão consequentemente menores (Leishman et al. 2000) e terão maior potencial de dispersão do que as grandes (Venable \& Brown 1988; Greene \& Johnson 1993). Por outro lado, pode haver pressão seletiva para a produção de sementes grandes, posto que estas tendem a apresentar maior capacidade de sobrevivência do que sementes pequenas em determinadas condições ambientais, tais como sombreamento (Bond et al. 1999), déficit hídrico (Leishman \& Westoby 1994; Murray et al. 2004), competição (Jakobsson \& Eriksson 2000; Leishman 2001), limitação nutricional (Jurado \& Westoby 1992) e ocorrência de fogo (Lahoreau et al. 2006). Entretanto, em condições ambientais “favoráveis", a probabilidade de recrutamento é a mesma para todas as sementes e, neste caso, espécies que investem na maior produção de sementes pequenas levariam vantagem (Henery \& Westoby 2001; Muller-Landau 2010).

O conhecimento sobre a biologia das sementes é fundamental para a compreensão da estrutura e da dinâmica das comunidades vegetais. A qualidade fisiológica das sementes e a resposta germinativa às condições do meio influenciam significativamente o sucesso reprodutivo de plantas, podendo afetar de forma distinta o potencial de sobrevivência de indivíduos jovens e adultos (Wulff 1995). Neste sentido, a adaptação às condições locais e plasticidade de resposta apresentadas pelas sementes durante a germinação são qualidades necessárias tanto para o estabelecimento efetivo dentro da população, como para a ocupação de novos ambientes.

\subsection{Tolerância de sementes a estresses ambientais}


A transição do estádio de semente para o de plântula é um período de risco elevado para a maioria das espécies vegetais (Fenner \& Thompson 2005). Em grande parte dos cerrados brasileiros, onde há notável separação temporal entre estação seca e chuvosa, um grande número de espécies dispersam suas sementes durante a estação seca, as quais podem permanecer no solo até o início da estação chuvosa (Gottsberger \& Silberbauer-Gottsberger 2006; Salazar 2010). Durante este período, o déficit hídrico do solo (Goldstein et al. 2008), a baixa umidade relativa (Tweddle et al. 2003) e temperaturas altas, geradas ou não pela ocorrência de fogo (Whelan 1995; Borghetti 2005), podem restringir as chances de sobrevivência das sementes. Sob tais aspectos, muitas espécies de plantas desenvolveram respostas funcionais no sentido de aumentar a probabilidade de que suas sementes apresentem-se aptas a germinar mesmo após serem expostas a diferentes condições de estresse (Fenner \& Thompson 2005).

\subsubsection{Tolerância à dessecação}

Em geral, durante o período de formação e maturação de uma semente, é necessário que o seu conteúdo de água permaneça elevado até o final do desenvolvimento (Castro et al. 2004a). A partir deste ponto, as sementes da maioria das espécies apresentam a fase de secagem, que reduz o seu conteúdo de água a valores relativamente baixos e que podem resultar na aquisição de tolerância à dessecação que venha a ocorrer após a dispersão (Hong \& Ellis 1996). Sementes que toleram dessecação a baixos conteúdos de água (em geral em torno de 7\%) são denominadas ortodoxas (Tweddle et al. 2003).

Embora a maioria das espécies produzam sementes tolerantes à dessecação na maturidade, muitas outras espécies produzem sementes que não sofrem secagem natural na planta-mãe e são dispersas com teor de água elevado (Pammenter \& Berjak 2000a). Tais 
sementes são denominadas recalcitrantes e, de modo geral, não toleram dessecamentos abaixo de $20 \%$ de umidade (Pritchard 2004). Existem também espécies cujas sementes apresentam comportamento intermediário (entre ortodoxo e recalcitrante) quanto à tolerância ao dessecamento. Tais sementes podem tolerar a desidratação a níveis de umidade situados entre 7 e $12 \%$, mas são intolerantes à baixas temperaturas de armazenamento $\left(\leq 10^{\circ} \mathrm{C}\right)$, sobretudo por período de tempo superior a três meses (Hong \& Ellis 1996).

Em florestas tropicais, a maioria das espécies tem sementes frequentemente sensíveis à dessecação, sendo dispersas com alto conteúdo de água (Tweddle et al. 2003), e apresentam germinação rápida, longevidade curta e não formam bancos de sementes permanentes (Farnsworth 2000; Daws et al. 2005). Embora nestes ambientes pareça não haver pressão seletiva que impulsione a evolução da tolerância à dessecação (Pammenter \& Berjak 2000b), existem espécies cujas sementes apresentam esta característica, principalmente espécies pioneiras e/ou as de sucessão secundária, típicas de borda de floresta (Tweddle et al. 2003).

Por outro lado, em habitats mais secos e/ou sazonais, tais como as savanas, a maioria das espécies de plantas tem sementes com baixo conteúdo de água, tolerantes à dessecação e que apresentam alta longevidade, germinação lenta e dispersão durante a estação seca (Baskin \& Baskin 2001; Pritchard et al. 2004). Espécies com sementes sensíveis à dessecação ocorrem em baixa abundância nesses habitats e elas podem evitar a perda de viabilidade, por dessecação, através da dispersão concentrada durante a estação chuvosa (Pritchard et al. 2004; Berjak \& Pammenter 2008) e/ou atrasando sua germinação até a ocorrência de períodos com alta disponibilidade de água (Baskin \& Baskin 2001).

Diante do exposto, fica evidente que a sensibilidade de sementes à dessecação pode ser fator limitante à colonização de ambientes frequentemente sujeitos a altos níveis de estresse hídrico e a grandes flutuações de umidade e temperatura do solo, características estas comuns aos cerrados brasileiros. 


\subsubsection{Tolerância ao déficit hídrico}

A disponibilidade de água é um dos fatores que mais influenciam a germinação das sementes, estando direta e indiretamente envolvida em todas as suas etapas (Bradford 1995). Neste sentido, há a necessidade de a semente alcançar um nível adequado de hidratação que permita a reativação do seu metabolismo (Verslues et al. 2006). Por outro lado, potenciais hídricos muito baixos, especialmente nos períodos anteriores ao início da embebição, impedem a absorção de água pela semente, inviabilizando a reativação do seu metabolismo e, consequentemente, impedindo a sequência de acontecimentos fisiológicos que culminariam com a germinação e com o posterior estabelecimento da plântula (Castro et al. 2004b).

A resposta germinativa, em função do déficit hídrico, pode estar relacionada tanto a fatores endógenos quanto a fatores ambientais (Khurana \& Singh 2004; Daws et al. 2008). Fatores endógenos, tal como a massa da semente, podem ser determinantes na resposta germinativa de sementes submetidas ao estresse hídrico. Sob tal aspecto, alguns estudos têm mostrado que sementes grandes são mais tolerantes ao déficit hídrico do que sementes pequenas (Leishman \& Westoby 1994; Khurana \& Singh 2004; Daws et al. 2008), sendo esta tolerância fundamentada em dois fatores principais: 1. Maior quantidade de recursos metabólicos presentes no embrião e no endosperma (Khurana \& Singh 2001; Muller-Landau 2010); 2. Formação de bancos de sementes localizados mais superficialmente no solo, onde o déficit hídrico tende a ser mais acentuado (Khurana \& Singh 2001).

Por outro lado, fatores ambientais (principalmente aqueles relacionados às características edáficas), ao invés de fatores endógenos, têm sido apontados como os mais importantes em relação à tolerância de sementes ao estresse hídrico (Schütz et al. 2002; Kos \& Poschlod 2008). Neste caso, espécies presentes em ambientes cujos solos possuem baixa capacidade de retenção de água tendem a manter a germinação em potenciais hídricos mais 
baixos do que aquelas que ocorrem em solos com alta capacidade de retenção de água (Schütz et al. 2002; Kos \& Poschlod 2008).

O período de dispersão de sementes anemocóricas nos cerrados brasileiros ocorre principalmente na estação seca e/ou na transição desta para a estação chuvosa (Gottsberger \& Silberbauer-Gottsberger 2006). Por outro lado, espécies com síndrome de dispersão zoocórica tendem a dispersar suas sementes no decorrer da estação chuvosa (Lenza \& Klink 2005; Gottsberger \& Silberbauer-Gottsberger 2006). As sementes dispersas durante a estação seca tendem a germinar imediatamente após as primeiras chuvas e a concentração da germinação no início da estação chuvosa parece ser uma característica selecionada evolutivamente em savanas neotropicais, que resulta em maior probabilidade de estabelecimento e desenvolvimento de plântulas (Garwood 1983).

Em determinados ambientes, tais como nos cerrados brasileiros, o período de tempo existente entre eventos de precipitação e, consequentemente, a alternância entre condições favoráveis e desfavoráveis de umidade do solo, afetarão diretamente a resposta germinativa das sementes. $\mathrm{O}$ atraso nas primeiras chuvas e a ocorrência de veranicos (períodos secos durante a estação chuvosa) são frequentes nas regiões dos cerrados brasileiros (Assad et al. 1993; Araújo et al. 2001; INMET 2014) e, sob tais condições, o banco de sementes presente nas camadas superficiais do solo poderá experimentar períodos consideráveis de déficit hídrico. Como o déficit hídrico do solo é uma das principais causas de mortalidade de sementes e plântulas (Moles \& Westoby 2004; Engelbrecht et al. 2006; Lima et al. 2008; Walck et al. 2011), a capacidade de recrutamento em condições desfavoráveis de umidade no solo é um dos principais atributos responsáveis à manutenção de espécies dentro de comunidades vegetais.

\subsubsection{Tolerância ao fogo}


No Brasil, os cerrados estão situados em zonas de forte sazonalidade na precipitação, onde a ocorrência de queimadas é frequente, principalmente durante a estação seca (Pivello 2011; Miranda et al. 2009). A precipitação que ocorre na região dos cerrados brasileiros fornece suporte para produção considerável de biomassa aérea (Castro \& Kauffman 1998; Barbosa \& Fearnside 2005a), especialmente a herbácea, que se torna muito inflamável durante a estação seca e contribui para a ocorrência de queimadas (Miranda et al. 2002). Embora queimadas naturais (causadas por raios) sejam comuns nos cerrados brasileiros, especialmente durante a estação seca (Ramos-Neto \& Pivello 2000), a grande maioria delas é causada delas por ação antrópica, principalmente com o intuito de remover a vegetação natural, substituindo-a por pastagem ou culturas agrícolas (Pivello 2011).

O fogo está presente no Cerrado há mais de 30 mil anos (Salgado-Labouriau 1997) e, assim como em outros ecossistemas onde sua ocorrência é comum, ele pode atuar como importante filtro ambiental que exclui sementes, plântulas e/ou indivíduos jovens e adultos sensíveis a temperaturas muito altas (Bond et al. 2005; Hoffmann et al. 2009), as quais podem ocorrer desde a superfície do solo até alturas consideráveis acima desta (Miranda et al. 1993). Neste sentido, o fogo atua modificando o padrão de recrutamento de plantas na comunidade (Hoffmann 1998) e, consequentemente, tornando-se fator ecológico importante na estrutura, dinâmica e composição da vegetação (Moreira 2000; Hoffmann et al. 2012).

Em ambientes sujeitos a queimadas, o fogo pode atuar nos aspectos reprodutivos de plantas (Hoffmann 1998; Whelan et al. 2002), interferindo diretamente na capacidade germinativa das espécies principalmente através dos seus efeitos sobre o banco de sementes do solo (Williams et al. 2005; Keeley et al. 2011). Sob tal aspecto, o efeito do fogo pode ser tanto negativo, levando a mortalidade das sementes (Keeley \& Fotheringham 2000; Auld \& Denham 2006), quanto positivo, promovendo a germinação de sementes, especialmente 
daquelas que apresentam algum tipo de dormência (Auld \& Bradstock 1996; Baker et al. 2005; Newton et al. 2006).

A tolerância das sementes aos efeitos do fogo dependerá da frequência, intensidade e duração da queimada (Keeley \& Fotheringham 2000). De modo geral, as sementes são capazes de tolerar temperaturas altas combinadas com tempos de exposição mais curtos ou, ainda, temperaturas baixas a moderadas combinadas com tempos de exposição mais longos (Escudero et al. 2000; Hanley \& Lamont 2000; Ribeiro et al. 2013). Entretanto, a combinação de temperaturas elevadas e tempos de exposição mais longos costumam ser letais para as sementes (Gashaw \& Michelsen 2002; Reyes \& Trabaud 2009).

Outro aspecto a ser considerado em relação à tolerância de sementes aos efeitos do fogo é o ambiente de ocorrência da espécie (Keeley \& Fotheringham 2000) Neste sentido, a sensibilidade aos efeitos do fogo tende a ser maior em sementes de espécies que ocorrem em ambientes cuja frequência e intensidade de queimadas são menores (Hoffmann 2000; Ribeiro \& Borghetti 2014).

\subsubsection{Germinação em temperaturas altas}

Temperaturas altas ocorrem amplamente entre os biomas do mundo e podem interferir significativamente na estrutura da vegetação (Moles et al. 2014). Em relação às savanas, temperaturas altas no solo podem ocorrer não apenas devido à ocorrência de queimadas (Miranda et al. 1993; Whelan 1995; Auld \& Bradstock 1996), mas também em função da exposição direta aos raios solares (Coutinho 1990; Borghetti 2005).

A temperatura é fator determinante na germinação das sementes, influenciando este processo especialmente por alterar a velocidade de absorção de água e das reações metabólicas de mobilização de reservas (Bewley \& Black 1994). As temperaturas mais 
apropriadas para a germinação, assim como as temperaturas limitantes, podem variar entre espécie, populações e indivíduos (Probert 2000; Baskin \& Baskin 2001). Além disso, a faixa de temperatura adequada para a germinação das sementes é correspondente àquela em que as plantas ficarão expostas durante todo o seu desenvolvimento (Baskin \& Baskin 2001; Teketay 1998).

Determinar a germinação das sementes em gradientes de temperatura permite definir as temperaturas cardeais, dentre as quais a temperatura ótima, ou seja, aquela em que o percentual de germinação é máximo, e ocorre no menor espaço de tempo; e a temperatura máxima, aquela acima da qual não ocorre germinação (Labouriau 1983). Em termos gerais, sementes de espécies arbóreas da região Neotropical apresentam temperaturas ótimas de germinação situadas entre 20 e $30^{\circ} \mathrm{C}$ (Brancalion et al. 2010). Entretanto, temperaturas de germinação mais elevadas (em geral acima de $35^{\circ} \mathrm{C}$ ) são mais prejudiciais para espécies que ocorrem em ambientes sujeitos a amplitudes térmicas diárias mais baixas (Ribeiro \& Borghetti 2014).

Portanto, a habilidade de uma espécie em germinar em temperaturas mais elevadas (acima da faixa ótima), é atributo importante para o recrutamento de suas sementes, principalmente em ecossistemas cujo banco de sementes seja transiente, de baixa densidade (Ikeda et al. 2008; Salazar et al. 2011) e exposto à alta insolação, como é o caso dos cerrados brasileiros (Coutinho 1990; Borghetti 2005; INMET 2014).

\subsection{Mudanças climáticas}

Mudanças climáticas têm sido reconhecidas como fatores importantes na origem e evolução da biodiversidade vegetal na região Neotropical (Hewitt 2004; Punyasena 2008). Em termos atuais, modelos climáticos globais prevêem mudanças nos regimes de 
pluviosidade, os quais se tornarão cada vez mais irregulares e se manisfestarão, provavelmente, em períodos de secas mais prolongadas, interrompidos por eventos de precipitação intensa (Hoffmann \& Jackson 2000; Groisman et al. 2005). Além disso, alguns modelos também preveem o aumento das temperaturas médias máximas globais e, consequentemente, o aumento na frequência de queimadas em regiões onde ocorrem savanas neotropicais (Hoffmann \& Jackson 2000; IPCC 2013).

Os aumentos na temperatura do ar refletirão em aumentos na temperatura do solo, principalmente em sua superfície. Sob tais aspectos, os bancos de sementes do solo estarão expostos a temperaturas mais altas e por períodos mais prolongados, sobretudo nos meses de verão (Ooi et al. 2009). Considerando que disponibilidade de água e temperatura são sinais ambientais determinantes para a germinação das sementes, quaisquer modificações nestes sinais poderão causar impacto direto no banco de sementes do solo, tais como a diminuição de viabilidade ou aumento do grau de dormência das sementes (Venable 2007; Ooi et al. 2009). Consequentemente, tais mudanças poderão interferir na persistência ou não de determinadas espécies em alguns ambientes (Hedhly et al. 2009; Walck et al. 2011).

A ampla plasticidade de respostas morfo-funcionais apresentada pelas plantas, em função de características ambientais, permite que tais organismos sejam excelentes indicadores de mudanças no clima (Woodward 1987; Walter \& Breckle 2002). O Cerrado brasileiro, sendo um domínio fitogeográfico complexo do ponto de vista fisionômico pode, naturalmente, favorecer a expressão de plasticidade fenotípica em resposta à heterogeneidade das condições ambientias. Neste sentido, a realização de estudos direcionados sobre aspectos funcionais da história de vida inicial de plantas, como por exemplo, a germinação de sementes, torna-se essencial para tentar prever o quão perto as espécies podem estar dos seus limites fisiológicos e como a intensificação nos níveis de estresse, especialmente hídrico e 
térmico, em função das iminentes mudanças climáticas (IPCC 2013), pode ameaçar a resiliência de alguns ecossistemas.

\section{Hipóteses}

Diferenças nas características funcionais de sementes podem influenciar a probabilidade de estabelecimento de plântulas, por exemplo, através da ocupação de habitats adequados para a sua germinação (Westoby et al. 1992; Westoby et al. 2002). Nos últimos anos, vários estudos têm mostrado a existência de uma variação significativa na massa de sementes entre espécies ou mesmo entre populações de uma mesma espécie (Moles et al. 2005; Rees \& Venable 2007). De modo geral, tem sido observado que a variação na massa das sementes tende a ser menor entre espécies filogeneticamente mais próximas e que, neste caso, essa característica tende a não ser significativa para a resposta fisiológica de espécies submetidas a condições de estresse semelhantes (Gómez 2004). Considerando tais aspectos, a seguinte hipótese foi testada:

(1) A massa da semente não é um atributo significativo na resposta germinativa de populações vegetais (pares conespecíficos) ocorrentes nos cerrados de Roraima e do Brasil Central, quando submetidas às mesmas condições de estresse.

Em sentido amplo, os cerrados de Roraima e aqueles do Planalto Central brasileiro possuem muita similaridade, sobretudo quanto à sazonalidade na precipitação, nos quais há nítida separação temporal entre estação seca e chuvosa ao longo do ano (INMET 2014). Entretanto, tais cerrados apresentam, do ponto de vista ambiental, peculiaridades que os tornam marcadamente distintos, sobretudo em termos edáficos (ver Furley \& Ratter 1988; Furley \& Ratter 1990). De modo geral, os solos ocorrentes nos cerrados de Roraima 
apresentam textura média a arenosa, com teores de argila nos horizontes subsuperficiais que variam de 150 a 326 g. $\mathrm{kg}^{-1}$ e, consequentemente, possuem baixa capacidade de retenção de água (ver Benedetti et al. 2011). Por outro lado, os solos ocorrentes nos cerrados do Sudeste de Goiás e do Distrito Federal (Planalto Central brasileiro) apresentam textura argilosa a muito argilosa, com teor médio de argila de $572 \mathrm{~g} \cdot \mathrm{kg}^{-1}$ nos horizontes subsuperficiais, em ambas as áreas (ver Gomes et al. 2004; Barbosa et al. 2009). A menor capacidade de retenção de água apresentada por solos com textura arenosa (Roraima) faz com que estes estejam expostos a potencias hídricos mais baixos, em relação àqueles com textura argilosa (Brasil Central), especialmente nos horizontes subsuperficiais, onde o banco de sementes costuma se estabelecer. Considerando tais aspectos, a seguinte hipótese foi testada:

(2) Sementes de populações vegetais (pares conespecíficos) ocorrentes nos cerrados de Roraima são mais tolerantes à dessecação e ao déficit hídrico do que aquelas ocorrentes nos cerrados do Brasil Central.

Os cerrados ocorrentes no Planalto Central brasileiro e os de Roraima estão frequentemente sujeitos à ocorrência de queimadas (Miranda et al. 2009). A frequência de queimadas em tais áreas é consideravelmente similar, ocorrendo a cada 2,5 anos em Roraima e a cada 2-3 anos no Brasil Central (ver Barbosa \& Fearnside 2005b). No entanto, nos cerrados do Brasil Central há maior quantidade de biomassa aérea total de combustíveis para queima (gramíneas, ciperáceas e outras espécies herbáceas, plântulas de dicotiledôneas e componentes de serapilheira) em comparação àquela dos cerrados de Roraima (ver Kauffman et al. 1994; Barbosa \& Fearnside 2005a). Nesse sentido, é de se esperar que queimadas ocorrentes nos cerrados do Planalto Central brasileiro sejam mais intensas e duradouras do que aquelas ocorrentes nos cerrados de Roraima. Considerando os aspectos discutidos acima, a seguinte hipótese foi testada: 
(3) Sementes de populações vegetais (pares conespecíficos) ocorrentes nos cerrados de Roraima são menos tolerantes a choques térmicos (fogo) do que aquelas ocorrentes nos cerrados do Brasil Central.

Os solos ocorrentes nos cerrados do Brasil Central e nos de Roraima estão sujeitos à exposição de altas temperaturas, também em função da elevada incidência de raios solares (Borghetti 2005; INMET 2013, 2014). Entretanto, pela maior proximidade em relação ao Equador, nos cerrados de Roraima ocorrem temperaturas médias máximas maiores que aquelas ocorrentes nos cerrados do Brasil Central, tanto na estação seca quanto na estação chuvosa (INMET 2013, 2014). Considerando tais aspectos, a seguinte hipótese foi testada:

(4) Sementes de populações vegetais (pares conespecíficos) ocorrentes nos cerrados de Roraima apresentam temperaturas máximas de germinação superiores àquelas ocorrentes nos cerrados do Brasil Central.

\section{Objetivos}

1. Determinar e comparar a plasticidade de resposta em parâmetros de germinação (germinabilidade e tempo médio) de sementes de populações vegetais ocorrentes em cerrado de Roraima e do Brasil Central, submetidas a diferentes condições de estresse (dessecação, déficit hídrico e choques térmicos).

2. Determinar e comparar os efeitos de temperaturas crescentes em parâmetros de germinação (germinabilidade e tempo médio) de sementes de populações vegetais ocorrentes em cerrado de Roraima e do Brasil Central. 
3. Identificar de que forma a intensificação de estresses ambientais, previstos por modelos climáticos globais, poderão modificar os padrões de reprodução de algumas espécies e/ou populações vegetais, baseados em sua plasticidade de resposta germinativa.

4. Identificar espécies e/ou populações vegetais que poderão apresentar maior potencial de sobrevivência em cenários de possíveis mudanças ambientais.

\section{Material e métodos}

\subsection{Locais de coleta}

As coletas de sementes foram realizadas nos lavrados de Roraima (Figura 2a), em março de 2012, e nos cerrados do Planalto Central brasileiro (Figura 2), nos meses de outubro e novembro de 2012. A descrição das áreas de coleta, bem como de suas condições ambientais, são descritas a seguir:

Área 1. Universidade Federal de Roraima, campus Cauamé (RR): localizada cerca de $15 \mathrm{~km}$ ao norte de Boa Vista/RR, entre as geocoordenadas $02^{\circ} 38^{\prime} \mathrm{N}$ e $60^{\circ} 49^{\prime} \mathrm{W}$, a $77 \mathrm{~m}$ acima do nível do mar. O clima na área é classificado como tropical de inverno seco (Aw), com base no sistema de Köppen-Geiger (Peel et al. 2007). A precipitação média anual é de aproximadamente $1957 \mathrm{~mm}$, sendo o período mais seco ocorrente entre os meses de dezembro e março (cerca de $10 \%$ da precipitação anual) (Figura 3a), cujas temperaturas médias mínima e máxima são de 24,0 e $32,7^{\circ} \mathrm{C}$, respectivamente (INMET 2014). Já durante o pico da estação chuvosa, que ocorre entre maio e agosto (Figura 3a), as temperaturas médias mínima e máxima são de 22,3 e $30,0^{\circ} \mathrm{C}$, respectivamente (INMET 2014). Nesta área, a umidade relativa 
do ar é mais baixa durante a estação seca, variando entre 68 e $73 \%$, e mais alta durante a estação chuvosa, variando entre 70 e $78 \%$ (INMET 2014).

Área 2. Fazenda Água Limpa (FAL): estação experimental localizada cerca de $35 \mathrm{~km}$ ao sul de Brasília/DF, entre as geocoordenadas $15^{\circ} 56^{\prime} \mathrm{S}$ e $47^{\circ} 56^{\prime} \mathrm{W}$, a uma elevação de aproximadamente 1080 m. O clima é classificado como Aw no sistema de Köppen-Geiger (Peel et al. 2007) e a pluviosidade média anual é de 1595 mm (INMET 2014), sendo o período mais seco do ano ocorrente entre os meses de maio e setembro (Figura 3b), com temperaturas médias mínima e máxima de 14,1 e $26,3^{\circ} \mathrm{C}$, respectivamente (INMET 2014). Já durante a estação chuvosa, ocorrente entre outubro e abril (Figura 3b), as temperaturas médias mínima e máxima foram de 18,0 e $30,2^{\circ} \mathrm{C}$, respectivamente (INMET 2014). A média mensal da umidade relativa do ar se mantém, geralmente, acima de $70 \%$ durante praticamente todo o período chuvoso e entre 50\% e 60\% durante o período seco (INMET 2014).

\section{Área 3. Fazenda Experimental da Universidade Estadual de Goiás, campus Ipameri (IPM):} localizada na região Sudeste do estado de Goiás, cerca de 190 km do município de Goiânia, entre as geocoordenadas $17^{\circ} 41^{\prime} \mathrm{S}$ e $48^{\circ} 11^{\prime} \mathrm{W}$, a uma elevação de aproximadamente $772 \mathrm{~m}$. O clima na região é classificado Aw, com base no sistema de Köppen-Geiger (Peel et al. 2007) e a precipitação média anual é de cerca de 1547 mm (INMET 2013). Durante a estação seca, que ocorre entre os meses de maio e setembro (Figura 3c), as temperaturas médias mínima e máxima são de 14,5 e $27,4^{\circ} \mathrm{C}$, respectivamente. Já durante o pico da estação chuvosa, que ocorre entre novembro e março, responsável por cerca de $80 \%$ da precipitação média anual (Figura 3c), as temperaturas médias mínima e máxima são de 19,6 e 30,3드. respectivamente (INMET 2013). A média mensal da umidade relativa durante o período chuvoso situa-se entre 70 e $75 \%$, e entre $50 \%$ e $60 \%$ durante a estação seca (INMET 2013). 

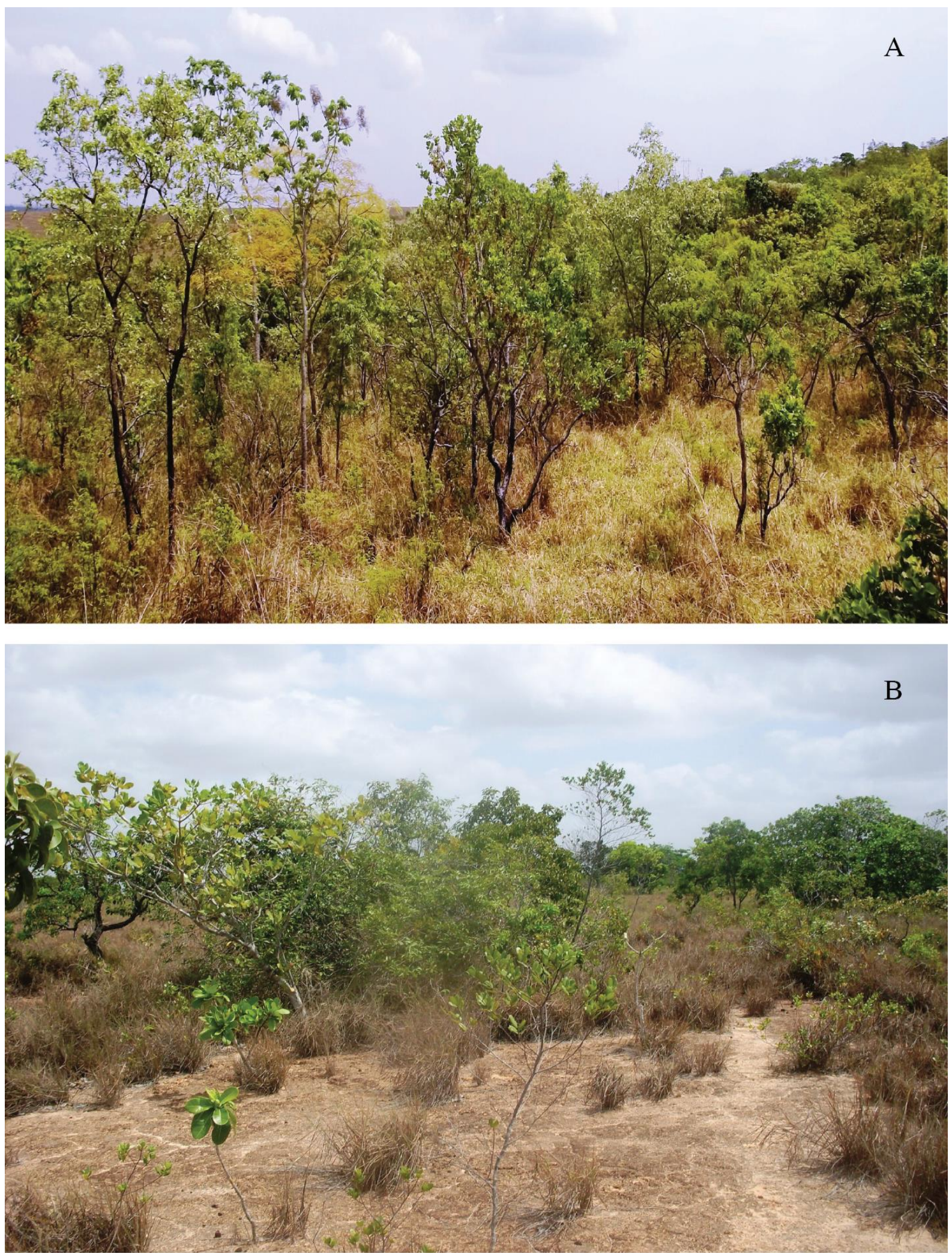

Figura 2. Visão geral da paisagem de uma savana do Planalto Central brasileiro, em Ipameri,

Goiás (A) e de uma savana de Boa Vista, Roraima (B). Fonte: Elaborada pelo autor. 

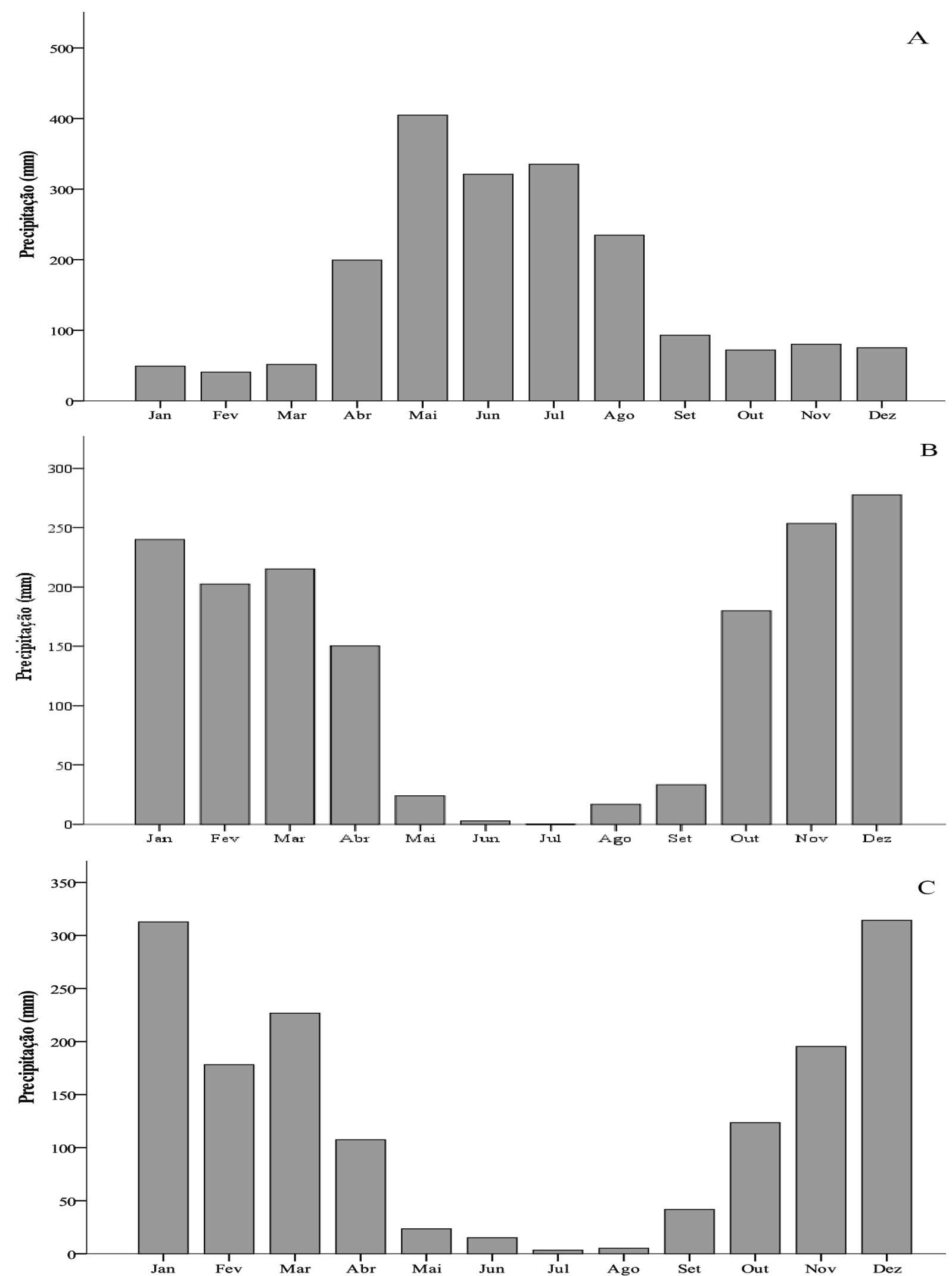

Figura 3. Precipitação média mensal ocorrente entre os anos 2004 e 2013 nas áreas de coleta de sementes, em Boa Vista/RR (A), Brasília/DF (B) e Ipameri/GO (C). Fonte: Instituto Nacional de Meteorologia, 2014. 


\subsection{Seleção de espécies e coleta de sementes}

Para o desenvolvimento deste trabalho, foram escolhidas três espécies arbóreas (Tabela 1; Figura 4), de acordo com dois critérios principais: ocorrência simultânea nos cerrados de Roraima e do Planalto Central brasileiro (Miranda \& Absy 1997; Ratter et al. 2003; Libano \& Felfili 2006) e espécies com indivíduos em fase de dispersão de sementes (Silva-Junior 2005; Melo \& Barbosa 2007). Foram coletadas sementes maduras de 10 indivíduos de cada espécie (Figura 5), tanto em populações localizadas nos cerrados de Roraima, quanto naquelas localizadas nos cerrados do Brasil Central. Após a coleta, as sementes foram beneficiadas e homogeneizadas em amostras compostas, separadas por espécie e área de coleta. A fim de prolongar ao máximo sua viabilidade, as sementes foram colocadas dentro de sacos de papel, sendo posteriormente armazenadas em laboratório, nas seguintes condições: umidade (65$85 \%)$ e temperatura $\left(20-24^{\circ} \mathrm{C}\right)$. Os experimentos foram desenvolvidos no Instituto Nacional de Pesquisas da Amazônia (INPA) / Núcleo de Pesquisas de Roraima, em Boa Vista/RR, e na Universidade de Brasília (UnB) / Laboratório de Termobiologia, em Brasília/DF.

Tabela 1. Espécies estudadas, com suas respectivas informações fenológicas (fenologia foliar e dispersão) e fisionomias de ocorrência.

\begin{tabular}{|c|c|c|c|c|c|c|}
\hline Origem & Espécie & Família & $\begin{array}{c}\text { Grupo } \\
\text { fenológico }\end{array}$ & $\begin{array}{c}\text { Síndrome de } \\
\text { dispersão }\end{array}$ & Período de dispersão & $\begin{array}{c}\text { Fisionomia de } \\
\text { ocorrência }\end{array}$ \\
\hline $\begin{array}{l}\text { RR } \\
\text { FAL }\end{array}$ & Bowdichia virgilioides Kunth & Fabaceae & $\begin{array}{l}\text { Árvore } \\
\text { decídua }\end{array}$ & Anemocoria & $\begin{array}{c}\text { Fevereiro a Abril }^{\dagger} \\
\text { Setembro a Dezembro }\end{array}$ & Savana \\
\hline $\begin{array}{l}\mathrm{RR} \\
\mathrm{IPM}\end{array}$ & Curatella americana $\mathrm{L}$. & Dilleniaceae & $\begin{array}{l}\text { Árvore } \\
\text { decídua }\end{array}$ & Zoocoria & $\begin{array}{c}\text { Março a Maio }^{\dagger} \\
\text { Outubro a Dezembro }\end{array}$ & Savana \\
\hline $\begin{array}{l}\text { RR } \\
\text { FAL }\end{array}$ & $\begin{array}{l}\text { Anadenanthera peregrina (L.) } \\
\text { Speg. }\end{array}$ & Fabaceae & $\begin{array}{l}\text { Árvore } \\
\text { decídua }\end{array}$ & Autocoria & $\begin{array}{c}\text { Março a Maio }^{\dagger} \\
\text { Setembro a Novembro }\end{array}$ & Floresta \\
\hline
\end{tabular}

RR - Universidade Federal de Roraima ; FAL - Fazenda Água Limpa, DF; IPM - Ipameri, GO.

* Época de dispersão de sementes nos cerrados do Brasil Central; † Época de dispersão de sementes nos cerrados de Roraima. 

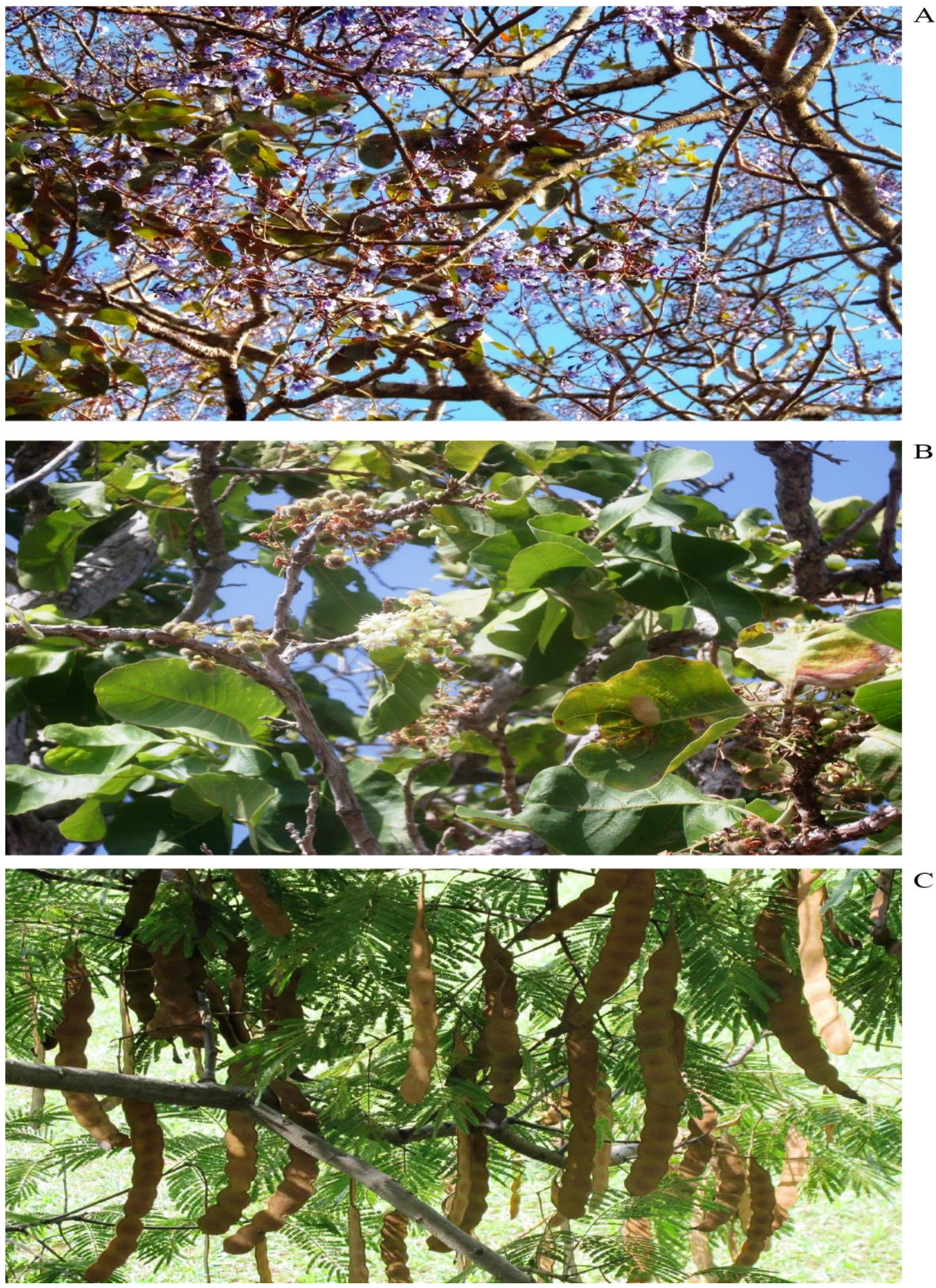

Figura 4. Espécies selecionadas para o estudo, em fase reprodutiva. Bowdichia virgilioides (A), Curatella americana (B) e Anadenanthera peregrina (C). Fonte: Elaborada pelo autor. 


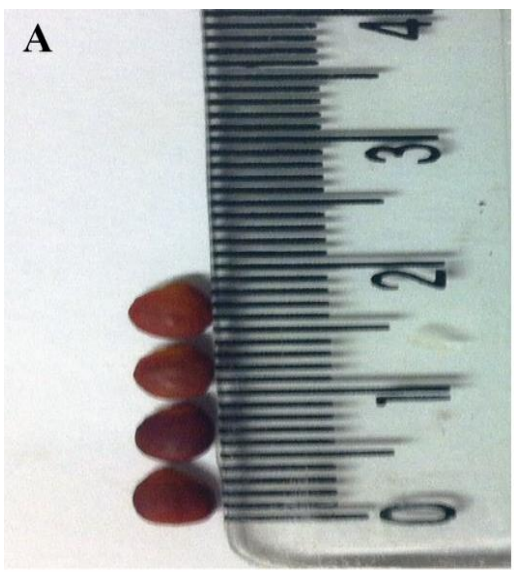

B
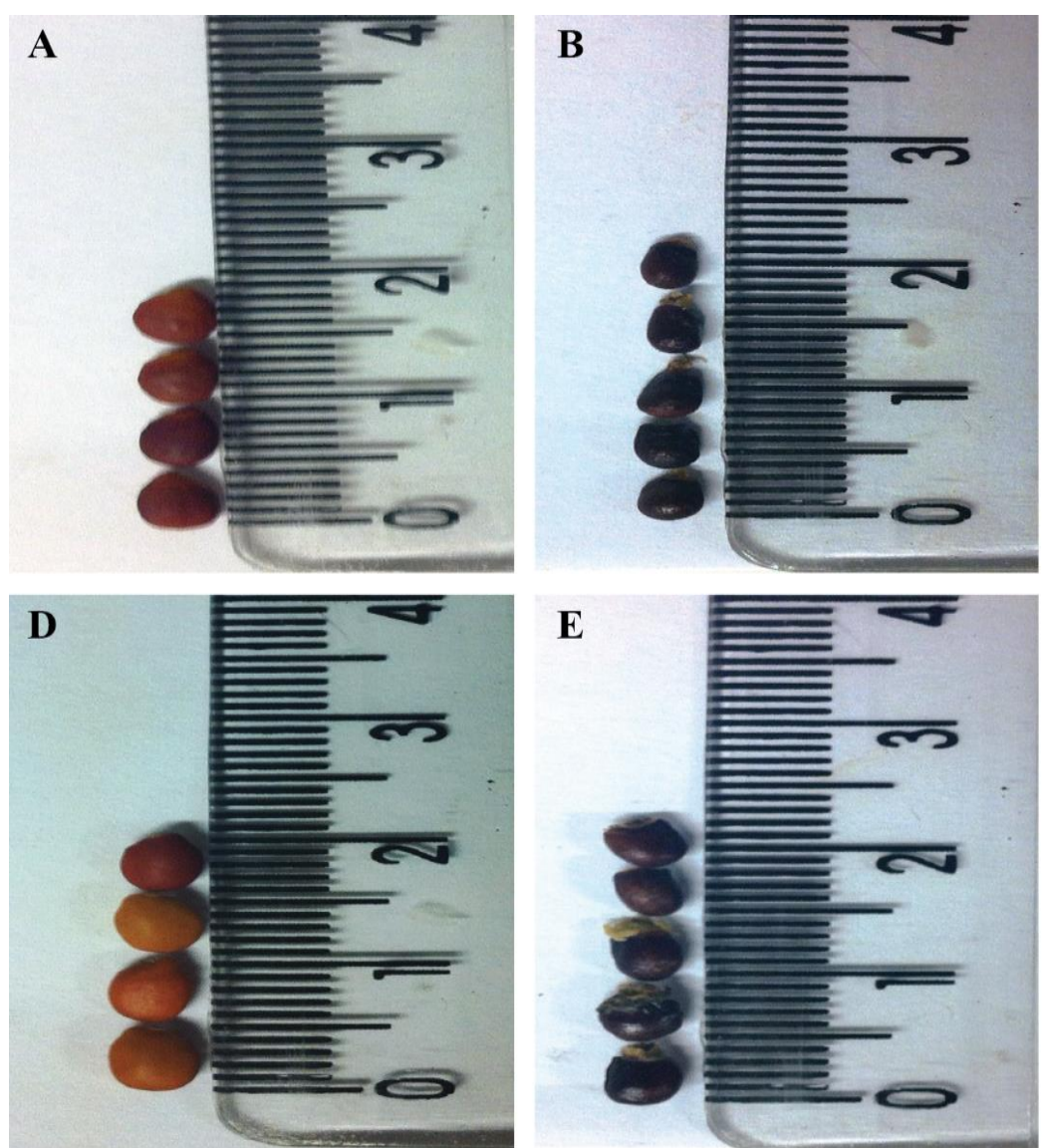

$\mathbf{E}$

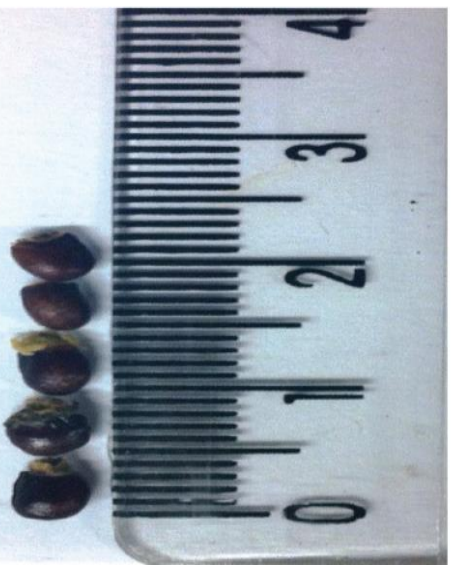

C

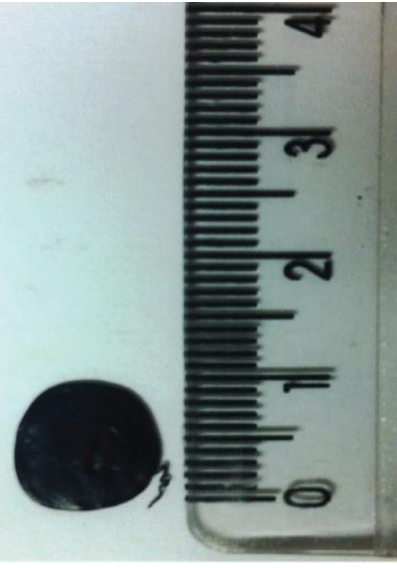

$\mathbf{F}$

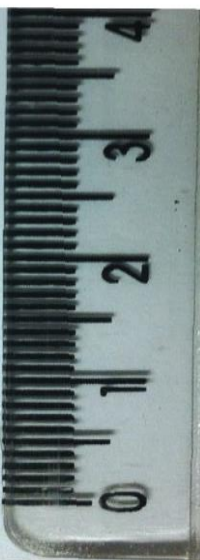

Figura 5. Sementes de Bowdichia virgilioides (A e D), Curatella americana (B e E) e Anadenanthera peregrina (C e F) coletadas nos cerrados de Roraima (A, B e C) e do Planalto Central brasileiro (D, E e F). Fonte: Elaborada pelo autor.

\subsection{Desenho experimental}

As três espécies utilizadas neste estudo foram separadas conforme com o local de procedência (origem) da população, da seguinte forma:

1. População dos “cerrados de Roraima" e;

2. População dos "cerrados do Brasil Central".

Em todos os ensaios experimentais, descritos nas seções a seguir, foram utilizadas amostras de 60 sementes, divididas em quatro réplicas de 15, para cada espécie e conforme a procedência da população. 


\subsection{Massa fresca, massa seca e conteúdo de água inicial de sementes ${ }^{1}$}

Para a determinação da biomassa das sementes, cada réplica foi pesada utilizando-se balança analítica de precisão (Mettler-Toledo B154, Switzerland), antes e após secagem por 24 horas em estufa com circulação e renovação de ar (Nova Técnica NT 516, Piracicaba-SP, Brasil) regulada à $105^{\circ} \mathrm{C}$. Os valores das biomassas fresca e seca das sementes foram obtidos através da média das quatro réplicas. O conteúdo de água inicial das sementes $(C)$ foi obtido de acordo com a seguinte equação:

$C=\left[\left(M_{f}-M_{s}\right) \cdot\left(M_{f}\right)^{-1}\right] .100(\%)$

em que $M_{f}$ é a massa fresca e $M_{s}$ é a massa seca das sementes.

\subsection{Teste de viabilidade}

Previamente à realização dos ensaios experimentais de germinação, foram realizados testes de viabilidade com as sementes de cada espécie e conforme sua população de origem, com o intuito de se quantificar a porcentagem de sementes vivas e, consequentemente, aptas a germinarem.

Para a realização dos testes de viabilidade, as sementes foram cortadas no sentido longitudinal, abrangendo-se os cotilédones e o eixo embrionário. Em seguida, as duas metades foram colocadas em placa de Petri forrada com uma folha de papel de filtro, umedecida com solução de cloreto de 2,3,5 trifenil tetrazólio a $1 \%$. Posteriormente, as sementes foram

${ }^{1}$ Destaca-se o fato de que o início deste ensaio experimental ocorreu no mesmo dia de coleta das sementes, evitando que estas entrassem em equilíbrio higroscópico com o meio externo. 
colocadas em câmara de germinação (Marconi MA 402, Piracicaba/SP, Brasil) regulada a $30^{\circ} \mathrm{C}$, na ausência total de luz, durante 24 horas (ver Moore 1973).

Após este período de tempo, cada metade foi individualmente examinada e, de acordo com a extensão, intensidade dos tons avermelhados, presença de áreas brancas, aspecto dos tecidos e localização destas colorações em relação às áreas essenciais ao crescimento, os embriões foram classificados como viáveis ou não viáveis (ver ISTA 2003).

\subsection{Germinação de sementes submetidas à dessecação}

Para avaliar os efeitos da dessecação sobre a germinação, as sementes tiveram seu conteúdo de água reduzido a 5\%. Para a obtenção deste grau de umidade, as sementes foram colocadas em dessecador hermeticamente fechado contendo sílica gel, a qual foi trocada, em média, a cada 48 horas. A massa das sementes foi obtida a cada duas horas durante as primeiras 12 horas e, posteriormente, a cada 24 horas (ver Ribeiro \& Borghetti 2014), até que massa encontrada coincidiu com o conteúdo de água desejado. Para encontrar a massa das sementes correspondente ao conteúdo de água desejado, foi utilizada a seguinte equação (ver Cromarty et al. 1985):

$M_{d}=\left[\left(100-C_{i}\right) \cdot\left(100-C_{d}\right)^{-1}\right] \cdot M_{i}$

em que $M_{d}$ é a massa (g) no conteúdo de água desejado; $M_{i}$ é a massa (g) no conteúdo de água inicial; $C_{i}$ é o conteúdo de água inicial; e $C_{d}$ é o conteúdo de água desejado.

Após a obtenção do conteúdo de água desejado $\left(C_{d}=5,0 \%\right)$, as sementes dessecadas foram colocadas em placas de Petri forradas com duas folhas de papel de filtro e umedecidas com água destilada. Posteriormente, as placas contendo as sementes foram colocadas em 
câmara de germinação (Marconi MA 402, Piracicaba/SP, Brasil) regulada a $30^{\circ} \mathrm{C}$, temperatura situada dentro da faixa ótima para germinação de espécies arbóreas do Cerrado (ver Brancalion et al. 2010), e fotoperíodo de 12 horas (luz branca, $30 \mu \mathrm{mol} \cdot \mathrm{m}^{-2} \cdot \mathrm{s}^{-1}$ ). O controle experimental consistiu em avaliar a germinação de sementes não submetidas à dessecação.

\subsection{Germinação de sementes submetidas ao déficit hídrico}

Para avaliar os efeitos do déficit hídrico sobre a germinação das sementes, foram utilizadas soluções aquosas de polietilenoglicol 6000 (PEG 6000), em diferentes potenciais osmóticos $\left(\Psi_{\pi}\right)$, preparadas de acordo com as concentrações de soluto indicadas por Villela et al. (1991). O PEG 6000 não penetra no tegumento, é quimicamente inerte e atóxico para as sementes e suas soluções tem a capacidade de simular condições de déficit hídrico do solo (Hardegree \& Emmerich 1994).

Sementes foram colocadas para germinar em placas de Petri forradas com duas folhas de papel de filtro, umedecidas com as soluções aquosas de PEG 6000 nos potenciais osmóticos de $-0,2 ;-0,4 ;-0,6 ;-0,8 ;-1,0$ e $-1,2 \mathrm{MPa}$, que são comumente registrados em solos do Cerrado, mesmo durante a estação chuvosa (ver Nardoto et al. 1998; Franco 2002). Em seguida, as placas com as sementes foram colocadas em câmara de germinação (Marconi MA 402, Piracicaba/SP, Brasil) regulada a $30^{\circ} \mathrm{C}$ e fotoperíodo de 12 horas (luz branca, 30

$\left.\mu \mathrm{mol} \cdot \mathrm{m}^{-2} \cdot \mathrm{s}^{-1}\right)$. O controle experimental consistiu em avaliar a germinação das sementes em água destilada $\left(\Psi_{\pi}=0,0 \mathrm{MPa}\right)$.

\subsection{Germinação de sementes submetidas a choques térmicos}


Para os tratamentos de choques térmicos, as sementes foram colocadas em estufa com circulação e renovação de ar (Marconi MA 035, Piracicaba/SP, Brasil), ajustada para fornecer as seguintes temperaturas: $80,110,140,170$ e $200^{\circ} \mathrm{C}$. Os tempos de exposição, para cada temperatura utilizada, foram de 2,5 e 5 minutos. Tais combinações de temperaturas por tempo de exposição foram estabelecidas com base em medidas feitas na superfície do solo de fisionomias savânicas do Cerrado durante queimadas prescritas (ver Miranda et al. 1993; Neves \& Miranda 1996).

Após a aplicação dos choques térmicos, as sementes foram colocadas em placas de Petri forradas com duas folhas de papel de filtro, umedecidas com água destilada e, posteriormente, colocadas em câmara de germinação (Marconi MA 402, Piracicaba/SP, Brasil), regulada nas mesmas condições de temperatura e fotoperíodo descritas para os experimentos de dessecação e de déficit hídrico. O controle experimental consistiu em avaliar a germinação de sementes não submetidas a choques térmicos.

\subsection{Germinação de sementes em temperaturas crescentes}

Para avaliar o efeito de temperaturas crescentes na germinação, as sementes foram colocadas em placas de Petri forradas com duas folhas de papel de filtro, umedecidas com água destilada e, posteriormente, levadas para câmaras de germinação (Marconi MA 402, Piracicaba/SP, Brasil), reguladas nas seguintes temperaturas: $20,25,30,35,40$ e $45^{\circ} \mathrm{C}$, sob fotoperíodo de 12 horas (luz branca, $30 \mu \mathrm{mol} \cdot \mathrm{m}^{-2} \cdot \mathrm{s}^{-1}$ ). Tais temperaturas estão dentro da faixa de amplitude térmica considerada ótima $\left(20,25\right.$ e $\left.30^{\circ} \mathrm{C}\right)$ e supra ótima $\left(35\right.$ e $\left.40^{\circ} \mathrm{C}\right)$ para a germinação de espécies arbóreas do Cerrado (Brancalion et al. 2010).

\subsection{Contagem de sementes germinadas}


Em todos os experimentos de germinação, as placas de Petri foram examinadas diariamente para a contagem e remoção de sementes germinadas, até a estabilização da resposta. O critério utilizado para considerar a semente germinada foi a emissão da radícula, seguida de sua curvatura gravitrópica, a fim de evitar a falsa germinação (para mais detalhes, ver Labouriau 1983).

Após o término de cada ensaio experimental de germinação (itens 4.6 a 4.9), as sementes não germinadas, de todos os tratamentos aplicados e de seus respectivos controles, também foram submetidas a teste de viabilidade, conforme metodologia descrita no item 4.5.

\subsection{Medidas de Germinação}

Após a realização dos ensaios experimentais de germinação foram calculadas a porcentagem de germinação ou germinabilidade $(\mathrm{G})$ e o tempo médio de germinação $\left(\mathrm{T}_{\mathrm{m}}\right)$ como variáveis de resposta, conforme as equações a seguir (ver Labouriau 1983):

$$
\begin{aligned}
& G=\left(\sum n_{i} \cdot N^{-1}\right) \cdot 100(\%) \\
& T_{m}=\left(\sum n_{i} \cdot t_{i}\right) \cdot\left(\sum n_{i}\right)^{-1}
\end{aligned}
$$

em que $\Sigma \mathrm{n}_{\mathrm{i}}$ é o número total de sementes germinadas em relação ao número de sementes colocadas para germinar $(\mathrm{N}) ; \mathrm{n}_{\mathrm{i}}$ é o número de sementes germinadas dentro de determinado intervalo de tempo $t_{\mathrm{i}-1}$ e $t_{\mathrm{i}}$.

\subsection{Análise estatística}

As diferenças encontradas nos valores de massa fresca, massa seca e conteúdo de água inicial de sementes, entre espécies pertencentes a diferentes populações (pares 
conespecíficos), foram analisadas utilizando-se modelo linear geral (GLM), cuja procedência (origem) da população (Roraima vs. Planalto Central) foi considerada fator fixo, e massa fresca, massa seca e conteúdo de água das sementes foram as variáveis de resposta.

Modelos lineares gerais (GLMs) também foram utilizados para comparar os efeitos do dessecamento, do déficit hídrico, de choques térmicos e de temperaturas crescentes sobre os parâmetros de germinação $\left(\mathrm{G}\right.$ e $\left.\mathrm{T}_{\mathrm{m}}\right)$ de pares conespecíficos pertencentes a diferentes populações (Roraima vs. Planalto Central). Para tanto, foi utilizado modelo linear com dois fatores fixos (população de origem e conteúdo de água - tolerância à dessecação; população de origem e potencial osmótico - tolerância ao déficit hídrico; população de origem e temperatura-germinação em temperaturas crescentes). Já em relação aos choques térmicos, foi utilizado GLM com três fatores fixos: população de origem, temperatura e tempo de exposição. Em todas as análises, a massa das sementes foi utilizada como covariável, por se tratar de uma variável contínua (Crawley 2007). Tendo sido cumpridos os pressupostos de distribuição normal dos resíduos e de homogeneidade de variâncias e dos coeficientes de regressão, todas as análises foram feitas sem a transformação dos dados (Zar 1999).

Dada a importância das múltiplas interações entre variáveis explanatórias, foram selecionados os modelos estatísticos mais parcimoniosos, usando o método de seleção par a par (stepwise, em inglês), baseado no Critério de Informação de Akaike corrigido $\left(\mathrm{AIC}_{\mathrm{c}}\right)$ para amostras finitas (Burnham \& Anderson 2002). O AIC $c$ é uma ferramenta para seleção de modelos que oferece medida relativa da qualidade de ajuste do modelo estatístico (Burnham \& Anderson 2002). A comparação dos parâmetros de germinação ( $\mathrm{G}$ e $\mathrm{T}_{\mathrm{m}}$ ) entre os pares conespecíficos for realizada através do teste de Sidak $(\mathrm{P}<0,05)$. Todas as análises foram feitas usando o software SPSS, versão 21 (IBM SPSS Statistics, Chicago, IL, USA). 


\section{Resultados}

\subsection{Massa fresca, massa seca e conteúdo de água inicial de sementes}

De modo geral, os valores de massa fresca, massa seca e conteúdo de água inicial de sementes foram estatisticamente iguais, tanto para Curatella americana, quanto para Bowdichia virgilioides, comparando-se populações dos cerrados de Roraima e do Brasil Central (Tabela 2). Exceção foi observada apenas em relação ao conteúdo de água inicial de B. virgilioides, cujas sementes pertencentes às populações do Brasil Central apresentaram valores significativamente maiores que aquelas de Roraima (Tabela 2). Por sua vez, comparando-se as populações de Anadenanthera peregrina de Roraima e do Brasil Central, foram observadas diferenças significativas em relação aos valores de massa fresca, massa seca e conteúdo de água inicial de suas sementes (Tabela 2).

Tabela 2. Massa fresca, massa seca e conteúdo de água de sementes de pares conespecíficos ocorrentes nos cerrados do Brasil Central e de Roraima. (Dados expressos como média \pm desvio padrão).

\begin{tabular}{ccccc}
\hline Espécie & Local de Ocorrência & Massa Fresca (mg) & Massa Seca (mg) & Conteúdo de Água (\%) \\
\hline & Savana do Brasil Central & $32,57 \pm 5,68$ & $26,24 \pm 4,24$ & $19,25 \pm 4,02$ \\
Bowdichia virgilioides & Savana de Roraima & $26,00 \pm 1,63$ & $23,75 \pm 0,95$ & $8,67 \pm 1,97$ \\
& & $\mathrm{P}=0,067$ & $\mathrm{P}=0,317$ & $21,02 \pm 2,78$ \\
Curatella americana & Savana do Brasil Central & $17,84 \pm 1,83$ & $14,08 \pm 1,41$ & $30,60 \pm 10,88$ \\
& Savana de Roraima & $19,12 \pm 2,56$ & $13,12 \pm 1,43$ & $\mathrm{P}=0,137$ \\
Anadenanthera peregrina & Savana de Roraima & $100,50 \pm 5,80$ & $84,75 \pm 5,31$ & $27,35 \pm 4,83$ \\
& & $\mathrm{P}=0,550$ & $\mathrm{P}=0,618$ & $15,70 \pm 1,50$
\end{tabular}

$\mathrm{P}$ - Valor de significância estatística obtido pelo teste de Sidak. 


\subsection{Tolerância à dessecação}

Diferentes padrões de resposta germinativa em relação à tolerância à dessecação de sementes foram observados para as populações de $B$. virgilioides, $C$. americana e $A$. peregrina dos cerrados de Roraima e do Brasil Central. Além disso, as variáveis incluídas dentro dos modelos estatísticos selecionados (ambiente de origem da população, conteúdo de água e massa das sementes) foram distintas para os três pares conespecíficos (B. virgilioides, C. americana e A. peregrina).

Sementes de B. virgilioides e de A. peregrina ocorrentes nos cerrados do Brasil Central mostraram-se significativamente mais sensíveis à dessecação do que aquelas dos cerrados de Roraima (Figuras 6 e 7). Em relação a B. virgilioides, o conteúdo de água das sementes, e a interação entre ambiente de origem da população e conteúdo de água, mostraram-se fatores altamente significativos dentro do modelo estatístico selecionado, sendo responsáveis por $74 \%\left(\mathrm{R}^{2}=0,743\right)$ da variação encontrada na germinação de suas sementes, quando submetidas à dessecação (Tabela A1, Apêndice). Já para A. peregrina foi observada elevada significância do conteúdo de água das sementes e do ambiente de origem da população dentro do modelo estatístico, fatores estes responsáveis por $54 \%\left(\mathrm{R}^{2}=0,536\right)$ da variação encontrada na germinação de suas sementes, quando submetidas à dessecação (Tabela A1, Apêndice).

Por outro lado, sementes dessecadas de C. americana pertencentes às populações dos cerrados do Brasil Central foram menos sensíveis aos efeitos da dessecação do que aquelas ocorrentes em Roraima (Figura 8), embora não tenha sido observada diferença estatística significativa em relação aos valores de germinabilidade (Figura 8). Para as populações desta espécie, apenas o conteúdo de água das sementes mostrou-se fator significativo dentro do modelo selecionado, sendo responsável por $37 \%\left(R^{2}=0,372\right)$ da variação encontrada na germinação de suas sementes, quando submetidas à dessecação (Tabela A1, Apêndice). 


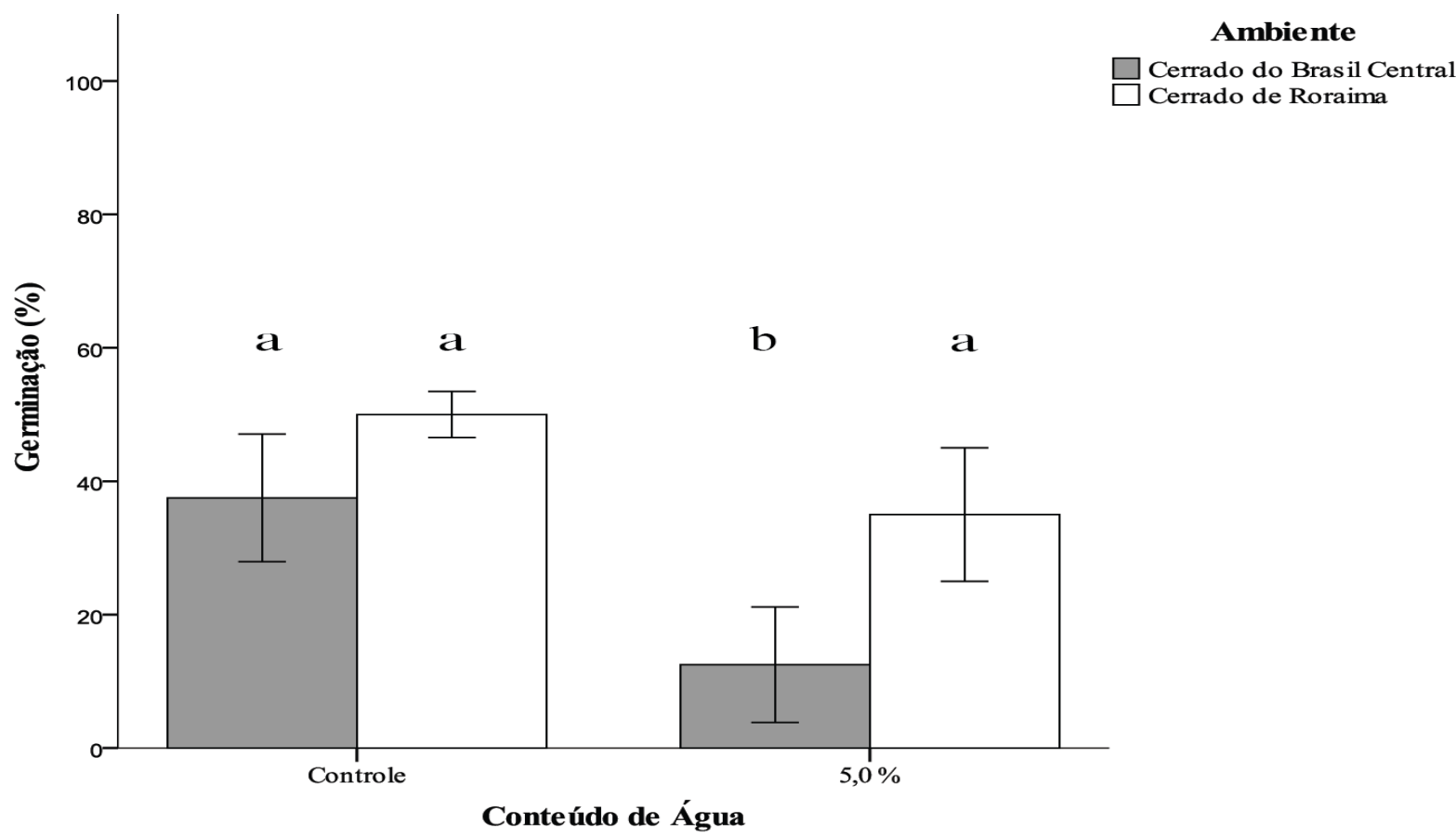

Figura 6. Germinação (média \pm desvio padrão) de sementes de populações de Bowdichia virgilioides submetidas à dessecação. Valores representados pela mesma letra, sobre as barras, não diferem entre si pelo teste de Sidak $(\mathrm{P}<0,05)$.

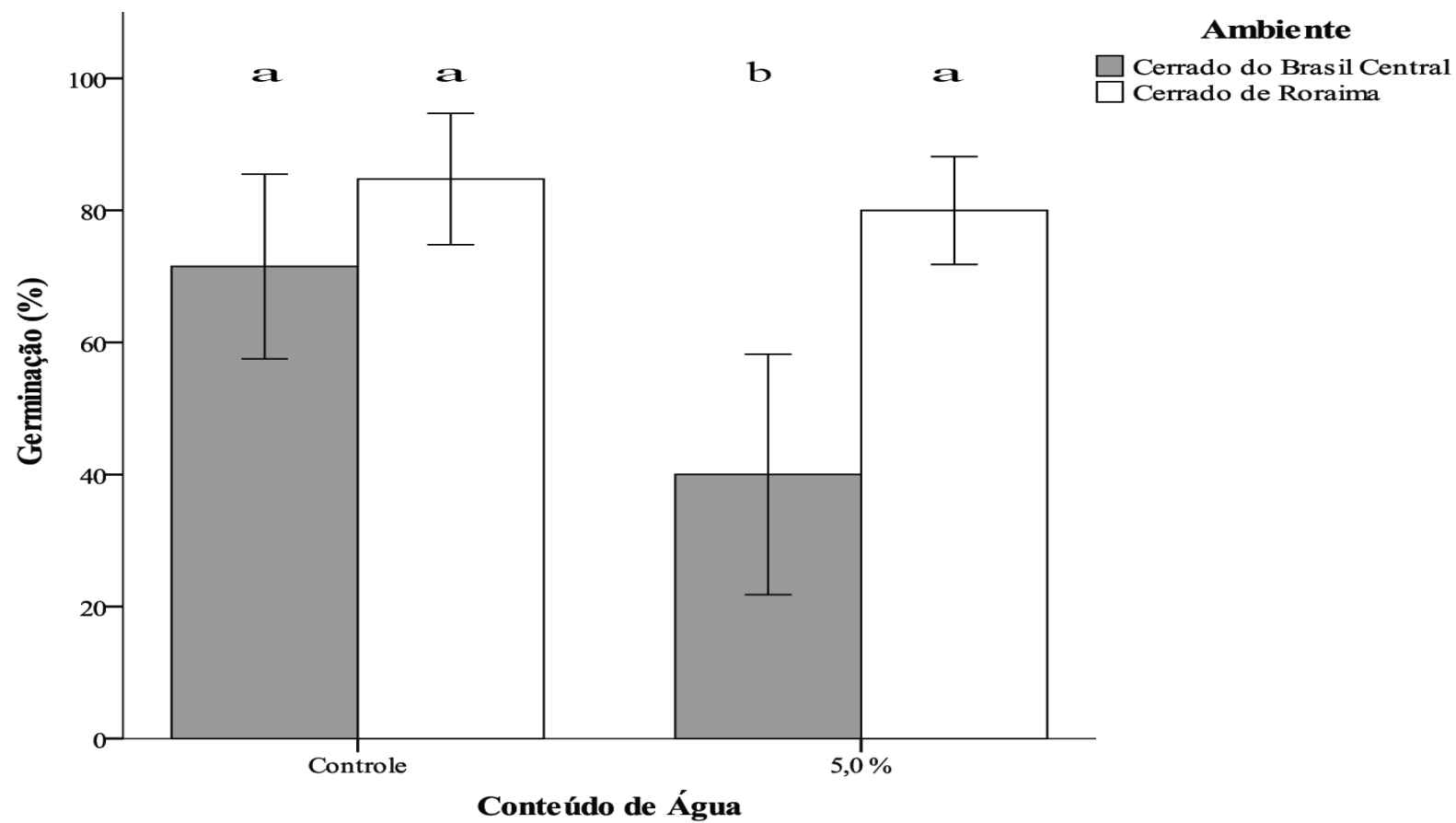

Figura 7. Germinação (média \pm desvio padrão) de sementes de populações de Anadenanthera peregrina submetidas à dessecação. Valores representados pela mesma letra, sobre as barras, não diferem entre si pelo teste de Sidak $(\mathrm{P}<0,05)$. 


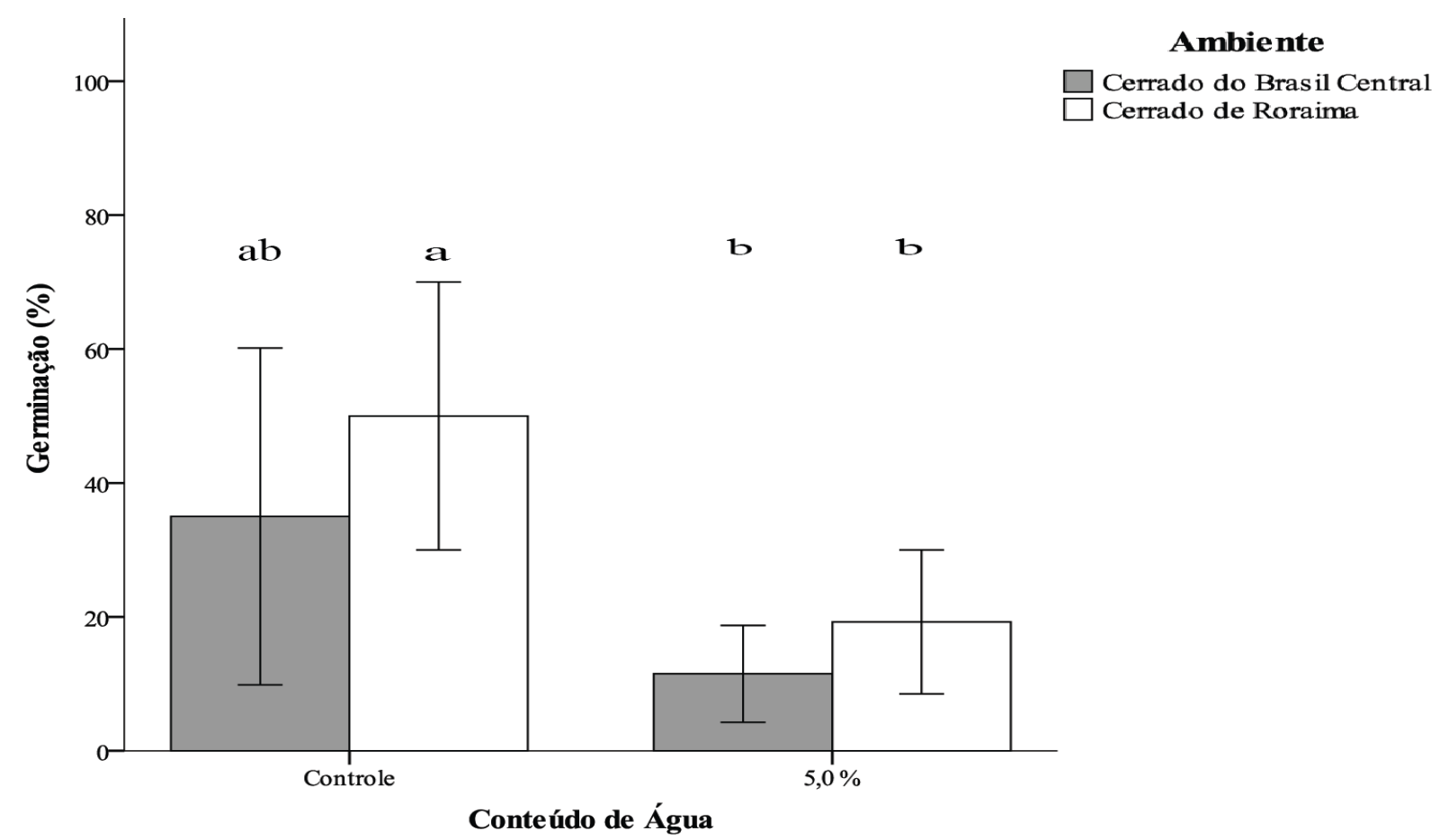

Figura 8. Germinação (média \pm desvio padrão) de sementes de populações de Curatella americana submetidas à dessecação. Valores representados pela mesma letra, sobre as barras, não diferem entre si pelo teste de Sidak $(\mathrm{P}<0,05)$.

Para a ocorrência da máxima germinabilidade, observou-se que sementes não dessecadas de $B$. virgilioides, de $C$. americana e de $A$. peregrina germinaram em tempos médios similares, comparando-se populações pertencentes aos cerrados de Roraima e do Brasil Central (Figuras 9, 10 e 11). Além disso, a redução no conteúdo de água das sementes não afetou o tempo médio de germinação destas espécies, independente da origem da população (Figuras 9, 10 e 11). 


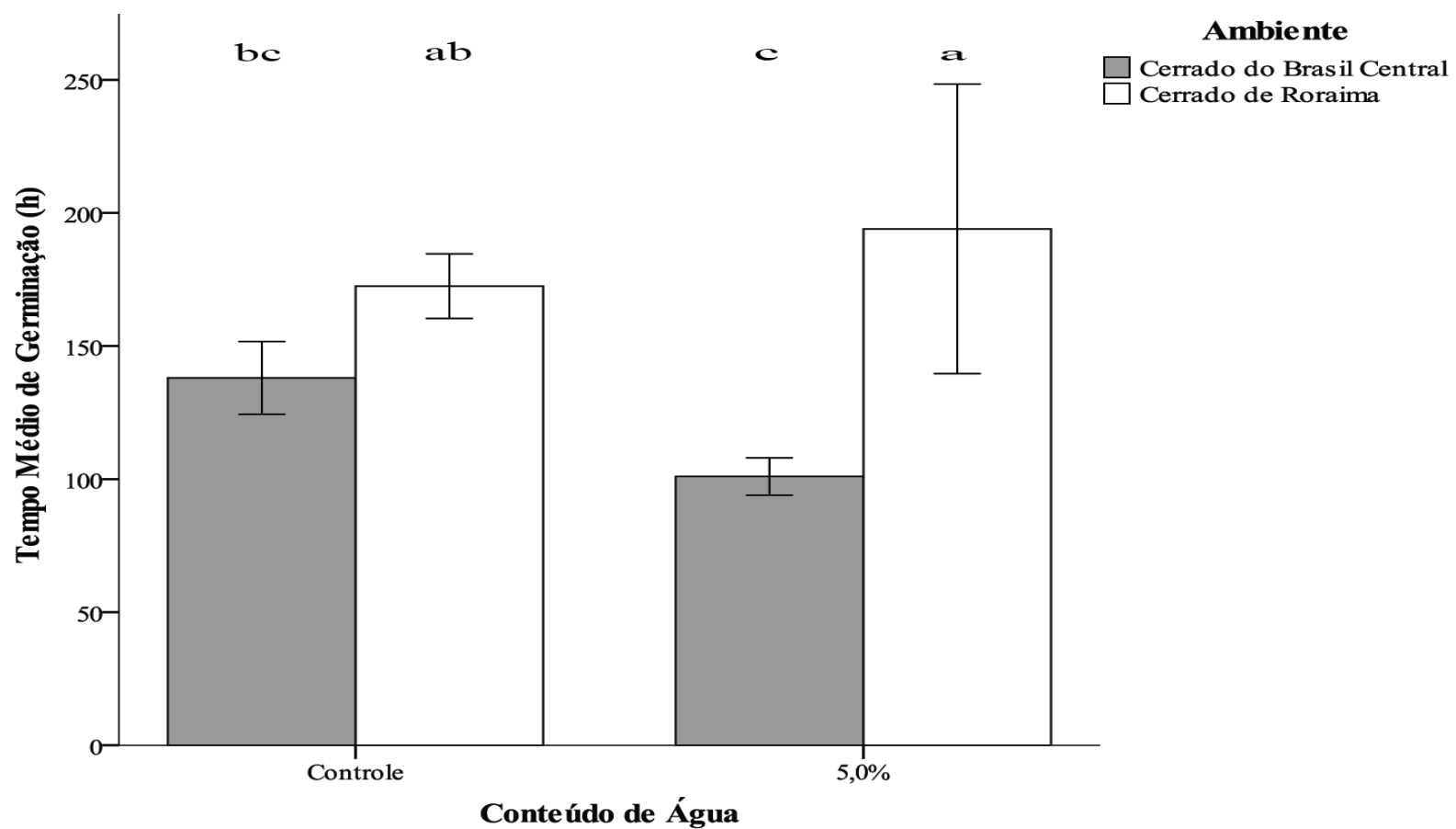

Figura 9. Tempo médio de germinação (média \pm desvio padrão) de sementes de Bowdichia virgilioides submetidas à dessecação. Valores representados pela mesma letra, sobre as barras, não diferem entre si pelo teste de Sidak $(\mathrm{P}<0,05)$.

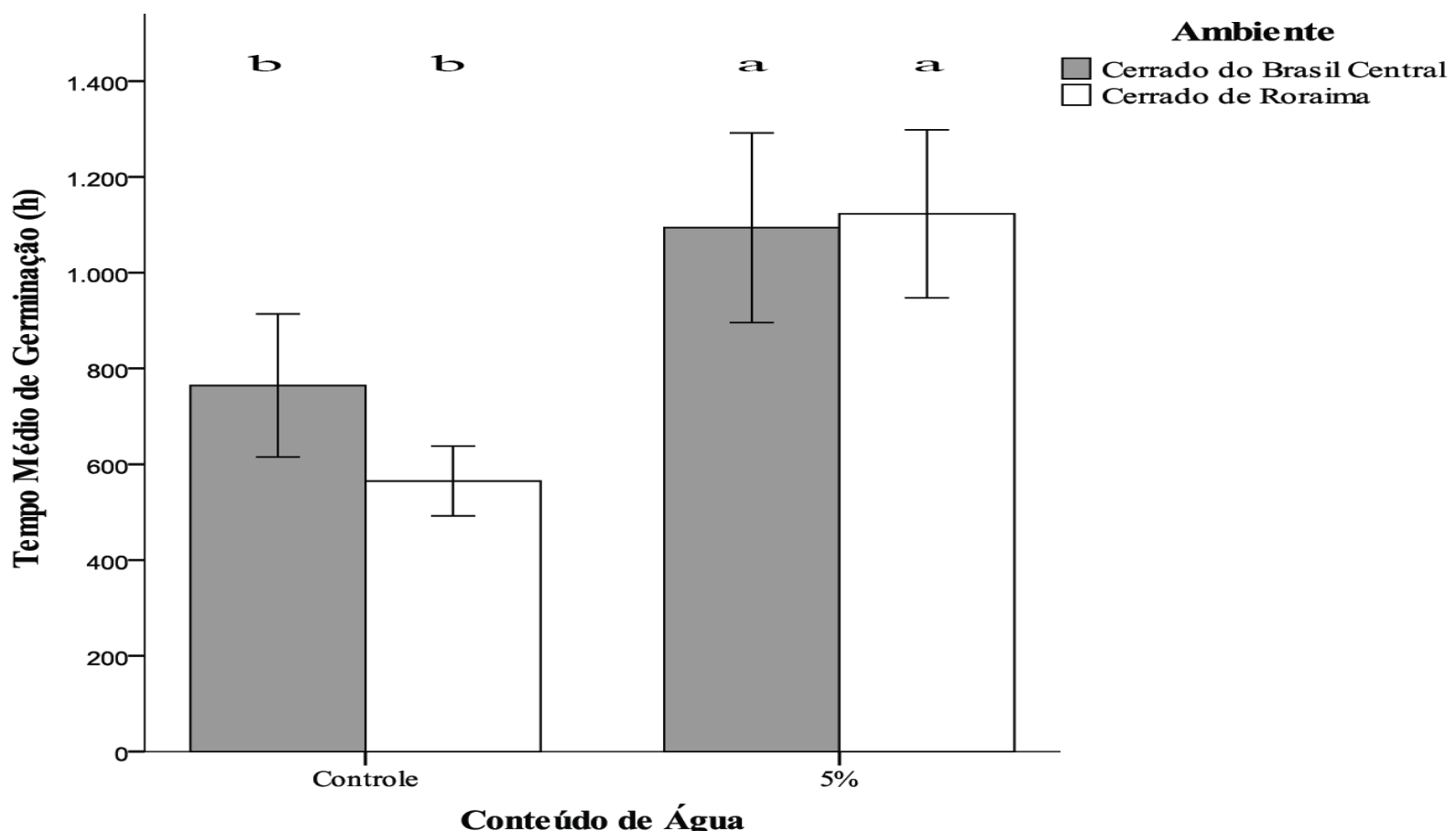

Figura 10. Tempo médio de germinação (média \pm desvio padrão) de sementes de Curatella americana submetidas à dessecação. Valores representados pela mesma letra, sobre as barras, não diferem entre si pelo teste de Sidak $(\mathrm{P}<0,05)$. 


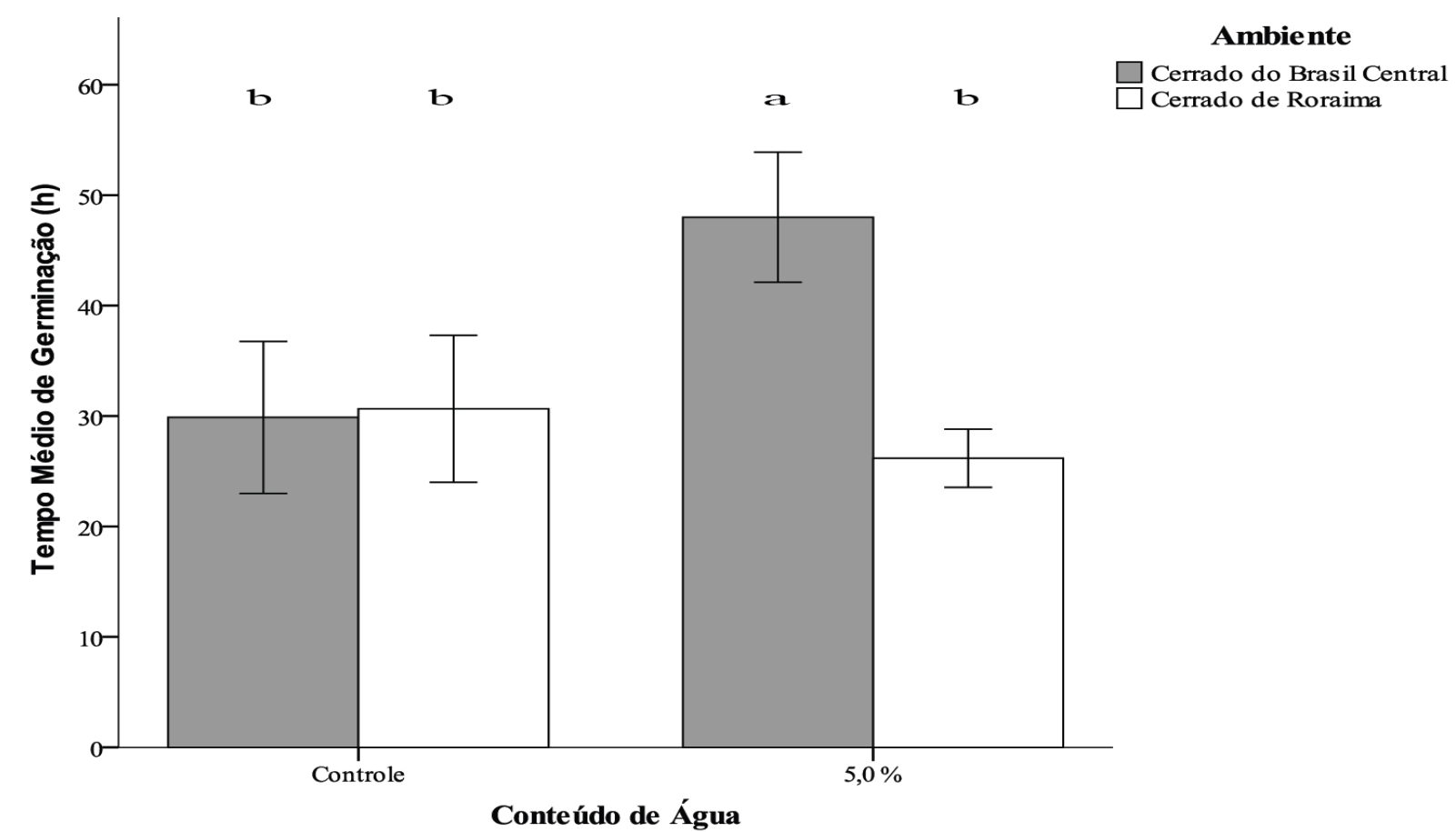

Figura 11. Tempo médio de germinação (média \pm desvio padrão) de sementes de Anadenanthera peregrina $(\mathrm{C})$ submetidas à dessecação. Valores representados pela mesma letra, sobre as barras, não diferem entre si pelo teste de Sidak $(\mathrm{P}<0,05)$.

\subsection{Tolerância ao déficit hídrico}

Para as três espécies deste estudo, independente do ambiente de origem de sua população, a porcentagem de germinação diminuiu à medida que o potencial osmótico se tornou mais negativo, embora diferentes padrões de resposta germinativa, em relação à tolerância ao déficit hídrico, tenham sido observados para as suas respectivas populações. Além disso, diferenças significativas na germinabilidade entre pares conespecíficos de $B$. virgilioides, C. americana e A. peregrina variaram em função do ambiente de origem da população (Cerrado de Roraima vs Cerrado do Brasil Central) e do potencial osmótico.

Sementes das populações de B. virgilioides ocorrentes nos cerrados de Roraima e do Brasil Central mostraram comportamento germinativo similar quando expostas a gradientes crescentes de déficit hídrico. Para esta espécie, potenciais osmóticos de até $-0,6 \mathrm{MPa}$ não 
reduziram a potencial germinativo de suas sementes, independente da origem da população (Figura 12). Para B. virgilioides, apenas o potencial osmótico mostrou-se significativo dentro do modelo estatístico selecionado, sendo tal fator responsável por $38 \%\left(R^{2}=0,383\right)$ da variação encontrada na germinação de suas sementes, quando submetidas a déficit hídrico crescente (Tabela A2, Apêndice).

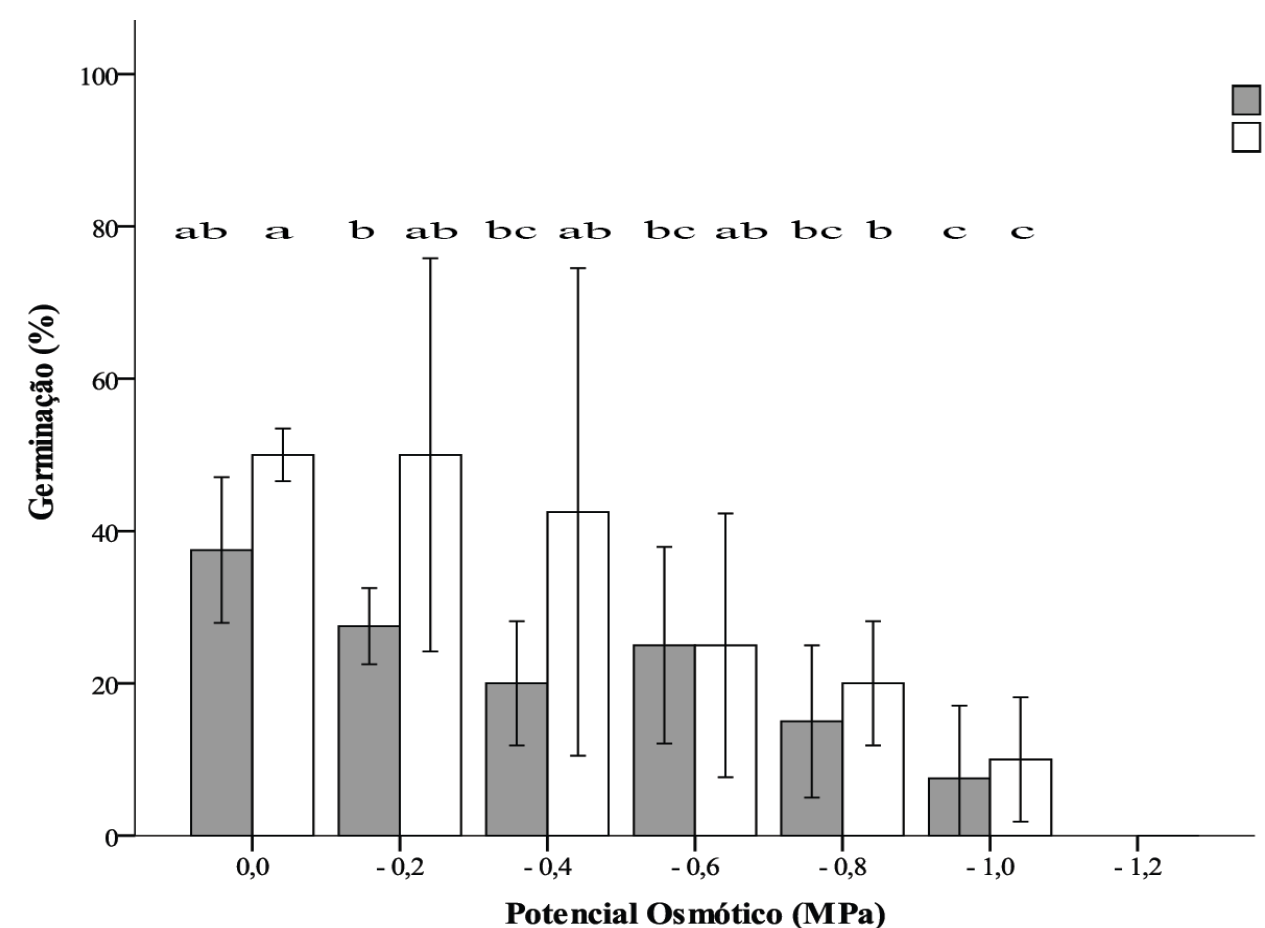

\section{Ambiente}

Cerrado do Brasil Central Cerrado de Roraima

Figura 12. Germinação (média \pm desvio padrão) de sementes de populações de Bowdichia virgilioides submetidas ao déficit hídrico. Valores representados pela mesma letra, sobre as barras, não diferem entre si pelo teste de $\operatorname{Sidak}(\mathrm{P}<0,05)$.

Sementes de populações de A. peregrina ocorrentes nos cerrados de Roraima e do Brasil Central também mostraram comportamento germinativo similar quando expostas a gradientes crescentes de déficit hídrico. Para esta espécie, potencial osmótico igual ou inferior a $-0,4$ MPa reduziu significativamente a germinabilidade de suas sementes, independente da origem da população (Figura 13). Ainda em relação à A. peregrina, o potencial osmótico mostrou-se altamente significativo dentro do modelo estatístico selecionado, sendo responsável por $81 \%$ 
$\left(\mathrm{R}^{2}=0,808\right)$ da variação encontrada na germinação de suas sementes, quando submetidas a déficit hídrico crescente (Tabela A2, Apêndice).

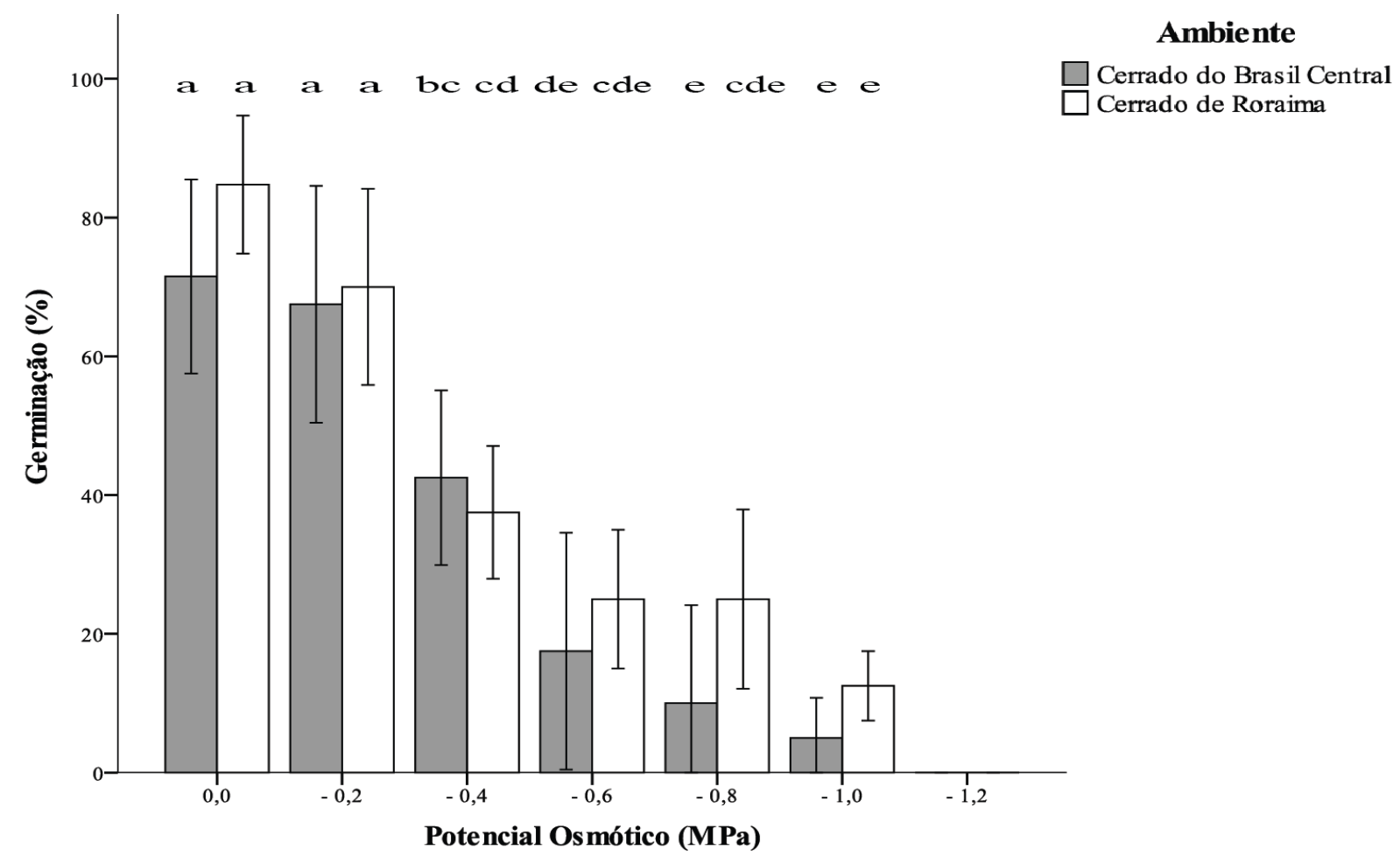

Figura 13. Germinação (média \pm desvio padrão) de sementes de populações de Anadenanthera peregrina submetidas ao déficit hídrico. Valores representados pela mesma letra, sobre as barras, não diferem entre si pelo teste de Sidak $(\mathrm{P}<0,05)$.

Por outro lado, sementes de $C$. americana pertencentes às populações dos cerrados de Roraima mostraram maior tolerância aos efeitos do déficit hídrico do que aquelas dos cerrados Brasil Central, principalmente em potenciais osmóticos mais negativos $\left(\Psi_{\pi} \leq-0,6\right.$ $\mathrm{MPa}$ ), em que diferenças significativas nos percentuais de germinação foram observadas (Figura 14). Para C. americana, apenas o potencial osmótico e o ambiente de origem da população mostraram-se fatores significativos dentro do modelo estatístico selecionado, sendo responsáveis por $61 \%\left(\mathrm{R}^{2}=0,609\right)$ da variação encontrada na germinação de suas sementes, quando submetidas a déficit hídrico crescente (Tabela A2, Apêndice). 


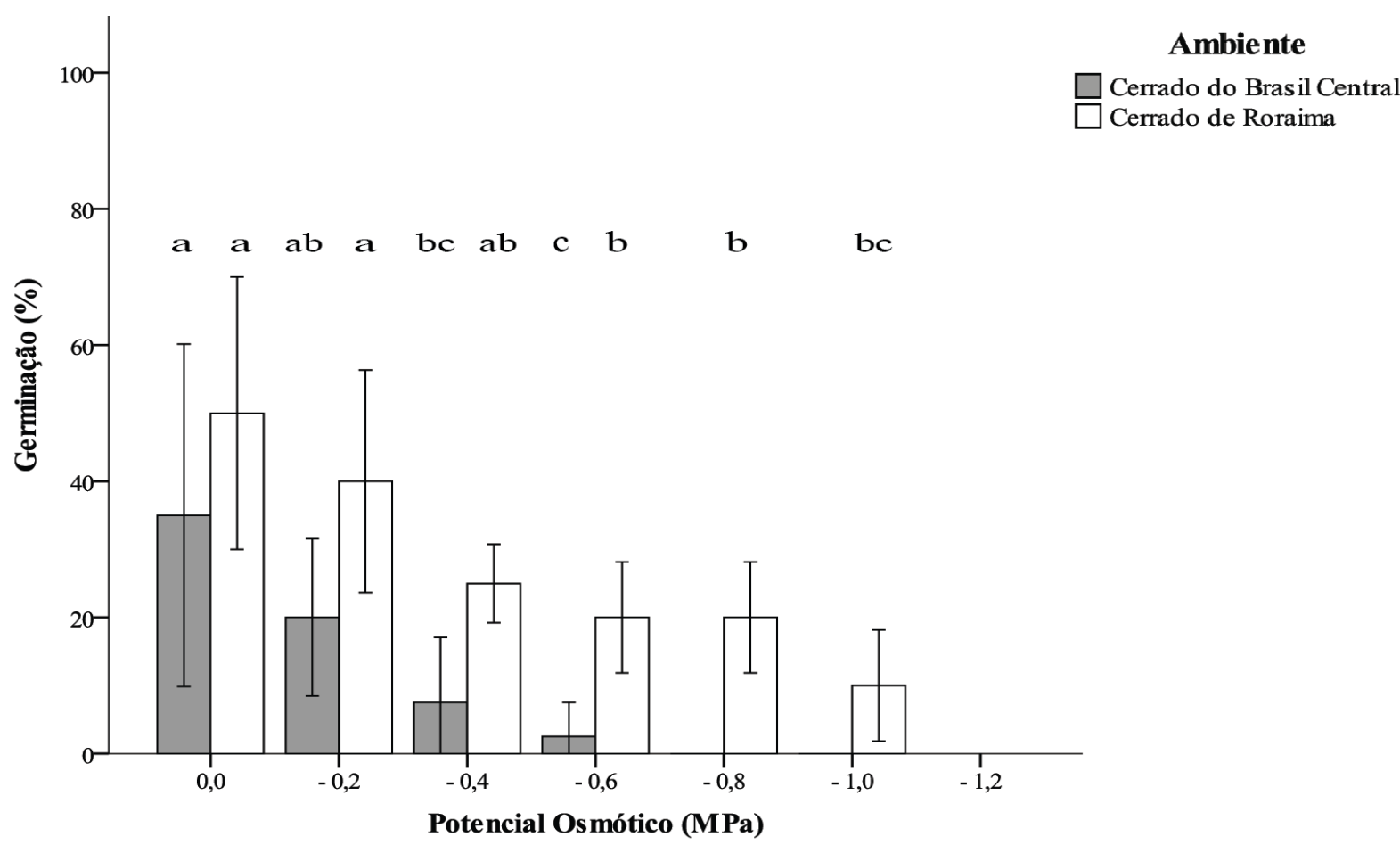

Figura 14. Germinação (média \pm desvio padrão) de sementes de populações de Curatella americana submetidas ao déficit hídrico. Valores representados pela mesma letra, sobre as barras, não diferem entre si pelo teste de $\operatorname{Sidak}(\mathrm{P}<0,05)$.

De modo geral, observou-se que para a ocorrência da máxima germinabilidade, aumentos significativos nos tempos médios de germinação foram mais comuns para as populações ocorrentes nos cerrados de Roraima do que para aquelas dos cerrados do Brasil Central, principalmente em potenciais osmóticos mais negativos (Figuras 15, 16 e 17). 


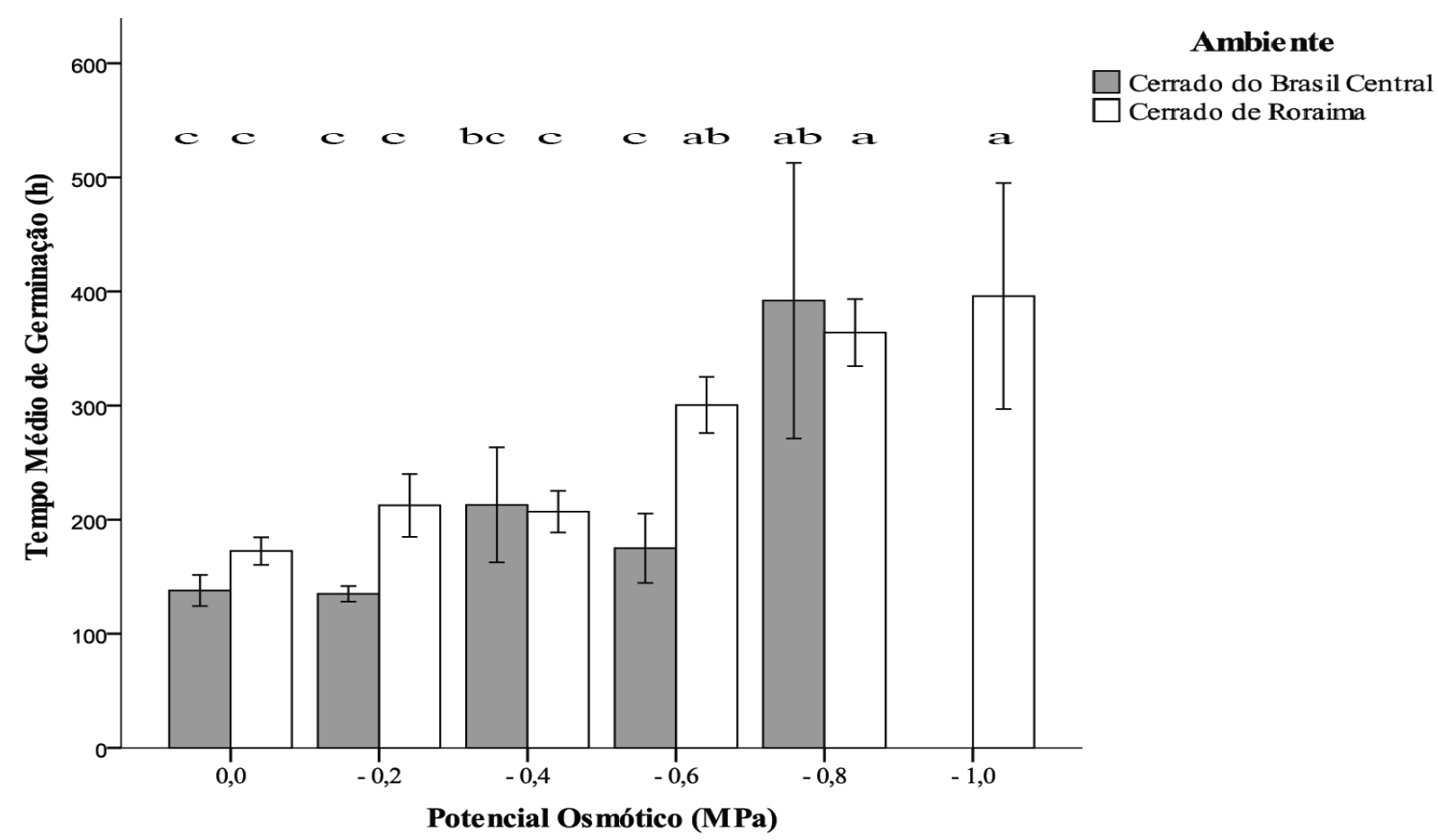

Figura 15. Tempo médio de germinação (média \pm desvio padrão) de sementes de Bowdichia virgilioides submetidas ao déficit hídrico. Valores representados pela mesma letra, sobre as barras, não diferem entre si pelo teste de $\operatorname{Sidak}(\mathrm{P}<0,05)$.

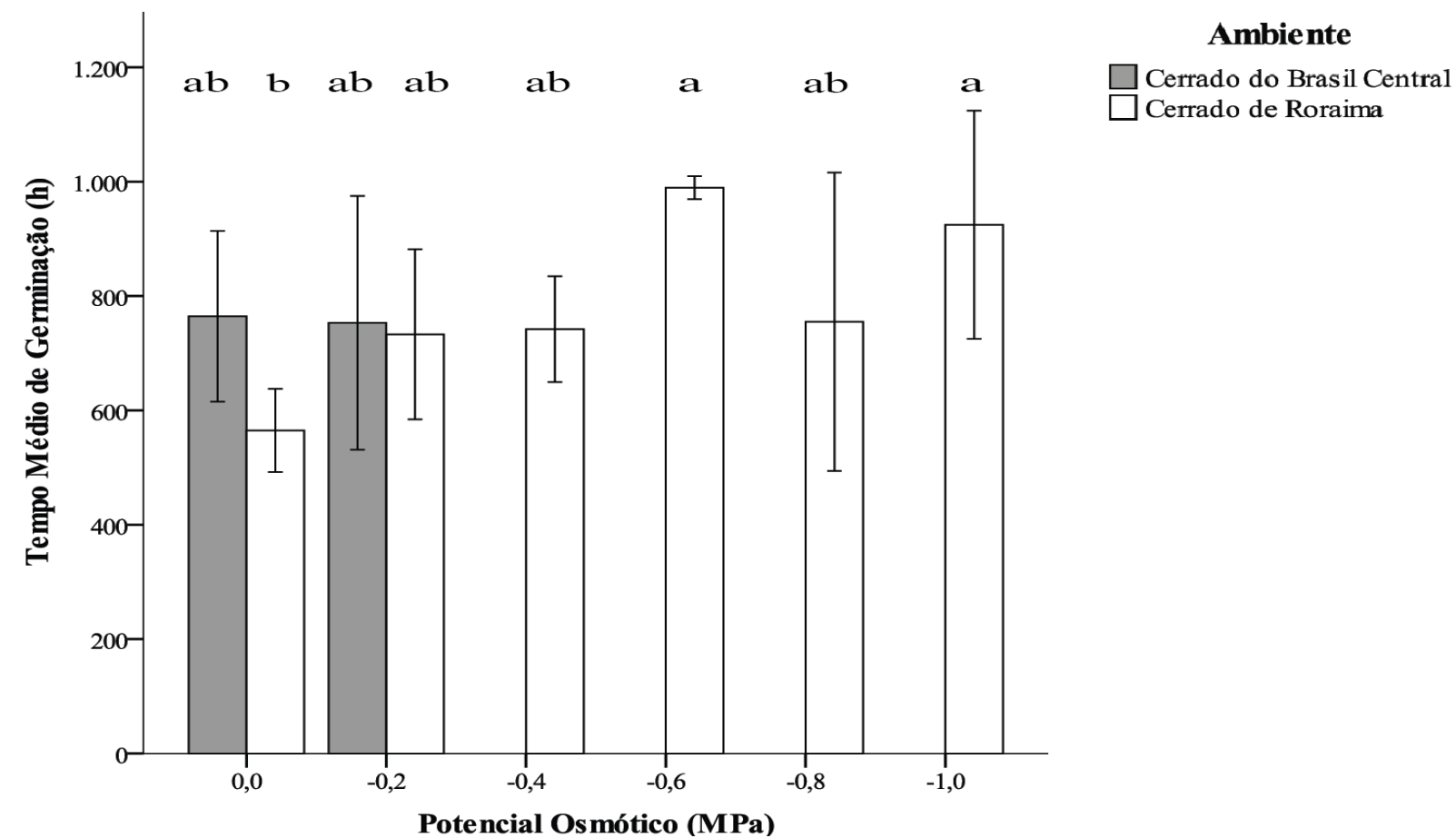

Figura 16. Tempo médio de germinação (média \pm desvio padrão) de sementes de Curatella americana submetidas ao déficit hídrico. Valores representados pela mesma letra, sobre as barras, não diferem entre si pelo teste de Sidak $(\mathrm{P}<0,05)$. 


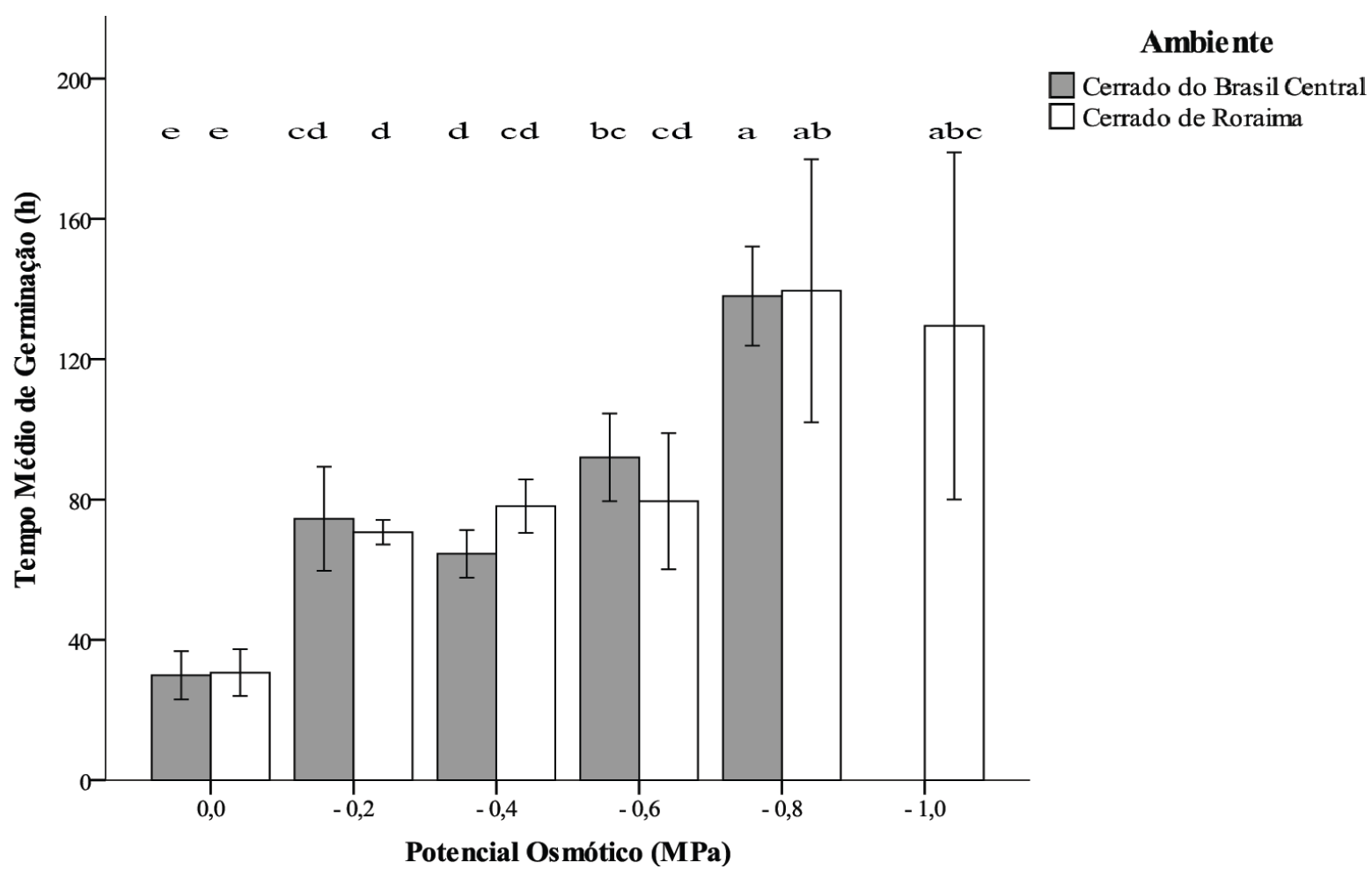

Figura 17. Tempo médio de germinação (média \pm desvio padrão) de sementes de Anadenanthera peregrina submetidas ao déficit hídrico. Valores representados pela mesma letra, sobre as barras, não diferem entre si pelo teste de Sidak $(\mathrm{P}<0,05)$.

\subsection{Tolerância a choques térmicos}

A exposição aos choques térmicos mostrou que o nível tolerância das sementes a este tipo de estresse foi variável entre as espécies (B. virgilioides, C. americana e A. peregrina) e também entre populações da mesma espécie (Cerrado de Roraima vs Cerrado do Brasil Central). De modo geral, sementes pertencentes às populações dos cerrados de Roraima apresentaram maior tolerância aos efeitos dos choques térmicos do que aquelas dos cerrados do Brasil Central. Além disso, as variáveis incluídas dentro dos modelos estatísticos selecionados (ambiente de origem da população, temperatura, tempo de exposição e massa das sementes) foram distintas para os três pares conespecíficos estudados.

Em relação a $B$. virgiliodes, sementes de populações ocorrentes nos cerrados de Roraima e do Brasil Central apresentaram padrão similar de reposta germinativa quando 
expostas a choques térmicos de $80^{\circ} \mathrm{C}$, independente do tempo de exposição (Figura 18). Já a exposição a $110^{\circ} \mathrm{C}$ por 2,5 minutos foi praticamente letal para sementes de $B$. virgiliodes ocorrentes nos cerrados do Brasil Central, mas não para aquelas dos cerrados de Roraima, as quais mostraram tolerância a temperaturas de até $140^{\circ} \mathrm{C}$, em tempo de exposição equivalente (Figura 15). Entretanto, a combinação de temperaturas moderadas a altas $\left(\geq 110^{\circ} \mathrm{C}\right)$ com o maior tempo de exposição (5 minutos) foi letal para as sementes de B. virgiliodes, independente da origem da população (Figura 18). Ainda para esta espécie, apenas a temperatura e a interação entre ambiente de origem e temperatura mostraram-se significativos dentro do modelo estatístico selecionado, sendo tais fatores responsáveis por $55 \%\left(\mathrm{R}^{2}=\right.$ 0,551) da variação encontrada na germinação de suas sementes, quando submetidas a choques térmicos (Tabela A3, Apêndice).

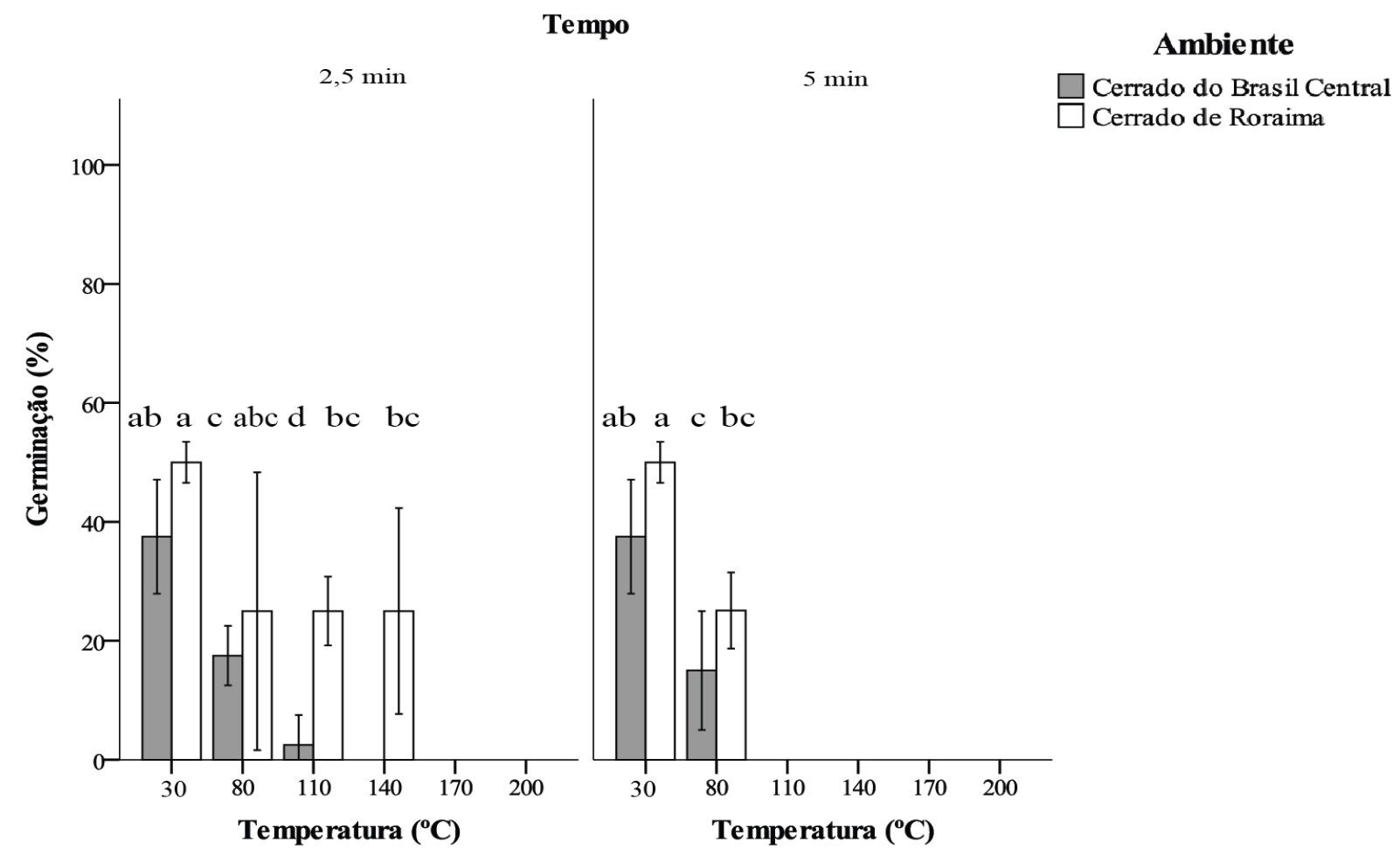

Figura 18. Germinação (média \pm desvio padrão) de sementes de populações de Bowdichia virgilioides submetidas a choques térmicos. Valores representados pela mesma letra, sobre as barras, não diferem entre si pelo teste de $\operatorname{Sidak}(\mathrm{P}<0,05)$. 
Para $C$. americana, sementes das populações ocorrentes nos cerrados de Roraima e do Brasil Central apresentaram tolerância similar aos efeitos dos choques térmicos de 80 e $110^{\circ} \mathrm{C}$ por 2,5 minutos (Figura 19). Entretanto, em tempo de exposição equivalente, o aumento da temperatura para $140^{\circ} \mathrm{C}$ foi letal para as sementes das populações de $C$. americana dos cerrados do Brasil Central, mas não para aquelas dos cerrados de Roraima (Figura 19). Por outro lado, temperaturas moderadas a altas $\left(\geq 110^{\circ} \mathrm{C}\right)$, combinadas com o maior tempo de exposição (5 minutos), foram letais para as sementes desta espécie, independente da procedência da população (Figura 19). Ainda para C. americana, apenas o ambiente de origem da população e a interação entre temperatura e tempo de exposição mostraram-se significativos dentro do modelo estatístico selecionado, sendo tais fatores responsáveis por $36 \%\left(\mathrm{R}^{2}=0,361\right)$ da variação encontrada na germinação de suas sementes, quando submetidas a choques térmicos (Tabela A3, Apêndice).

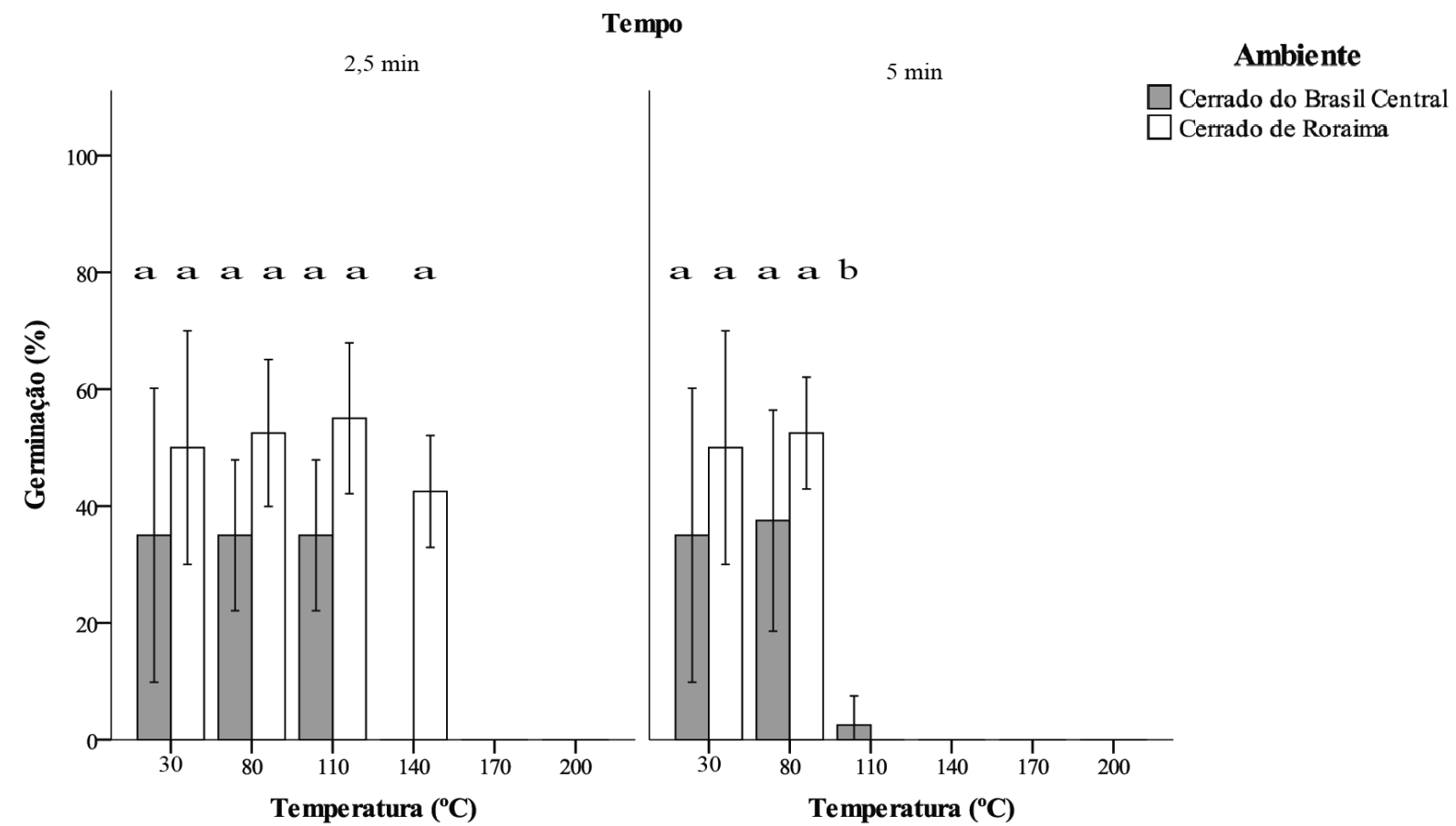

Figura 19. Germinação (média \pm desvio padrão) de sementes de populações de Curatella americana submetidas a choques térmicos. Valores representados pela mesma letra, sobre as barras, não diferem entre si pelo teste de $\operatorname{Sidak}(\mathrm{P}<0,05)$. 
Em relação a A. peregrina, sementes de populações dos cerrados de Roraima e do Brasil Central apresentaram percentual de germinação estatisticamente igual quando expostas a choques térmicos de 80,110 e $170^{\circ} \mathrm{C}$ por 2,5 minutos (Figura 20). Entretanto, as sementes de A. peregrina das populações de Roraima foram mais tolerantes ao choque térmico de $140^{\circ} \mathrm{C}$ por 2,5 minutos do que aquelas ocorrentes no Brasil Central (Figura 20). Já a combinação entre temperaturas moderadas a altas $\left(\geq 110^{\circ} \mathrm{C}\right)$ e tempo de exposição elevado (5 minutos) foi letal para as sementes de A. peregrina, independente da origem da população (Figura 20). Ainda para esta espécie, o ambiente de origem da população, a temperatura, o tempo de exposição, bem como a interação entre tais fatores, mostraram-se significativos dentro do modelo estatístico selecionado, sendo responsáveis por $54 \%\left(\mathrm{R}^{2}=0,536\right)$ da variação encontrada na germinação de suas sementes, quando submetidas a choques térmicos (Tabela A3, Apêndice).

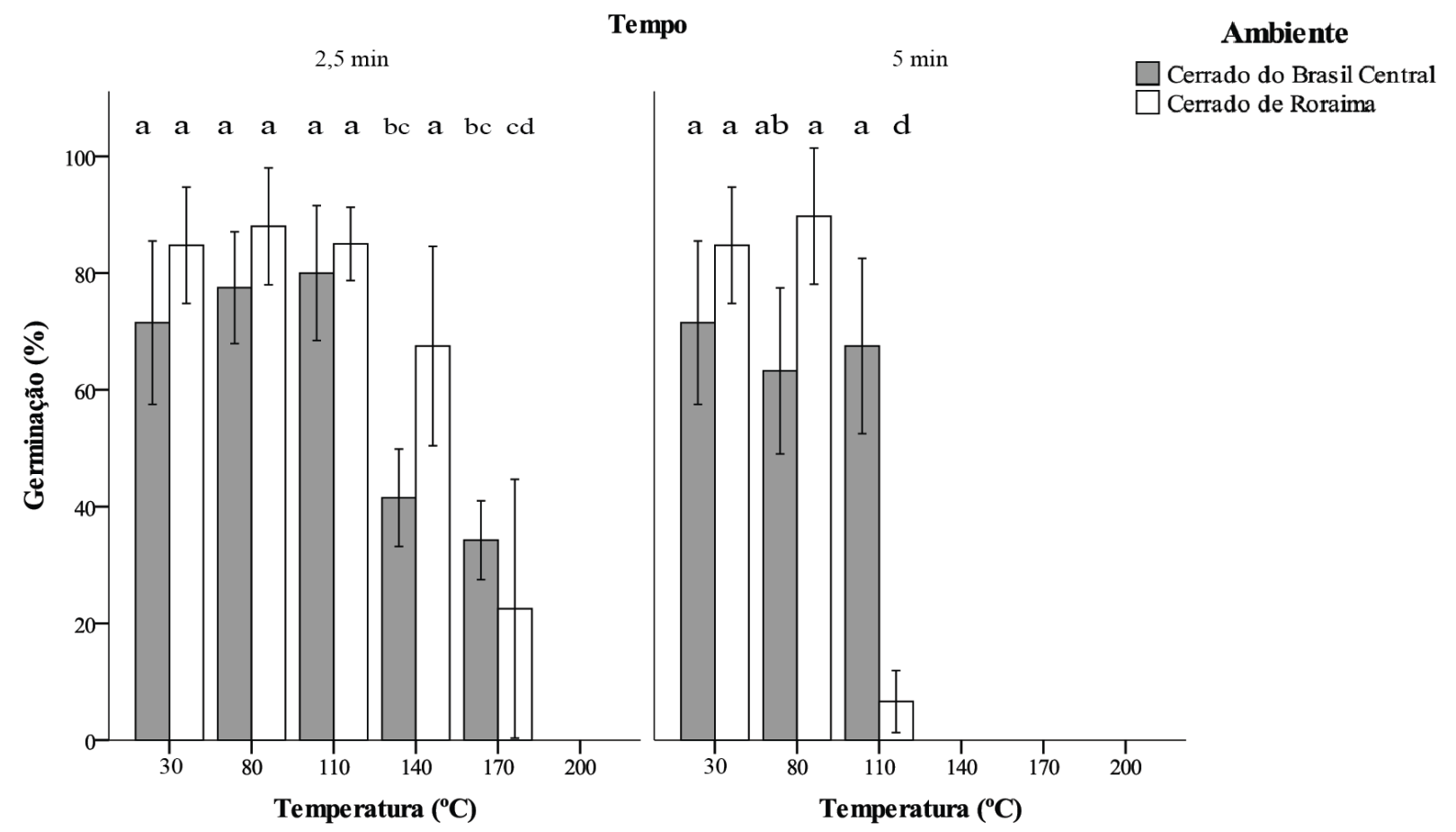

Figura 20. Germinação (média \pm desvio padrão) de sementes de populações de Anadenanthera peregrina submetidas a choques térmicos. Valores representados pela mesma letra, sobre as barras, não diferem entre si pelo teste de Sidak $(\mathrm{P}<0,05)$. 
Para a ocorrência da máxima germinabilidade, tanto para populações ocorrentes nos cerrados de Roraima, quanto para aquelas ocorrentes nos cerrados do Brasil Central, os tempos médios de germinação se mostraram muito similares quando comparadas sementes expostas e não expostas aos choques térmicos (Figuras 21, 22 e 23), embora aumentos significativos neste parâmetro tenham sido observados em alguns choques térmicos que ocasionaram perda significativa de germinabilidade (ver Figuras 18 a 23).

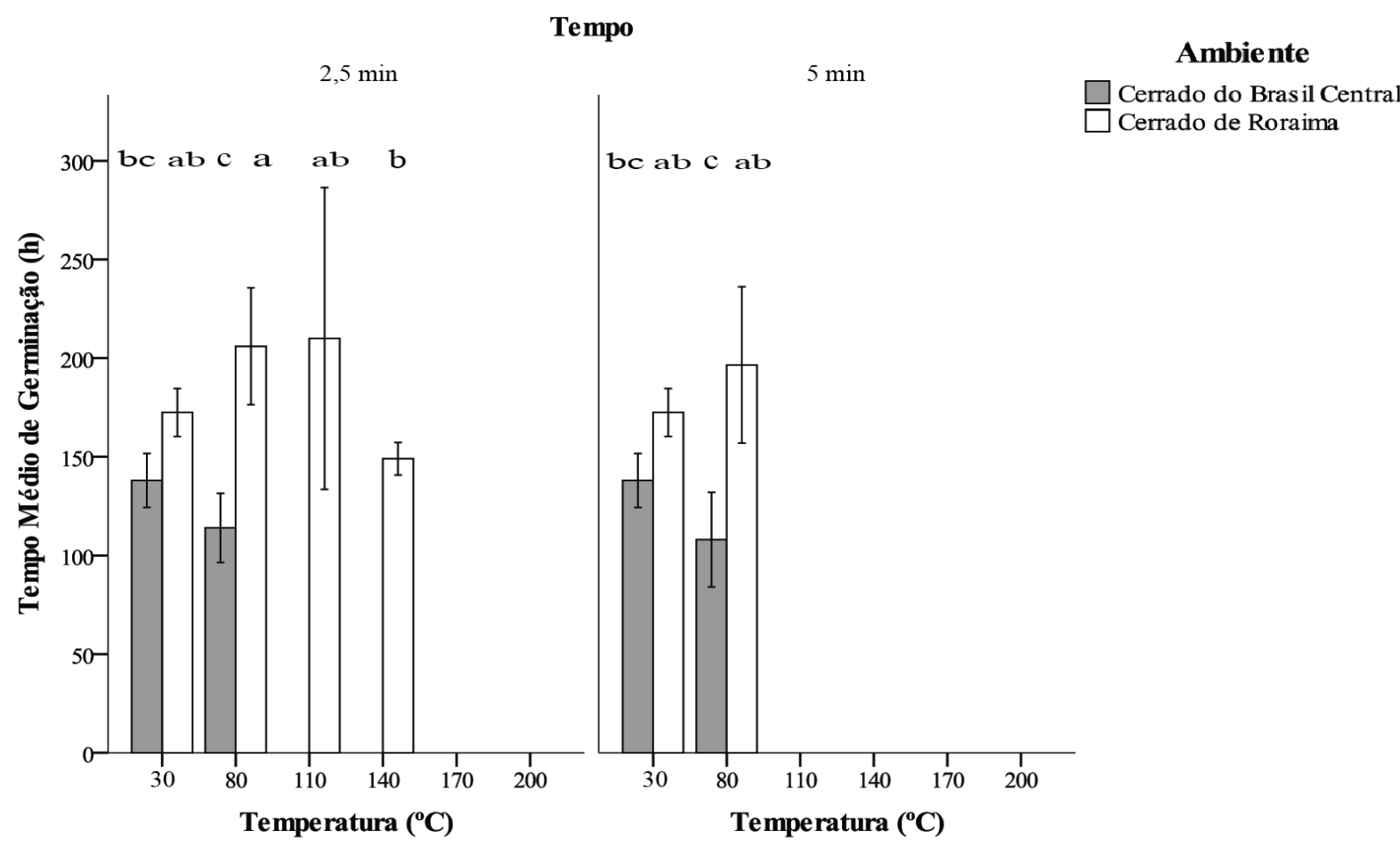

Figura 21. Tempo médio de germinação (média \pm desvio padrão) de sementes de Bowdichia virgilioides submetidas a choques térmicos. Valores representados pela mesma letra, sobre as barras, não diferem entre si pelo teste de Sidak $(\mathrm{P}<0,05)$. 


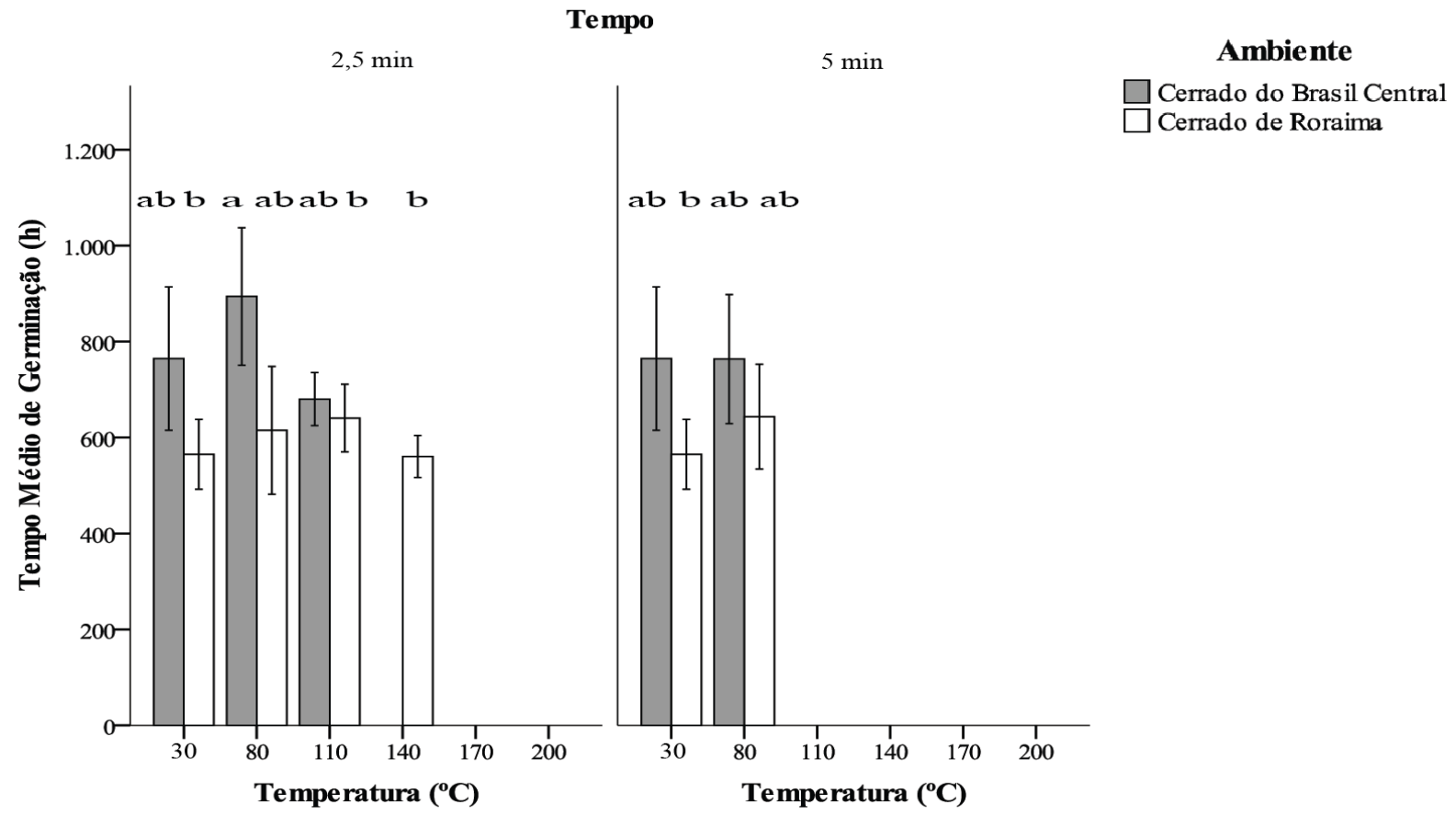

Figura 22. Tempo médio de germinação (média \pm desvio padrão) de sementes de Curatella americana submetidas a choques térmicos. Valores representados pela mesma letra, sobre as barras, não diferem entre si pelo teste de $\operatorname{Sidak}(\mathrm{P}<0,05)$.

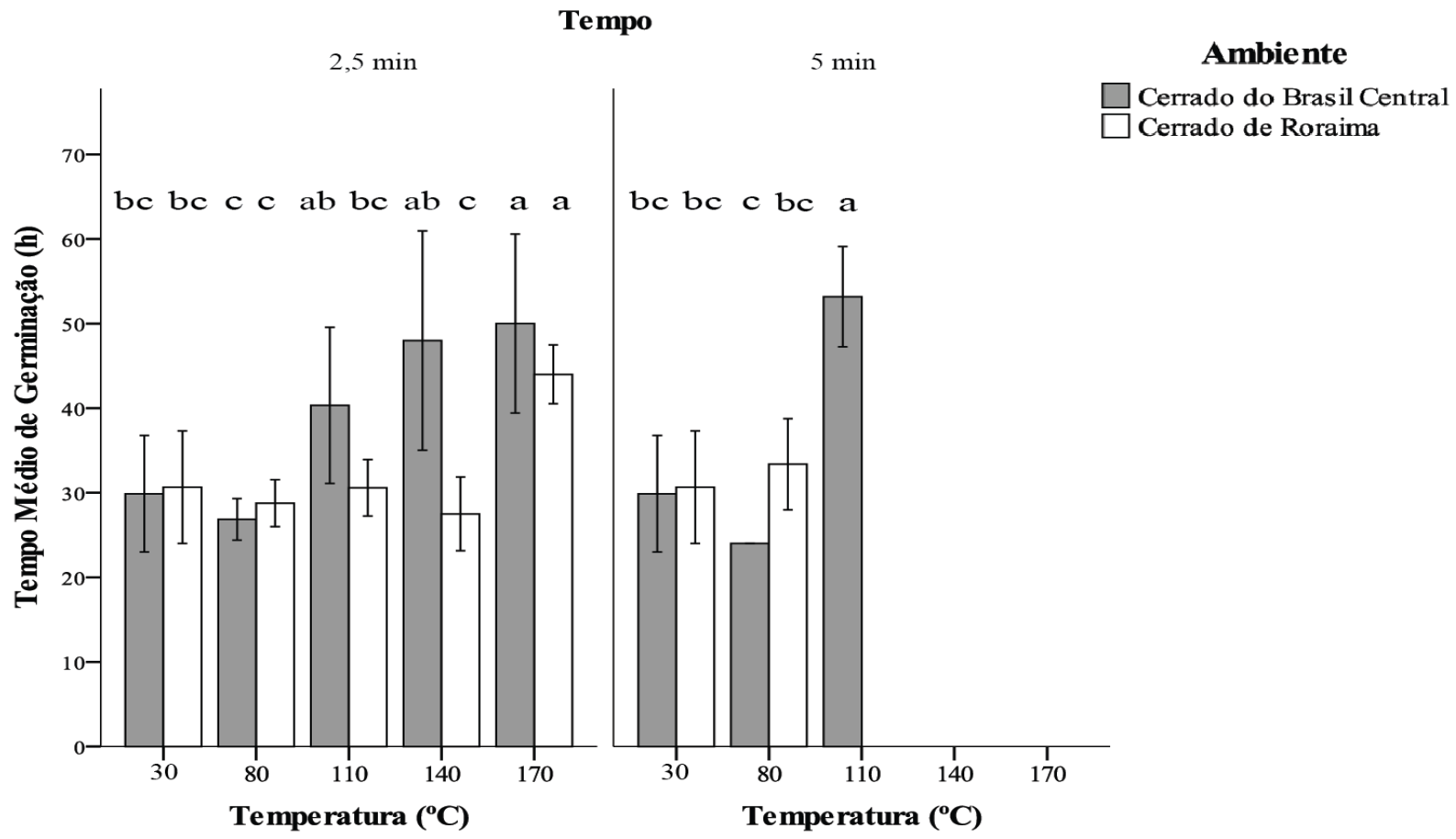

Figura 23. Tempo médio de germinação (média \pm desvio padrão) de sementes de Anadenanthera peregrina submetidas a choques térmicos. Valores representados pela mesma letra, sobre as barras, não diferem entre si pelo teste de Sidak $(\mathrm{P}<0,05)$. 


\subsection{Germinação em temperaturas crescentes}

Em relação à resposta germinativa em temperaturas crescentes, observou-se que a germinabilidade das populações de B. virgilioides, C. americana e A. peregrina, ocorrentes nos cerrados de Roraima e do Brasil Central, foi similar nas temperaturas de 20,25 e $30^{\circ} \mathrm{C}$ (Figuras 24, 25 e 26). Entretanto, quando a temperatura foi aumentada para 35 e $40^{\circ} \mathrm{C}$, as populações ocorrentes nos cerrados do Brasil Central apresentaram maiores reduções na germinabilidade em relação àquelas dos cerrados de Roraima (Figuras 24, 25 e 26).

Para B. virgilioides, temperatura igual ou superior a $35^{\circ} \mathrm{C}$ reduziu significativamente a germinabilidade de suas sementes, embora esta redução tenha se mostrado muito maior para a população dos cerrados do Brasil Central (Figura 24). Por outro lado, sementes de $C$. americana ocorrentes nos cerrados de Roraima e do Brasil Central mostraram-se mais tolerantes aos efeitos de altas temperaturas, posto que a germinabilidade em temperaturas de até $35^{\circ} \mathrm{C}$ não foi significativamente reduzida em relação às temperaturas mais baixas (Figura 25). Entretanto, sementes de B. virgilioides e C. americana ocorrentes nos cerrados do Brasil Central não germinaram a $40^{\circ} \mathrm{C}$, sendo esta temperatura letal para as mesmas (Figuras 24 e 25). O ambiente de origem da população e a temperatura de germinação foram os fatores significativos dentro do modelo estatístico, sendo responsáveis por $58 \%\left(\mathrm{R}^{2}=0,578\right)$ e $40 \%$ $\left(\mathrm{R}^{2}=0,405\right)$ da variação encontrada na germinação, em temperaturas crescentes, para populações de B. virgilioides e de C. americana, respectivamente (Tabela A4, Apêndice). 


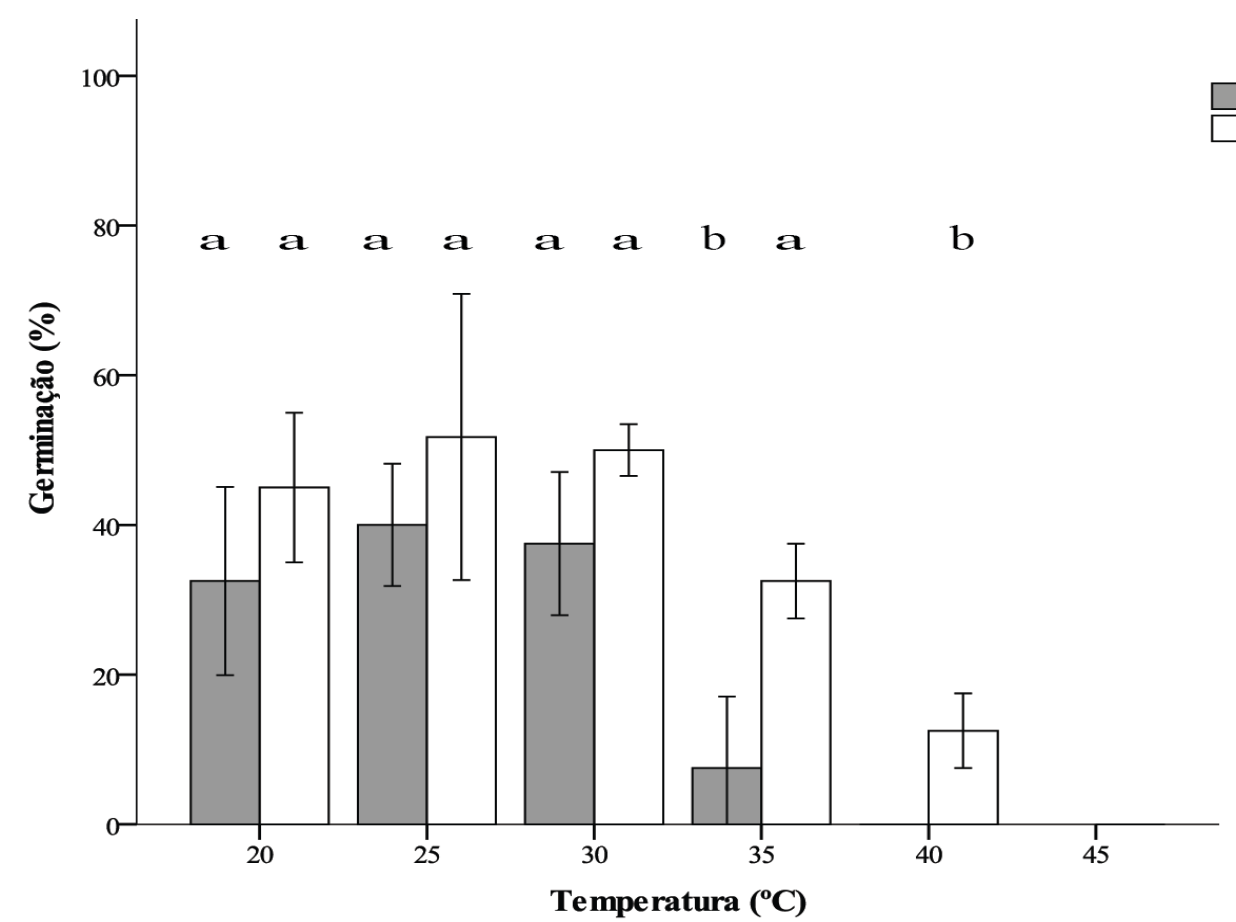

\section{Ambiente}

Cerrado do Brasil Central Cerrado de Roraima

Figura 24. Germinação (média \pm desvio padrão), em temperaturas crescentes, de sementes de populações de Bowdichia virgilioides. Valores representados pela mesma letra, sobre as barras, não diferem entre si pelo teste de Sidak $(\mathrm{P}<0,05)$.

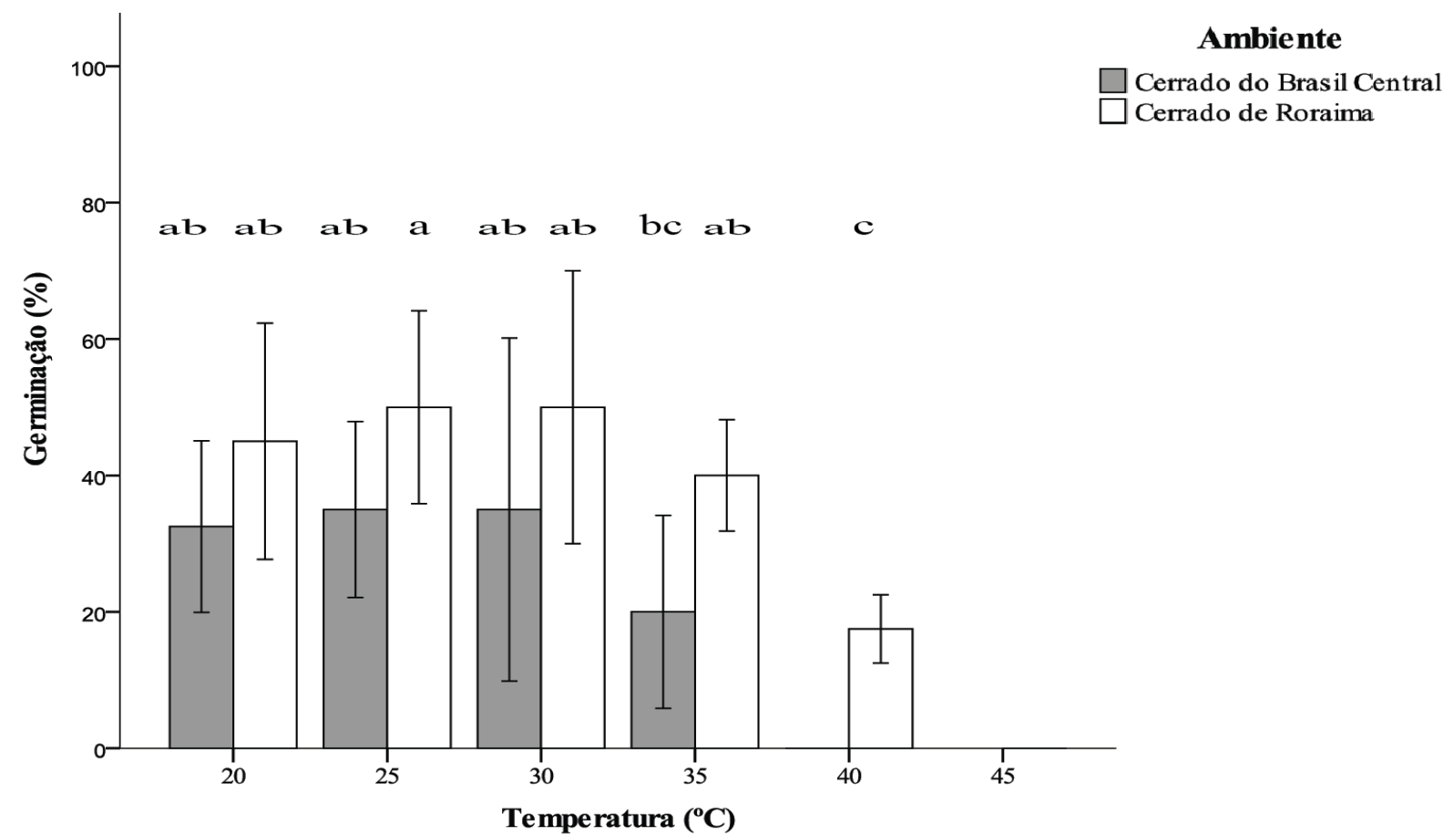

Figura 25. Germinação (média \pm desvio padrão), em temperaturas crescentes, de sementes de populações de Curatella americana. Valores representados pela mesma letra, sobre as barras, não diferem entre si pelo teste de Sidak $(\mathrm{P}<0,05)$. 
Para A. peregrina, as sementes ocorrentes nos cerrados de Roraima apresentaram percentuais de germinação significativamente maiores a 35 e $40^{\circ} \mathrm{C}$ do que aquelas dos cerrados do Brasil Central (Figura 26). A $45^{\circ} \mathrm{C}$, sementes de A. peregrina não germinaram, independente da origem da população. Ainda para esta espécie, apenas a temperatura, e a interação deste fator com o ambiente de origem da população mostraram-se significativos dentro do modelo estatístico selecionado, sendo responsáveis por $72 \%\left(R^{2}=0,720\right)$ da variação encontrada na germinação de suas sementes, em temperaturas crescentes (Tabela A4, Apêndice).

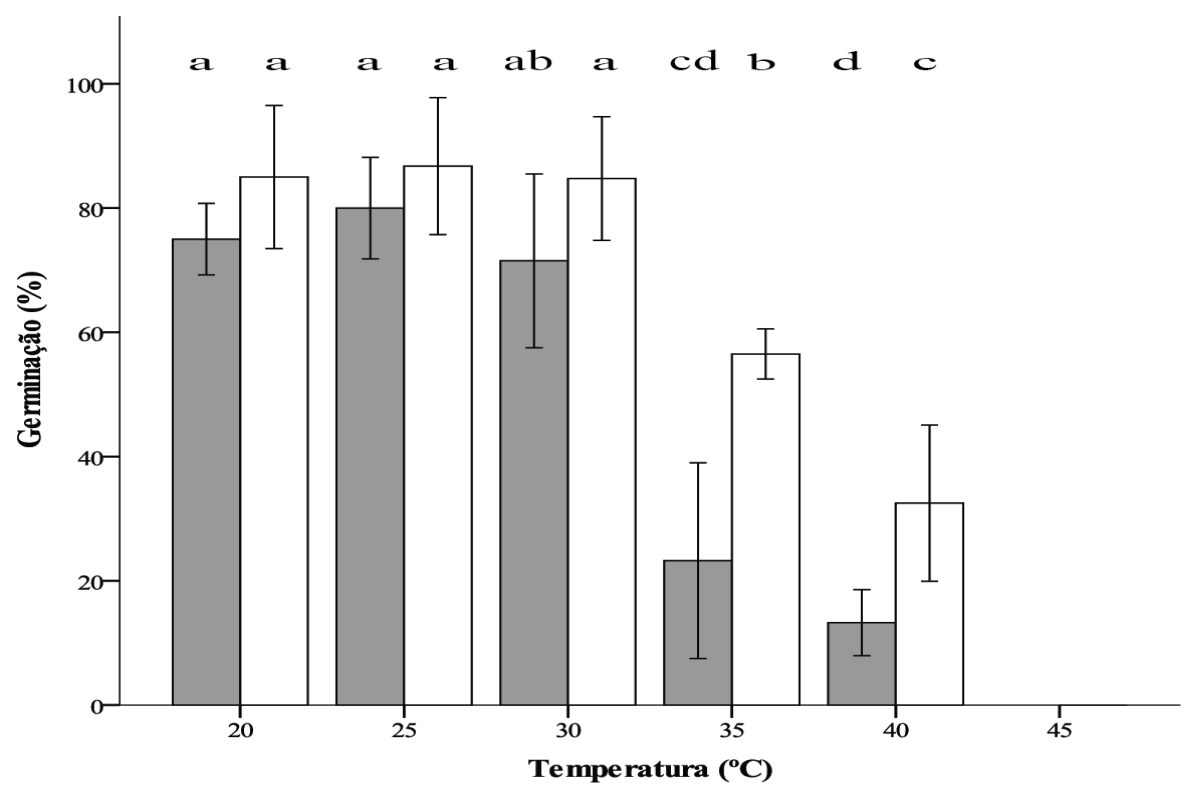

Ambiente

$\square$ Cerrado do Brasil Central Cerrado de Roraima

Figura 26. Germinação (média \pm desvio padrão), em temperaturas crescentes, de sementes de populações de Anadenanthera peregrina. Valores representados pela mesma letra, sobre as barras, não diferem entre si pelo teste de $\operatorname{Sidak}(\mathrm{P}<0,05)$.

Em relação aos tempos médios de germinação, os maiores valores foram observados para sementes germinadas na menor temperatura testada $\left(20^{\circ} \mathrm{C}\right)$, tanto para as populações ocorrentes nos cerrados de Roraima, quanto para aquelas dos cerrados do Brasil Central (Figuras 27, 28 e 29). Além disso, foi observado que sementes das populações de $B$. virgilioides, $C$. americana e A. peregrina dos cerrados de Roraima e do Brasil Central 
germinaram em tempos médios similares (Figuras 27, 28 e 29), considerando os tratamentos cuja germinabilidade foi igual ou superior a $10 \%$.

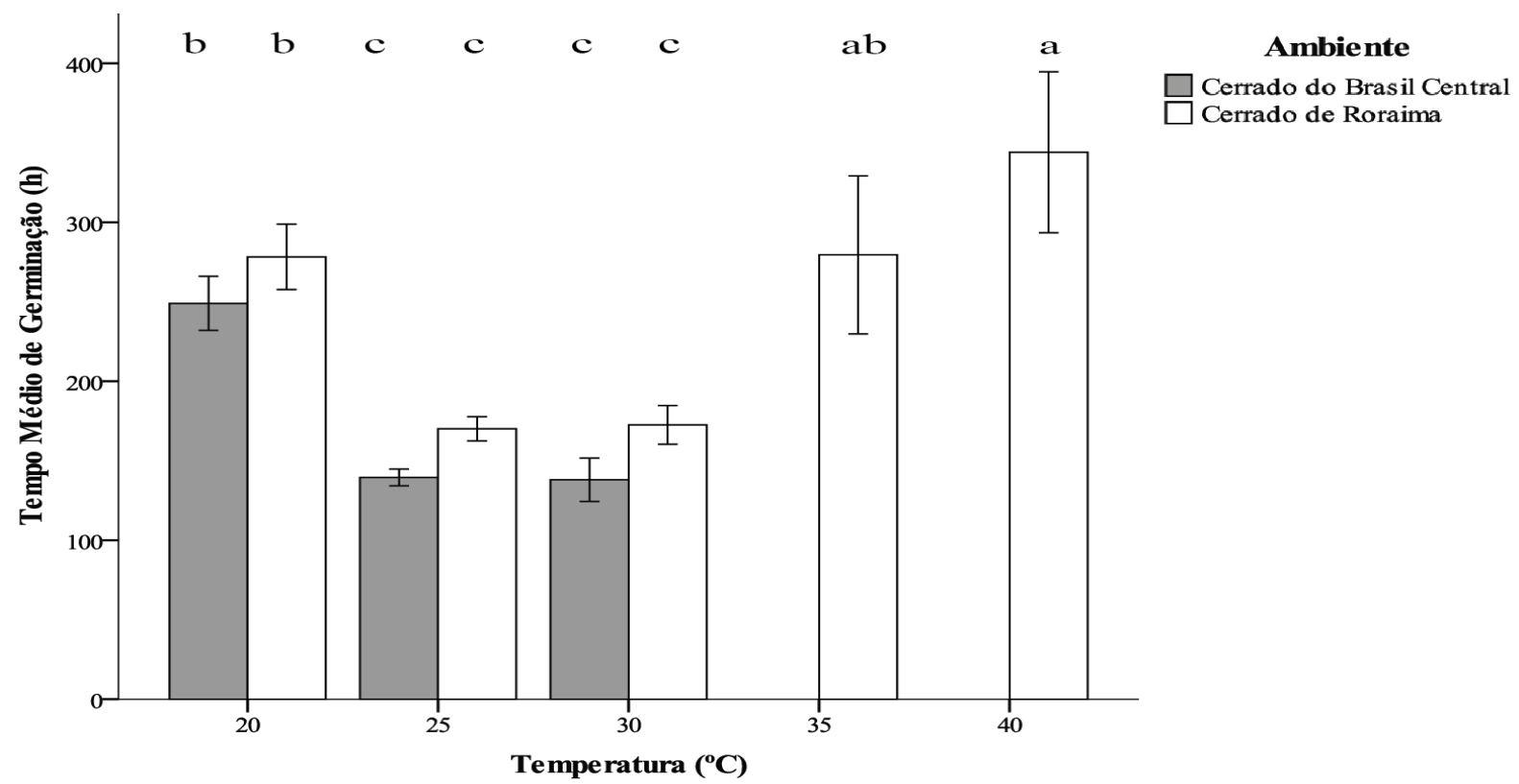

Figura 27. Tempo médio de germinação (média \pm desvio padrão), em temperaturas crescentes, de sementes de Bowdichia virgilioides. Valores representados pela mesma letra, sobre as barras, não diferem entre si pelo teste de Sidak $(\mathrm{P}<0,05)$.

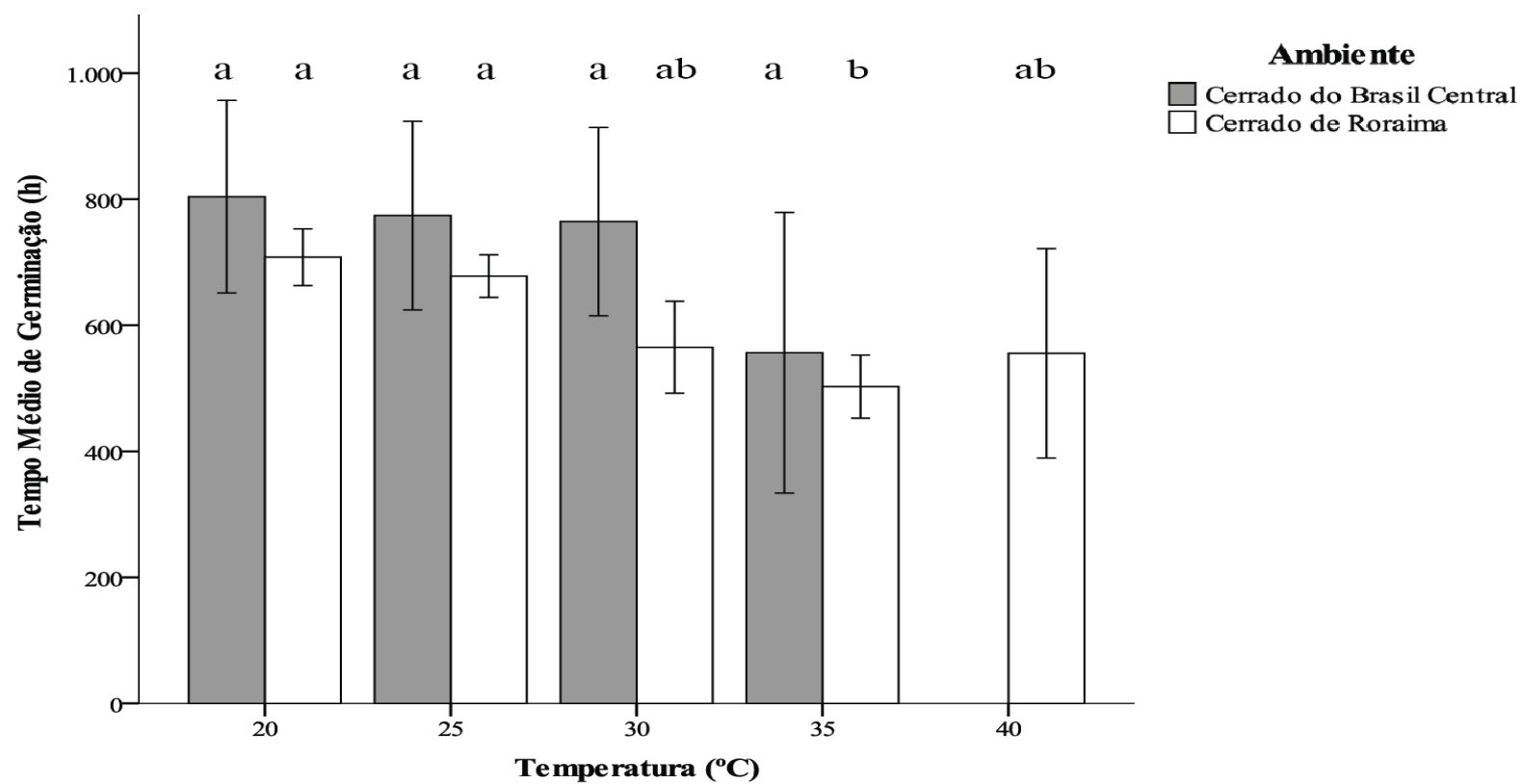

Figura 28. Tempo médio de germinação (média \pm desvio padrão), em temperaturas crescentes, de sementes de Curattela americana. Valores representados pela mesma letra, sobre as barras, não diferem entre si pelo teste de Sidak $(\mathrm{P}<0,05)$. 


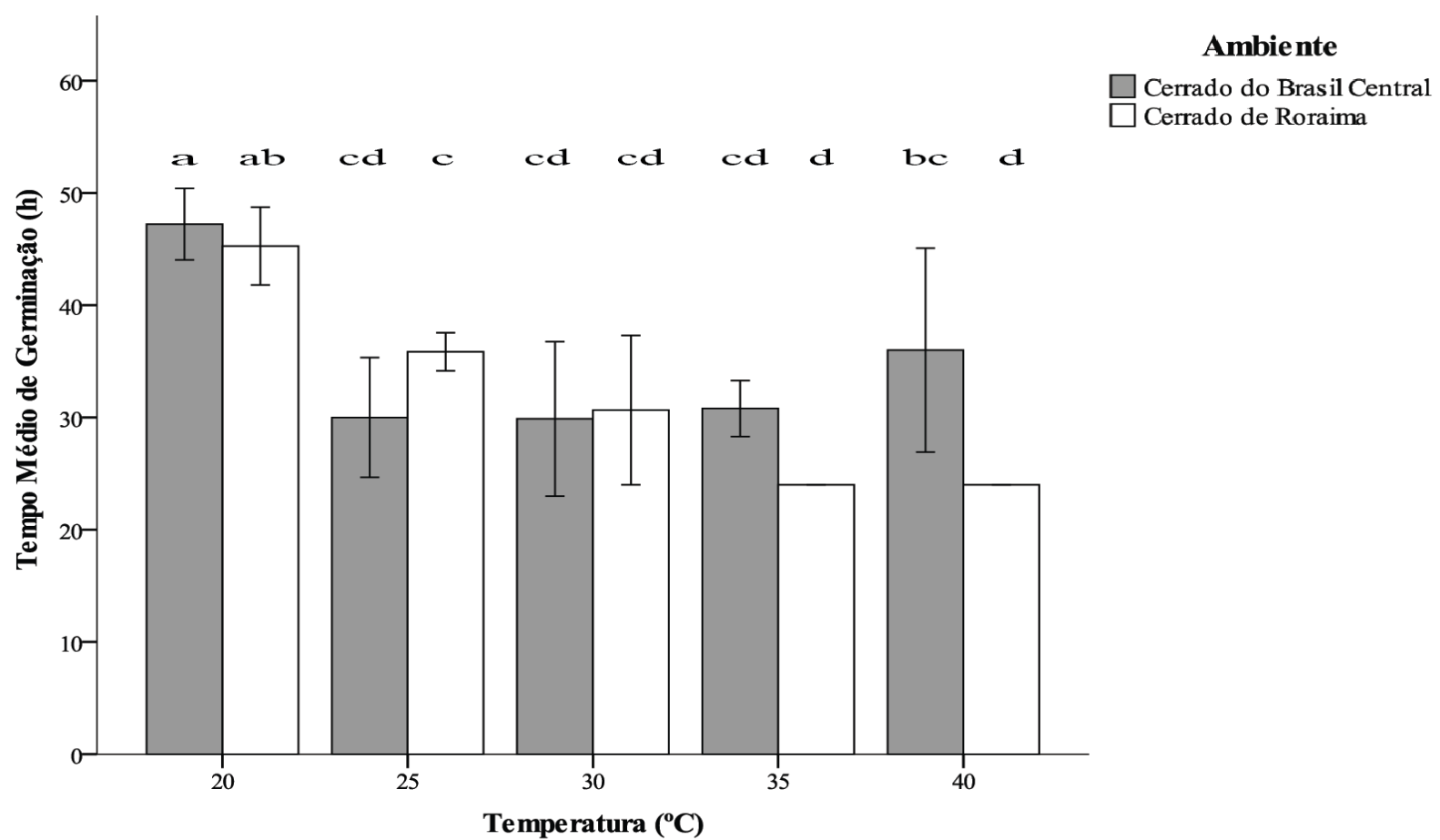

Figura 29. Tempo médio de germinação (média \pm desvio padrão), em temperaturas crescentes, de sementes de Anadenanthera peregrina. Valores representados pela mesma letra, sobre as barras, não diferem entre si pelo teste de Sidak $(P<0,05)$.

\subsection{Viabilidade de sementes}

Os testes de viabilidade realizados em sementes não germinadas de $B$. virgilioides, $C$. americana e A. peregrina, nos controles experimentais, evidenciaram sinais de viabilidade em poucas sementes. Padrão semelhante de resposta também foi observado nos tratamentos de estresse hídrico e de temperaturas crescentes de germinação. Já nos tratamentos de dessecamento e choques térmicos, os testes de viabilidade não evidenciaram sinais de viabilidade nas sementes que não germinaram. Neste sentido, pode-se afirmar que a porcentagem de sementes viáveis foi significativamente equivalente à porcentagem de germinação, independente do tratamento aplicado e que as sementes não germinadas perderam a viabilidade em decorrência dos tratamentos aplicados. 


\section{Discussão}

\subsection{Massa de sementes}

A massa da semente é uma característica funcional que pode variar significativamente dentro de uma espécie (Paz \& Martinez-Ramos 2003; Delgado et al. 2008; Guo et al. 2012), sobretudo naquelas pertencentes a ambientes contrastantes (Ellison 2001; Guo et al. 2012; Lönnberg \& Eriksson 2012), embora essa variação seja mais comum entre espécies (Coomes \& Grubb 2003; Ribeiro \& Borghetti 2014). Os resultados deste estudo mostraram que diferenças significativas com relação à massa de sementes foram encontradas apenas entre o par conespecífico de Anadenanthera peregrina (cerrados de Roraima vs cerraodos do Brasil Central), corroborando o fato de que a variação na massa das sementes tende a aumentar com o aumento da distância fillogenética entre indivíduos (Gómez et al. 2004; Moles et al. 2005).

A massa da semente é uma característica importante da história de vida inicial das plantas e pode influenciar significativamente aspectos relacionados à biologia reprodutiva das espécies, principalmente através de sua resposta germinativa (Leishman et al. 2000). De modo geral, existe uma relação positiva entre massa de sementes e tolerância a estresses ambientais, em que sementes grandes tendem a levar vantagem sobre as pequenas, quando expostas a níveis de estresse similares (Murray et al. 2004; Daws et al. 2008; Muller-Landau 2010). Entretanto, tal relação não foi observada para A. peregrina, única espécie deste estudo cujo tamanho das sementes foi significativamente diferente entre populações, sendo menor para aquelas dos cerrados de Roraima, em relação às dos cerrados do Brasil Central. Neste caso, a maior tolerância aos efeitos do dessecamento, do déficit hídrico e de temperaturas altas apresentanda por sementes de A. peregrina ocorrentes em Roraima mostra que, em condições 
de estresse similares, sementes maiores nem sempre levam vantagem sobre sementes menores (ver Hanley et al. 2003; Hill et al. 2012).

A resposta germinativa de espécies expostas a diferentes condições de estresse pode ser mais bem explicada em função dos fatores extrínsecos ou ambientais, ao invés de fatores intrínsecos ou endógenos (Paz et al. 1999; Kos \& Poschlod 2008), e os resultados encontrados neste estudo mostram que a variação nos parâmetros de germinação, comparando-se populações de A. falcata, Bowdichia virgilioide e Curatella americana ocorrentes nos cerrados de Roraima e do Brasil Central, está mais associada a fatores ambientais locais do que a fatores ligados à biologia das sementes (massa das sementes).

\subsection{Tolerância à dessecação}

Em geral, ao final do seu desenvolvimento, as sementes da maioria das espécies apresentam entre 5 e $20 \%$ de água em sua biomassa total (Bradbeer 1988; Ribeiro \& Borghetti 2014). Nesse estudo, isso foi observado para sementes de B. virgilioides ocorrentes nos cerrados de Roraima e do Brasil Central, e para populações de A. peregrina de Roraima.

O conteúdo de água das sementes ao final do desenvolvimento e, consequentemente, o seu nível de tolerância à dessecação podem estar relacionados, mesmo indiretamente, com o período e o tipo de dispersão de algumas espécies (Barbedo \& Marcos-Filho 1998). No Cerrado, espécies anemocóricas tendem a dispersar suas sementes com conteúdos de água baixos e durante a estação seca ou na transição desta para a estação chuvosa (Gottsberger \& Silberbauer-Gottsberger 2006). Consequentemente, tais sementes estão mais propensas a apresentar tolerância à dessecação (Pammenter \& Berjak 2000b; Ribeiro \& Borghetti 2014), como foi observado, nesse estudo, para sementes de $B$. virgilioides, independente do ambiente de origem da população. Por outro lado, espécies zoocóricas costumam dispersar suas 
sementes com conteúdo de água elevado e no decorrer da estação chuvosa (Lenza \& Klink 2005; Gottsberger \& Silberbauer-Gottsberger 2006). Consequentemente, tais sementes podem apresentar maior sensibilidade à dessecação (Pammenter \& Berjak 2000a; Ribeiro \& Borghetti 2014), tal como observado, nesse estudo, para sementes de C. americana de Roraima e para as de A. peregrina do Brasil Central. Tais resultados reforçam a ideia de que sementes dispersas com conteúdo de água elevado tendem a ser mais sensíveis à dessecação (Hill et al. 2012; Ribeiro \& Borghetti 2014).

O ambiente de ocorrência das espécies também tem sido considerado fator determinante na tolerância à dessecação de sementes (Tweddle et al. 2003; Pritchard et al. 2004). De modo geral, sementes de espécies que se desenvolvem em ambientes cujos solos estão frequentemente sujeitos a maiores níveis de déficit hídrico sazonal e a amplitudes térmicas diárias mais elevadas podem sofrer perda considerável de umidade para o meio externo e, consequentemente, apresentarem maior tolerância à dessecação (Tweddle et al. 2003; Engelbrecht et al. 2006). Tal relação pôde ser observada, nesse estudo, para sementes de $A$. peregrina e $B$. virgilioides ocorrentes nos cerrados de Roraima.

Sementes que não apresentam perda significativa de viabilidade quando dessecadas a baixos conteúdos de água (em torno de 5-7\%) são classificadas como ortodoxas (Hong \& Ellis 1996). Estima-se que cerca de $90 \%$ das espécies de Espermatófitas possuam sementes tolerantes à dessecação (Tweddle et al. 2003), muitas das quais podem ser encontradas no Cerrado (ver Salomão et al. 2003; Ribeiro \& Borghetti 2014). Este também parece ser o caso de sementes de A. peregrina e B. virgilioides ocorrentes nos cerrados de Roraima, e de sementes de C. americana dos cerrados do Brasil Central. Por outro lado, sementes que não toleram dessecação a baixos níveis de umidade são classificadas como recalcitrantes (Hong \& Ellis 1996) e este parece ser o caso das sementes de C. americana dos cerrados de Roraima e de A. peregrina dos cerrados do Brasil Central. 
De acordo com os resultados apresentados para as três espécies desse estudo, fica evidente que o nível de tolerância à dessecação pode variar em função de características ambientais locais (Roraima vs Brasil Central), filogenéticas (entre espécies ou mesmo dentro de uma espécie), e também devido a características endógenas das sementes, tais como o conteúdo de água no momento da dispersão.

\subsection{Tolerância ao déficit hídrico}

A relação entre os padrões de resposta germinativa em função do déficit hídrico fornecem informações importantes em termos de adaptação de espécies e/ou populações (Walck et al. 2011), principalmente em ambientes onde eventos de precipitação são altamente variáveis, mesmo durante a estação chuvosa (ocorrência de veranicos), fazendo com que os solos não mantenham condições favoráveis e constantes de umidade para o recrutamento de sementes (Kos \& Poschlod 2008; Köchy \& Tielbörger 2007). Sob tais aspectos, sementes de espécies e/ou populações ocorrentes em ambientes que experimentam condições recorrentes de déficit hídrico no solo, especialmente durante a estação chuvosa, tendem a levar vantagens no recrutamento sobre aquelas onde o déficit hídrico é menor.

A disponibilidade hídrica no solo é fator determinante para a germinação de sementes e, neste sentido, espécies e/ou populações podem diferir quanto ao potencial hídrico mínimo necessário para que a germinação ocorra (Allen et al. 2000; Daws et al. 2002). Neste estudo, observou-se que a germinabilidade de sementes de $B$. virgilioides em potenciais osmóticos de até -0,6 MPa não foi significativamente afetada, independente do ambiente de origem da população, corroborando os resultados descritos para esta mesma espécie, cuja capacidade germinativa foi afetada apenas em potenciais osmóticos inferiores a $-0,7 \mathrm{MPa}$ (ver Silva et al. 2001), e também para outras espécies de fisionomias tipicamente savânicas (ver Sy et al. 
2001; Kos \& Poschlod 2008). Já sementes de A. peregrina mostraram-se muito sensíveis ao déficit hídrico, independente da origem da população. Esta espécie é característica de fisionomias florestais nos cerrados de Roraima e do Brasil Central (Rezende et al. 2008) e, sob tal aspecto, o componente ambiental parece ser fator determinante na sensibilidade de suas sementes ao déficit hídrico, comportamento comumente descrito para sementes de espécies ocorrentes em florestais tropicais (Khurana \& Singh 2004; Daws et al. 2008; Marthews et al. 2008).

Neste estudo, o resultado mais conspícuo e que mostra os efeitos significativos tanto do ambiente de origem da população, quanto do potencial osmótico, foi observado para sementes de C. americana, em que o déficit hídrico foi notavelmente menos prejudicial para populações ocorrentes nos cerrados de Roraima, onde as características edafoclimáticas (solos com textura média a arenosa e com menor capacidade de retenção de água) sinalizam para a ocorrência de déficit hídrico mais intenso.

Como o déficit hídrico do solo está entre as principais causas de mortalidade de sementes e plântulas (Moles \& Westoby 2004; Engelbrecht et al. 2006), a capacidade de recrutamento em condições desfavoráveis de umidade no solo (déficit hídrico) é um dos principais atributos responsáveis à manutenção de espécies dentro de comunidades vegetais. Neste sentido, mudanças nos regimes de precipitação previstas por modelos climáticos globais (ver IPCC 2013), tais como o aumento do número de veranicos e, consequentemente, períodos mais longos de seca durante o período chuvoso, serão menos prejudiciais para espécies e/ou populações que mostrarem maior tolerância ao déficit hídrico, como observado para populações de C. americana dos cerrados de Roraima.

\subsection{Tolerância a choques térmicos}


O fogo está entre os fatores ecológicos de maior importantância na dinâmica de ecossistemas (Bond \& Keeley 2005; Staver et al. 2011b) e, sob tal aspecto, espera-se que espécies que ocorram em ambientes mais suscetíveis à ocorrência de queimadas sejam mais tolerantes às temperaturas elevadas geradas durante um evento de fogo (Little et al. 2011; Hoffmann et al. 2012). O banco de sementes do solo tem grande importância no processo de regeneração de comunidades vegetais (Keeley \& Fotheringham 2000; Baskin \& Baskin 2001). Entretanto, a ocorrência de queimadas pode afetar diretamente o recrutamento de espécies através do banco de sementes (Williams et al. 2005; Scott et al. 2010), seja reduzindo total ou parcialmente sua viabilidade (Bradstock et al. 1994; Marod et al. 2002), ou promovendo a germinação das sementes (Auld \& Bradstock 1996; Herranz et al. 1998; Newton et al. 2006). Como a densidade do banco de sementes em savanas neotropicais é relativamente baixa (García-Nuñez et al. 2001; Ikeda et al. 2008; Salazar et al. 2011), tolerar as altas temperaturas geradas durante a passagem do fogo torna-se essencial para a ocorrência do recrutamento de espécies através do banco de sementes.

A tolerância das sementes aos efeitos do fogo dependerá da intensidade e duração da queimada (Auld \& Denhan 2006; Stark et al. 2008). Nesse estudo, as sementes das três espécies, independente da origem da população, mostraram-se tolerantes aos choques térmicos de $80^{\circ} \mathrm{C}$ e $110^{\circ} \mathrm{C}$ por 2,5 minutos e à temperatura $80^{\circ} \mathrm{C}$ por 2,5 minutos. Tais resultados reforçam a ideia de que sementes são capazes de tolerar temperaturas moderadas a altas em tempos de exposição mais curtos, ou temperaturas baixas a moderadas em tempos mais de exposição mais longos (Escudero et al. 2000; Hanley \& Lamont 2000; Ribeiro et al. 2013). Por outro lado, a combinação de temperaturas mais elevadas e tempos de exposição mais longos costumam ser letais para as sementes (Gashaw \& Michelsen 2002; Schmidt et al. 2005; Reyes \& Trabaud 2009; Ribeiro \& Borghetti 2014), como foi constatado para as 
sementes das três espécies do presente estudo, quando expostas a temperatura igual ou maior que $140^{\circ} \mathrm{C}$, no tempo de exposição mais longo (5 minutos).

Outro aspecto a ser considerado em relação à tolerância das sementes aos efeitos do fogo é a frequência deste fator em determinado ambiente (Hoffmann 2000; Keeley \& Fotheringham 2000). De modo geral, a sensibilidade aos efeitos do fogo tende a ser maior em sementes de espécies e/ou população que ocorram em ambientes cuja frequência de queimadas é menor (Hoffmann et al. 2003; Cochrane 2009). Entretanto, este fator parece não ser determinante para explicar as diferenças observadas na germinação dos três pares conespecíficos deste estudo, posto que a frequência de queimadas nos cerrados de Roraima e do Brasil Central é similar (ver Barbosa \& Fearnside 2005b).

Os resultados descritos para as três espécies testadas nesse estudo mostraram que sementes das populações ocorrentes nos cerrados de Roraima foram mais tolerantes aos choques térmicos, embora a maior quantidade de biomassa total de combustíveis disponível para queima e fator de combustão mais elevado (ver Kauffman et al. 1994; Barbosa et al. 2005) sinalizem para uma maior tolerância aos efeitos do fogo para populações dos cerrados do Brasil Central, onde a queimada seria mais intensa e duradoura. Neste sentido, características geomorfológicas locais podem fornecer explicações mais concisas em relação à maior tolerância das sementes de Roraima aos choques térmicos. Solos de textura mais arenosa, característicos dos cerrados de Roraima, possuem menor condutividade térmica e concentram a maior parte da energia térmica incidente em sua superfície, onde o banco de sementes costuma se estabelecer. Assim, durante uma queimada, as sementes dos cerrados de Roraima estariam expostas a temperaturas mais elevadas e por um maior período de tempo do que aquelas dos cerrados do Brasil Central, característica que as tornariam mais tolerantes aos efeitos de choques térmicos. 
Diante dos diferentes padrões de germinação em reposta à exposição aos choques térmicos observados para as sementes dos três pares conespecíficos desse estudo, existe a tendência de que sementes das populações ocorrentes nos cerrados de Roraima serão mais tolerantes aos efeitos do aumento na frequência e na intensidade de queimadas, já previstos por modelos climáticos globais (Hoffmann \& Jackson 2000; IPCC 2013), do que aquelas dos cerrados do Brasil Central e que o nível de tolerância das espécies aos efeitos do fogo poderão variar, especialmente, em função de características ambientais locais e de acordo com a instensidade da queimada.

\subsection{Germinação em temperaturas crescentes}

Em termos comparativos, a faixa de temperatura ótima para a germinação $\left(25-30^{\circ} \mathrm{C}\right)$ mostrou-se equivalente para os três pares conespecíficos testados nesse estudo, tanto para populações dos cerrados de Roraima quanto para aquelas ocorrentes nos cerrados do Brasil Central, e está de acordo com a faixa esperada para sementes de espécies savânicas e florestais tropicais (ver Brancalion et al. 2010).

Temperaturas acima da faixa considerada ótima para a germinação de sementes, frequentemente aquelas até o limite de $35^{\circ} \mathrm{C}$, geralmente não reduzem significativamente a germinabilidade de espécies e/ou populações típicas de fisionomias savânicas (Garcia et al. 2007; Ribeiro \& Borghetti 2014), tal como foi observado para B. virgilioides (cerrados de Roraima) e C. americana (cerrados de Roraima e do Brasil Central) nesse estudo. Por outro lado, temperatura igual ou superior a $35^{\circ} \mathrm{C}$ tende a reduzir significativamente a germinabilidade de espécies e/ou populações pertencentes a ambientes florestais (FerrazGrande \& Takaki 2001; Socolowski \& Takaki 2004; Ribeiro \& Borghetti 2014), como foi constatado, nesse estudo, para sementes de A. peregrina. 
A relação entre germinação e temperatura está frequentemente associada às temperaturas as quais as plantas ficam expostas durante o todo o seu desenvolvimento (Teketay 1998; Baskin \& Baskin 2001). Os maiores percentuais de germinação a 35 e $40^{\circ} \mathrm{C}$ apresentados para as sementes de espécies ocorrentes nas populações de Roraima, em comparação com aquelas do Brasil Central, podem estar relacionados às condições ambientais locais, tais como a ocorrência de temperaturas máximas mais elevadas durante a estação chuvosa (INMET 2013, 2014), período em que, geralmente, há disponibilidade hídrica suficiente para promover a germinação.

De modo geral, espécies arbóreas tropicais apresentam temperatura máxima de germinação próxima de $40^{\circ} \mathrm{C}$ (Sy et al. 2001; Borghetti 2005; Ribeiro \& Borghetti 2014), embora algumas espécies também sejam capazes de germinar acima dessa temperatura (Lima et al. 1997; Tambelini \& Perez 1999). Entretanto, nenhuma das espécies deste estudo germinou a $45^{\circ} \mathrm{C}$, independente da origem da população, mostrando que a faixa de temperatura situada entre 40 e $45^{\circ} \mathrm{C}$ parece ser a máxima para espécies ocorrentes em savanas brasileiras.

A capacidade de uma semente de germinar em temperaturas mais elevadas $\left(>30^{\circ} \mathrm{C}\right)$ torna-se um importante atributo para o recrutamento de espécies em ambientes cuja exposição à radiação solar é geralmente intensa, tal como ocorre em nas savanas brasileiras (INMET 2014). Modelos climáticos atuais sinalizam para o aumento de temperaturas médias máximas globais (IPCC 2013) e, consequentemente, aumentos na temperatura do ar refletirão em aumentos na temperatura do solo, principalmente nos horizontes superficiais, fazendo com que o banco de sementes esteja exposto a temperaturas mais altas e por períodos mais prolongados, sobretudo durante a transição da estação seca para a estação chuvosa (Ooi et al. 2009). Nestes cenários de mudanças e conforme os resultados apresentados para as três espécies deste estudo, fica evidente que aumentos nas temperaturas máximas serão menos 
prejudiciais ao recrutamento de espécies, através de sementes, para populações dos cerrados de Roraima, em comparação àquelas dos cerrados do Brasil Central.

\subsection{Estresses ambientais e tempo de germinação}

O tempo médio de germinação é um importante atributo do ponto de vista ecofisiológico, servindo como parâmetro de avaliação da rapidez de ocupação de uma espécie em determinado ambiente (Labouriau 1983; Kos \& Poschlod 2010). De modo geral, a germinação espaçada temporalmente está mais associada a ambientes cujas variações nas condições climáticas são estocásticas, tal como ocorre em savanas (Venable 2007; Ooi et al. 2009). No presente estudo, independente do tratamento aplicado, germinação lenta (Tm > 120 horas) foi observada para $B$. virgilioides e $C$. americana, espécies típicas de ambientes savânicos (Rezende et al. 2008). Por outro lado, a germinação rápida (Tm < 120 horas) está mais associada a ambientes cujas variações nas condições climáticas são mais tênues, tal como ocorre em florestas tropicais (Kenny 2000; Ribeiro \& Borghetti 2014). Tal relação também pôde ser constatada, nesse estudo, para A. peregrina, espécie típica de fisionomias florestais dos cerrados brasileiros (ver Rezende et al. 2008).

Ainda para os pares conespecíficos desse estudo, é importante mencionar que diferentes tipos de estresse (dessecação, déficit hídrico, temperaturas altas) resultaram em diferentes estratégias de germinação, em relação ao tempo médio. Por exemplo, as espécies que germinaram lenta ou rapidamente, não alteraram sua estratégia de germinação quando suas as sementes foram expostas ou não à dessecação e a choques térmicos, resultados que também têm sido frequentemente descritos para outras espécies de fisionomias savânicas e florestais do Cerrado (ver Ribeiro \& Borghetti 2014). 
Por outro lado, potenciais hídricos baixos podem ser limitantes tanto à germinabilidade quanto à velocidade de germinação, pois este processo fisiológico inicia-se com a absorção de água pelas sementes, mediante embebição, sendo a velocidade dessa absorção determinada pela disponibilidade hídrica no meio (Bewley \& Black 1994). Para as três espécies desse estudo, independente da origem da população, a velocidade de germinação decresceu com a redução gradativa do potencial hídrico. Embora o déficit hídrico seja fator limitante do processo germinativo, situações de restrição hídrica no meio podem ser vantajosas para algumas espécies e/ou populações, pois pode resultar em germinação mais lenta e espalhada no tempo, especialmente durante os veranicos, estratégia que pode favorecer o sucesso reprodutivo em longo prazo.

A temperatura é uma variável ambiental determinante sobre alguns parâmetros de germinação de sementes (Labouriau 1983; Bradford 2002). Em termos atuais, está bem estabelecido que as sementes germinam dentro de determinada faixa de temperatura, que é característica para cada espécie (Baskin \& Baskin 2001), mas o tempo necessário para que ocorra a máxima germinabilidade depende da temperatura (Bewley \& Black 1994). Para as três espécies desse estudo, independente da origem da população, os maiores percentuais de germinação, no menor espaço de tempo, foram observados a 25 ou $30^{\circ} \mathrm{C}$, faixa de temperatura considerada ótima para espécies arbóreas ocorrentes em biomas brasileiros (Brancalion et al. 2010; Ribeiro \& Borghetti 2014).

Os fatores ambientais considerados mais importantes para a regulação da germinação são a disponibilidade hídrica do solo e a temperatura (Bewley \& Black 1994; Baskin \& Baskin 2001). Em condições naturais, a limitação hídrica e temperaturas elevadas no solo podem favorecer o recrutamento de plântulas, causando atraso considerável no tempo de germinação, de forma a minimizar os riscos de mortalidade das sementes do banco, 
especialmente durante a estação chuvosa, quando ocorrem os veranicos e as temperaturas mais elevadas durante o ano nos cerrados brasileiros (INMET 2013, 2014).

\subsection{Mudanças climáticas}

Modelos climáticos globais têm previsto a ocorrência de mudanças nos regimes de pluviosidade, que se tornarão mais irregulares, manifestando-se em períodos de secas mais prolongadas e no aumento no número de veranicos ao longo do ano, bem como mudanças nas temperaturas máximas do planeta, que aumentarão (IPCC 2013). Tais mudanças poderão refletir diretamente nos regimes hídrico e térmico do solo, causando impactos diretos sobre o banco de sementes em ecossistemas tropicais (Ooi et al. 2009; Walck et al. 2011).

Considerando tais aspectos e de acordo com os resultados obtidos para as espécies deste estudo, tanto o aumento do período em que os solos estarão mais expostos ao déficit hídrico, quanto o aumento nas temperaturas do solo, em função ou não da ocorrência de queimadas, serão mais limitantes ao recrutamento, por sementes, de espécies e/ou populações dos cerrados do Brasil Central, em comparação àquelas dos cerrados de Roraima. Isso reforça a ideia de que mudanças climáticas globais poderão interferir na biologia das sementes, tanto em nível espécie-específico, quanto em nível populacional, selecionando os genótipos tolerantes e eliminado aqueles sensíveis à intensificação no nível de estresses ambientais.

\section{Considerações finais}

Nesse estudo, sementes das populações ocorrentes nos cerrados de Roraima apresentaram, de modo geral, maior tolerância à dessecação, ao déficit hídrico, aos choques térmicos e a altas temperaturas do que sementes das populações dos cerrados do Brasil 
Central. As maiores diferenças na germinabilidade foram observadas para Curatella americana e Anadenanthera peregrina nos tratamentos com choques térmicos e na germinação a temperaturas acima da faixa ótima $\left(25\right.$ a $\left.30^{\circ} \mathrm{C}\right)$, e para Bowdichia virgilioides, nos tratamento de dessecamento, choques térmicos e na germinação em temperaturas elevadas. As diferenças encontradas na germinação dos três pares conespecíficos deste estudo, bem como a própria heterogendeidade ambiental existente entre os cerrados de Roraima e os do Planalto Central brasileiro, permitem sugerir a existência de ecótipos para C. americana, A. peregrina e $B$. virgilioides.

Modelos relacionados a mudanças climáticas prevêem a intensificação nos níveis de alguns estresses ambientais, que podem ter efeito direto sobre a germinação de sementes, tais como aumento no déficit hídrico do solo, maiores temperaturas máximas e aumento na frequência de fogo em diversas regiões onde o bioma Cerrado ocorre. Considerando tais aspectos e baseado nos resultados descritos para as três espécies deste estudo, populações arbóreas dos cerrados de Roraima estarão mais aptas a tolerar os efeitos do aumento nos níveis de estresse do que aquelas dos cerrados do Planalto Central brasileiro. 


\section{Referências bibliográficas}

Allen P.S., Meyer S.E. \& Khan M.A. (2000) Hydrothermal time as a tool in comparative germination studies. In: Black M., Bradford K.J. \& Vazquez-Ramos J. (Eds), Seed biology: advances and applications. CAB International, Wallingford, UK: 401-410.

Araújo W.F., Andrade Jr A.S., Medeiros R.D. \& Sampayo R.A. (2001) Precipitação pluviométrica mensal provável em Boa Vista, Estado de Roraima, Brasil. Revista Brasileira de Engenharia Agrícola e Ambiental, 5, 563-567.

Assad E.D., Sano E.E., Masutomo R., Castro L.H.R. \& Silva F.A.M. (1993) Veranicos na região dos cerrados brasileiros: freqüência e probabilidade de ocorrência. Pesquisa Agropecuária Brasileira, 28, 993-1002.

Auld T.D. \& Bradstock R.A. (1996) Soil temperatures after the passage of a fire: Do they influence the germination of buried seeds? Australian Journal of Ecology, 21, 106-109.

Auld T.D. \& Denhan A.J. (2006) How much seed remains in the soil after a fire? Plant Ecology, 187, 15-24.

Baker K.S., Steadman K.J., Plummer J.A. \& Dixon K.W. (2005) Seed dormancy and germination responses of nine Australian fire ephemerals. Plant and Soil, 277, 345-358.

Baraloto C., Forget P. \& Goldberg D.E. (2005) Seed mass, seedling size and neotropical tree seedling establishment Journal of Ecology, 93, 1156-1166.

Barbedo C.J. \& Marcos-Filho J. (1998) Tolerância à dessecação de sementes. Acta Botanica Brasilica, 12, 145-164.

Barbosa E.R.M., van Langevelde F., Tomlinson K.W., Carvalheiro L.G., Kirkman K., de Bie S. \& Prins H.H.T. (2014) Tree species from different functional groups respond differently to environmental changes during establishment. Oecologia, 174, 1345-1357. 
Barbosa I.O., Lacerda M.P.C. \& Bilich M.R. (2009) Relações pedomorfogeológicas nas chapadas elevadas do Distrito Federal. Revista Brasileira de Ciência do Solo, 33, $1373-$ 1383.

Barbosa R.I. \& Fearnside P.M. (2005a) Above-ground biomass and the fate of carbon after burning in the savannas of Roraima, Brazilian Amazonia. Forest Ecology and Management, 216, 295-316.

Barbosa R.I. \& Fearnside P.M. (2005b) Fire frequency and area burned in the Roraima savannas of Brazilian Amazonia. Forest Ecology and Management, 204, 371-384.

Barbosa R.I., Nascimento S.P., Amorim P.A.F. \& Silva R.F. (2005) Notas sobre a composição arbóreo-arbustiva de uma fisionomia das savanas de Roraima, Amazônia Brasileira. Acta Botanica Brasilica, 19, 323-329.

Barbosa R.I., Campos C., Pinto F. \& Fearnside P.M. (2007) The "Lavrados" of Roraima: Biodiversity and Conservation of Brazil's Amazonian Savannas. Functional Ecosystems and Communities, 1, 29-41.

Barros F.V., Goulart M.F., Teles S.B.S., Lovato M.B., Valladares F. \& Lemos-Filho J.P. (2011) Phenotypic plasticity to light of two congeneric trees from contrasting habitats: Brazilian Atlantic Forest versus Cerrado (savanna). Plant Biology, 14, 208-215.

Baskin C.C. \& Baskin J.M. (2001) Seeds: Ecology, Biogeography, and Evolution of Dormancy and Germination. Academic Press, California, USA.

Bazzaz F.A. (1996) Plants in changing environments: linking physiological, population and community ecology. Cambridge University Press, Cambridge, UK.

Behling H. \& Hooghiemstra H. (2000) Neotropical savanna environments in space and time: Late Quaternary. In: Markgraf V. (Ed), Interhemispheric climate linkages. Academic Press, Oxford, UK: 307-323. 
Behling H. (2003) Late glacial and Holocene vegetation, climate and fire history inferred from Lagoa Nova in the southeastern Brazilian lowland. Vegetation History Archaeobotany, 12, 263-270.

Benedetti U.G., Júnior J.F.V., Schaefer C.E.G.R., Melo V.F. \& Uchôa S.C.P. (2011) Gênese, química e mineralogia de solos derivados de sedimentos pliopleistocênicos e de rochas vulcânicas básicas em Roraima, norte amazônico. Revista Brasileira de Ciência do Solo, 35, 299-312.

Berg H., Becker U. \& Matthies D. (2005) Phenotypic plasticity in Carlina vulgaris: effects of geographical origin, population size, and population isolation. Oecologia, 143, 220-231.

Berjak P. \& Pammenter N.W. (2008) From Avicennia to Zizania: Seed recalcitrance in perspective. Annals of Botany, 101, 213-228.

Bewley J.D. \& Black M. (1994) Seeds: Physiology of Development and Germination. Plenum Press, New York, USA.

Black-Samuelsson S. \& Andersson S. (1997) Reaction norm variation between and within populations of two rare plant species, Vicia pisiformis and V. dumetorum (Fabaceae). Heredity, 79, 268-276.

Bond W.J., Honig M. \& Maze K.E. (1999) Seed size and seedling emergence: an allometric relationship and some ecological implications. Oecologia, 120, 132-136.

Bond W.J. \& Keeley J. (2005) Fire as a global 'herbivore': the ecology and evolution of flammable ecosystems. Trends in Ecology \& Evolution, 20, 387-394.

Bond W.J., Woodward F.I. \& Midgley G.F. (2005) The global distribution of ecosystems in a world without fire. New Phytologist, 165, 525-537.

Bond W.J. (2008) What limits trees in C4 grasslands and savannas? Annual Review of Ecology, Evolution, and Systematics, 39, 641-659. 
Borghetti F. (2005) Temperaturas extremas e a germinação de sementes. In: Nogueira R.J.M.C., Araújo E.L., Willadino L.G. \& Cavalcante U.M.T. (Eds), Estresses ambientais: danos e benefícios em plantas. MXM Gráfica e Editora, Recife, Brasil: 207-218.

Bradbeer J.W. (1988) Seed Dormancy and Germination. Blackie Academic \& Professional, London, UK.

Bradford K.J. (1995) Water relations in seed germination. In: Kigel J. \& Galili G. (Eds), Seed development and germination. Marcel Dekker, New York, USA: 351-396.

Bradford K.J. (2002) Applications of hydrothermal time to quantifying and modeling seed germination and dormancy. Weed Science, 50, 248-260.

Bradshaw A.D. (2006) Unravelling phenotypic plasticity - why should we bother? New Phytologist, 170, 639-641.

Bradstock R.A., Gill A.M., Hastings S.M. \& Moore P.H.R. (1994) Survival of serotinous seed banks during bushfires: comparative studies of Hakea species from southeastern Australia. Ausralian Journal of Ecology, 19, 276-282.

Brancalion P.H.S., Novembre A.D.L.C. \& Rodrigues R.R. (2010) Temperatura ótima de germinação de sementes de espécies arbóreas brasileiras. Revista Brasileira de Sementes, 32, 15-21.

Burnham K.P. \& Anderson D.R. (2002) Model selection and multimodel inference: A pratical information-theoretic approach. Springer, Berlin, Germany.

Castro E.A. \& Kauffman J.B. (1998) Ecosystem structure in the Brazilian Cerrado: a vegetation gradient of aboveground biomass, root mass and consumption by fire. Journal of Tropical Ecology, 14, 263-283.

Castro R.D., Bradford K.J. \& Hilhorst H.W.M. (2004a) Desenvolvimento de sementes e conteúdo de água. In: Ferreira A.G. \& Borghetti F. (Orgs), Germinação: do básico ao aplicado. Artmed, Porto Alegre, Brasil: 51-67. 
Castro R.D., Bradford K.J. \& Hilhorst H.W.M. (2004b) Embebição e reativação do metabolismo. In: Ferreira A.G., Borghetti F. (Orgs), Germinação: do básico ao aplicado. Artmed, Porto Alegre, Brasil: 149-162.

Chevin L.M., Lande R. \& Mace G.M. (2010) Adaptation, Plasticity, and Extinction in a Changing Environment: Towards a Predictive Theory. PLoS Biology, 8, e1000357.

Cochrane M.A. (2009) Fire, land use, land cover dynamics, and climate change in the Brazilian Amazon. In: Cochrane M.A. (Ed), Tropical Fire Ecology: Climate Change, Land Use and Ecosystem Dynamics. Springer Praxis Books, Heidelberg, Germany: 389426.

Coomes D.A. \& Grubb P.J. (2003) Colonization, tolerance, competition and seed-size variation within functional groups. Trends in Ecology \& Evolution, 18, 283-291.

Coutinho L.M. (1990) Fire in the ecology of the Brazilian Cerrado. In: Goldammer J.G. (Ed), Fire in the Tropical Biota. Ecological Studies, 84. Springer Verlag, Berlin, Germany: 82105.

Crawley M.J. (2007) The R Book. John Wiley and Sons, Chichester, UK.

Cromarty A.S., Ellis R.H. \& Roberts E.H. (1985) Designing of seed storage facilities for genetic conservation. IPGRI, Rome, Italy.

Daws M.I., Burslem D.F.R.P., Crabtree L.M., Kirkman P., Mullins C.E. \& Dalling J.W. (2002) Differences in seed germination responses may promote coexistence of four sympatric Piper species. Functional Ecology, 16, 258-267.

Daws M.I., Garwood N.C. \& Pritchard H.W. (2005) Traits of recalcitrant seeds in a semideciduos tropical forest in Panama: Some ecological implications. Journal of Ecology, 19, 874-885. 
Daws M.I., Crabtree L.M., Dalling J.W., Mullins C.E. \& Burslem D.F.R.P. (2008) Germination responses to water potential in Neotropical pioneers suggest large-seeded species take more risks. Annals of Botany, 102, 945-951.

De Jong G. (2005) Evolution of phenotypic plasticity: patterns of plasticity and the emergence of ecotypes. New Phytologist, 166, 101-118.

Delgado J.A., Serrano J.M., López F. \& Acosta F.J. (2008) Seed size and seed germination in the Mediterranean fire-prone shrub Cistus ladanifer. Plant Ecology, 197, 269-276.

Ellison A.M. (2001) Interspecific and intraspecific variation in seed size and germination requirements of Sarracenia (Sarraceniaceae). American Journal of Botany, 88, 429-437.

Engelbrecht B.M.J., Dalling J.W., Pearson T.R.H., Wolf R.L., Gálvez D.A., Koehler T., Tyree M.T. \& Kursar T.A. (2006) Short dry spells in the wet season increase mortality of tropical pioneer seedlings. Oecologia, 148, 258-269.

Escudero A., Núñez Y. \& Pérez-García F. (2000) Is fire a selective force of seed size in pine species? Acta Oecologica, 21, 245-256.

Farnsworth E. (2000) The ecology and physiology of viviparous and recalcitrant seeds. Annual Review of Ecology and Systematics, 31, 107-138.

Fenner M. \& Thompson K. (2005) The Ecology of Seeds. Cambridge University Press, Cambridge, UK.

Ferraz-Grande F.G.A. \& Takaki M. (2001) Temperature dependent seed germination of Dalbergia nigra Allem (Leguminosae). Brazilian Archives of Biology and Technology, 44, 401-404.

Franco A.C. (2002) Ecophysiology of woody plants. In: Oliveira P.S. \& Marquis R.J. (Eds), The Cerrados of Brazil: Ecology and Natural History of a Neotropical Savanna. Columbia University Press, New York, USA: 178-197. 
Furley P.A. (1999) The nature and diversity of neotropical savanna vegetation with particular reference to the Brazilian cerrados. Global Ecology and Biogeography, 8, 223-241.

Furley P.A. \& Ratter J.A. (1988) Soil resource and plant communities of the Central Brazil cerrado and their development. Journal of Biogeography, 15, 97-108.

Furley P.A. \& Ratter J.A (1990) Pedological and botanical variations across the forestsavanna transition on Maracá Island. Geographical Journal, 156, 251-266.

Galloway L.F. (2005) Maternal effects provide phenotypic adaptation to local environmental conditions. New Phytologist, 166, 93-100.

Garcia Q.S., Jacobi C.M. \& Ribeiro B.A. (2007) Resposta germinativa de duas espécies de Vellozia (Velloziaceae) dos campos rupestres de Minas Gerais, Brasil. Acta Botanica Brasilica, 21, 451-456.

García-Nuñes C., Azocar A. \& Silva J.F. (2001) Seed production and soil seed bank in the evergreen woody species from a neotropical savanna. Journal of Tropical Ecology, 17, $563-576$.

Garwood N.C. (1983) Seed germination in a seasonal tropical forest in Panama: a community study. Ecological Monographs, 53, 159-181.

Gashaw M. \& Michelsen A. (2002) Influence of heat shock on seed germination of plants from regularly burnt savanna woodlands and grasslands in Ethiopia. Plant Ecology, 159, 83-93.

Goldstein G., Meinzer F.C., Bucci S., Scholz F.G., Franco A.C. \& Hoffmann W.A. (2008) Water economy of Neotropical savanna tress: Six paradigms revisited. Tree Physiology, 28, 395-404.

Gomes J.B.V., Curi N., Motta P.E.F., Ker J.C., Marques J.J.G.S. \& Schulze D.G. (2004) Análise de componentes principais de atributos físicos, químicos e mineralógicos de solos do bioma Cerrado. Revista Brasileira de Ciência do Solo, 28, 137-153. 
Gómez J.M. (2004) Bigger is not always better: conflicting selective pressures on seed size in Quercus ilex. Evolution, 58, 71-80.

Gottsberger G. \& Silberbauer-Gottsberger I. (2006) Life in the cerrado: a South American Tropical seasonal ecosystem, Vol 1: Origin, structure, dynamics and plant use. Reta Verlag, Ulm, Germany.

Greene D.F. \& Johnson E.A. (1993) Seed mass and dispersal capacity in wind-dispersed diaspores. Oikos, 67, 69-74.

Groisman P.Y., Knight R.W., Easterling D.R., Karl T.R., Hegerl G.C. \& Razuvaev V.N. (2005) Trends in intense precipitation in the climate record. Journal of Climate, 18, $1326-1350$.

Guo H., Mazer S.J. \& Du G. (2010) Geographic variation in seed mass within and among nine species of Pedicularis (Orobanchaceae): effects of elevation, plant size and seed number per fruit. Journal of Ecology, 98, 1232-1242.

Hanley M.E. \& Lamont B.B. (2000) Heat pre-treatment and the germination of soil and canopy-stored seeds of south-western Australian species. Acta Oecologica, 21, 315-321.

Hanley M.E., Unna J.E. \& Darvill B. (2003) Seed size and germination response: a relationship for fire-following plant species exposed to thermal shock. Oecologia, 134, $18-22$.

Hardegree S.P. \& Emmerich W.E. (1994) Seed germination in response to polyetilene glycol solution. Seed Science and Technology, 22, 1-7.

Hedhly A., Hormaza J.I. \& Herrero M. (2009) Global warming and sexual plant reproduction. Trends in Plant Science, 14, 30-36.

Henery M.L. \& Westoby M. (2001) Seed mass and seed nutrient content as predictors of seed output variation between species. Oikos, 92, 479-490. 
Henriques R.P.B. (2005) Influência da história, solo e fogo na distribuição e dinâmica das fitofisionomias no bioma do Cerrado. In: Scariot A., Souza-Silva J.C. \& Felfili J.M. (Orgs), Cerrado: ecologia, biodiversidade e conservação. Ministério do Meio Ambiente, Brasília, Brasil: 73-92.

Herranz J.M., Ferrandis P. \& Martínez-Sanchéz J.J. (1998) Influence of heat on seed germination of seven Mediterranean Leguminosae species. Plant Ecology, 136, 95-103.

Hewitt G.M. (2004) Genetic consequences of climatic oscillations in the Quaternary, Philosophical Transactions of the Royal Society London B, 359, 183-195.

Hill J.P., Edwards W. \& Franks P.J. (2012) Size is not everything for desiccation-sensitive seeds. Journal of Ecology, 100, 1131-1140.

Hirota M., Holmgren M., Van Nes E.H. \& Scheffer M. (2011) Global resilience of tropical forest and savanna to critical transitions. Science, 334, 232-235.

Hoffmann W.A. (1998) Post-burn reproduction of woody plants in a neotropical savanna: the relative importance of sexual and vegetative reproduction. Journal of Applied Ecology, 35, 422-433.

Hoffmann W.A. (2000) Post-establishment seedling success in the Brazilian Cerrado: a comparison of savanna and forest species. Biotropica, 32, 62-69.

Hoffmann W.A. \& Jackson R.B. (2000) Vegetation-climate feedbacks in the conversion of tropical savanna to grassland. Journal of Climate, 13, 1593-1601.

Hoffmann W.A. \& Franco A.C. (2003) Comparative growth analysis of tropical forest and savanna woody plants using phylogenetically independent contrasts. Journal of Ecology, 91, 475-484.

Hoffmann W.A., Orthen B. \& Nascimento P.K.V. (2003). Comparative fire ecology of tropical savanna and forest trees. Functional Ecology, 17, 720-726. 
Hoffmann W.A., Orthen B. \& Franco A.C. (2004) Constraints to seedling success of savanna and forest trees across the savanna-forest boundary. Oecologia, 140, 252-260.

Hoffmann W.A. \& Franco A.C. (2008) The importance of evolutionary history in studies of plant physiological ecology: examples from cerrados and forests of central Brazil. Brazilian Journal of Plant Physiology, 20, 247-256.

Hoffmann W.A., Adasme R., Haridasan M., Carvalho M.T., Geiger E., Pereira M.A.B., Gotsch S.G \& Franco A.C. (2009) Tree topkill, not mortality, governs the dynamics of alternate stable states at savanna-forest boundaries under frequent fire in central Brazil. Ecology, 90, 1326-1337.

Hoffmann W.A., Jaconis S.Y., McKinley K.L., Geiger E.L., Gotsch S.G. \& Franco A.C. (2012) Fuels or microclimate? Understanding the drivers of fire feedbacks at savannaforest boundaries. Austral Ecology, 37, 634-643.

Hong T.D. \& Ellis R.H. (1996) A protocol to determinate seed storage behaviour. IPGRI, Rome, Italy.

Hufford K.M. \& Mazer S.J. (2003) Plant ecotypes: genetic differentiation in the age of ecological restoration. Trends in Ecology and Evolution, 18, 147-155.

Ikeda F.S., Mitja D., Vilela L. \& Sousa-Silva J.C. (2008) Banco de sementes em cerrado sensu stricto sob queimada e sistemas de cultivo. Pesquisa Agropecuária Brasileira, 43, $667-673$.

INMET (2013) Normais climatológicas do Brasil: 1961-1990. Disponível em: http://www.inmet.gov.br/portal/index.php?r=clima/normaisClimatologicas. Acesso em: 25 setembro, 2013.

INMET (2014) Estações convencionais - gráficos. Disponível em: http://www.inmet.gov.br/portal/index.php?r=home/page\&page=rede_estacoes_conv_graf . Acesso em: 20 outubro, 2014. 
IPCC (2013) Climate Change 2013: The Physical Science Basis. IPCC, Switzerland.

ISTA (2003) International Rules for Seed testing - Working Sheets on Tetrazolium Testing. ISTA, Zurich, Switzerland.

Jacquemyn H., Brys R. \& Hermy M. (2001) Within and between plant variation in seed number, seed mass and germinability of Primula elatior: effect of population size. Plant Biology, 3, 561-568.

Jakobsson A. \& Eriksson O. (2000) A comparative study of seed number, seed size, seedling size and recruitment in grassland plants. Oikos, 88, 494-502.

Jeltsch F., Weber G.E. \& Grimm V. (2000) Ecological buffering mechanisms in savannas: a unifying theory of long-term tree-grass coexistence. Plant Ecology, 161, 161-171.

Jurado E. \& Westoby M. (1992) Germination biology of selected central Australian plants. Australian Journal of Ecology, 17, 341-348.

Kauffman J.B., Cummings D.L. \& Ward D.E. (1994) Relationships of fire, biomass and nutrient dynamics along a vegetation gradient in the Brazilian Cerrado. Journal of Ecology, 82, 519-531.

Keeley J.E. \& Fotheringham C.J. (2000) Role of fire in regeneration from seed. In: Fenner M. (Ed), Seeds: The Ecology of Regeneration in Plant Communities, 2nd edn. CABI Publishing, Wallingford, UK: 311-331.

Keeley J.E., Pausas J.G., Rundel P.W., Bond W.J. \& Bradstock R.A. (2011) Fire as an evolutionary pressure shaping plant traits. Trends in Plant Science, 8, 406-411.

Kenny B.J. (2000) Influence of multiple fire-related germination cues on three Sydney Grevillea (Proteaceae) species. Austral Ecology, 25, 664-669.

Khurana E. \& Singh J.S. (2001) Ecology of seed and seedling growth for conservation and restoration of tropical dry forest: a review. Environmental Conservation, 28, 39-52. 
Khurana E. \& Singh J.S. (2004) Germination and seedling growth of five tree species from tropical dry forest in relation to water stress: impact of seed size. Journal of Tropical Ecology, 20, 385-396.

Köchy M. \& Tielbörger K. (2007) Hydrothermal time model of germination: parameters for 36 Mediterranean annual species based on a simplified approach. Basic and Applied Ecology, 8, 171-182.

Kos M. \& Poschlod P. (2008) Correlates of inter-specific variation in germination response to water stress in a semi-arid savannah. Basic and Applied Ecology, 9, 645-652.

Kos M. \& Poschlod P. (2010) Why wait? Trait and habitat correlates of variation in germination speed among Kalahari annuals. Oecologia, 162, 549-559.

Labouriau L.G. (1983) A germinação das sementes. Secretaria Geral da Organização dos Estados Americanos, Washington, USA.

Lahoreau G., Barot S., Gignoux J., Hoffmann W.A., Setterfield S.A. \& Williams P.R. (2006) Positive effect of seed size on seedling survival in fire-prone savannas of Australia, Brazil and West Africa. Journal of Tropical Ecology, 22, 719-722.

Ledru M.P. (2002) Late Quaternary history and evolution of the cerradões as revealed by palynologycal records. In: Oliveira P.S. \& Marquis R.J. (Eds), The Cerrados of Brazil: Ecology and Natural History of a Neotropical Savanna. Columbia University Press, New York, USA: $33-50$.

Leishman M.R. \& Westoby M. (1994) The role of large seeds in seedling establishment in dry soil conditions - experimental evidence for semi-arid species. Journal of Ecology, 82, 249-258.

Leishman M.R., Wright I.J., Moles A.T. \& Westoby M. (2000) The evolutionary ecology of seed size. In: Fenner M. (Ed), Seeds: The Ecology of Regeneration in Plant Communities, 2nd edn. CABI Publishing, Wallingford, UK: 31-57. 
Leishman M.R. (2001) Does the seed size / number trade-off model determine plant community structure? An assessment of the model mechanisms and their generality. Oikos, 93, 294-302.

Lemos-Filho J.P., Figueiredo M. \& Goulart M.B.L. (2008) Populational approach in ecophysiological studies: the case of Plathymenia reticulata, a tree from Cerrado and Atlantic Forest. Brazilian Journal of Plant Physiology, 20, 205-216.

Lenza E. \& Klink C.A. (2006) Comportamento fenológico de espécies lenhosas em um cerrado sentido restrito de Brasília, DF. Revista Brasileira de Botânica, 29, 627-638.

Libano A.M. \& Felfili J.M. (2006) Mudanças temporais na composição florística e na diversidade de um cerrado sensu stricto do Brasil Central em um período de 18 anos (1985-2003). Acta Botanica Brasilica, 20, 927-936.

Lima C.M.R., Borghetti F. \& Sousa M.V. (1997) Temperature and germination of the Leguminosae Enterolobium contortisiliquum. Revista Brasileira de Fisiologia Vegetal, 9, 97-102.

Lima V.V.F., Vieira D.L.M., Sevilha A.C. \& Salomão A.N. (2008) Germinação de espécies arbóreas de floresta estacional decidual do vale do rio Paraná em Goiás após três tipos de armazenamento por até 15 meses. Biota Neotropica, 8, 89-97.

Linhart Y.B. \& Grant M.C. (1996) Evolutionary significance of local genetic differentiation in plants. Annual Review of Ecology and Systematics, 27, 237-277.

Little J.K., Prior L.D., Williamson G.J., Williams S.E. \& Bowman D.M.J.S. (2012) Fire weather risk differs across rain forest-savanna boundaries in the humid tropics of northeastern Australia. Austral Ecology, 37, 915-925.

Lönnberg K. \& Eriksson O. (2012) Seed size and recruitment patterns in a gradient from grassland to forest. Ecoscience, 19, 140-147. 
Lortie C.J. \& Aarssen L.W. (1996) The specialization hypothesis for phenotypic plasticity in plants. International Journal of Plant Science, 157, 484-487.

Lüttge U. \& Scarano F.R. (2004) Ecophysiology. Revista Brasileira de Botânica, 27, 1-10.

Marod D., Kutintara U., Tanaka H. \& Nakashikuza T. (2002) The effects of drought and fire on seed and seedling dynamics in a tropical seasonal Forest in Thailand. Plant Ecology, $161,41-57$.

Marthews T.R., Burslem D.F.R.P, Paton S.R., Yangüez F. \& Mullins C.E. (2008) Soil drying in a tropical forest: three distinct environments controlled by gap size. Ecological Modelling, 216, 369-384.

Melo M.C. \& Barbosa R.I. (2007) Árvores e arbustos das savanas de Roraima - Guia de Campo Ilustrado. Prefeitura Municipal de Boa Vista / Conselho Municipal de Conservação e Defesa do Meio Ambiente, Boa Vista, Brasil.

Miranda A.C., Miranda H.S., Dias I.F.O. \& Dias B.F.S. (1993) Soil and air temperatures during prescribed Cerrado fires in Central Brazil. Journal of Tropical Ecology, 9, 313320.

Miranda H.S., Bustamante M.M.C. \& Miranda A.C. (2002) The fire factor. In: Olivera P.S. \& Marquis R.J. (Eds), The cerrados of Brazil: Ecology and Natural History of a Neotropical Savanna. Columbia University Press, New York, USA: 51-68.

Miranda H.S., Sato M.N., Neto W.N. \& Aires F.S. (2009) Fires in the cerrado, the Brazilian savanna. In: Cochrane M.A. (Ed), Tropical fire ecology: climate change, land use, and ecosystem dynamics. Springer, Berlin, Germany: 427-450.

Miranda I.S. \& Absy M.L. (1997) Flora fanerogâmica das savanas de Roraima. In: Barbosa R.I., Ferreira E.J.G \& E. Castellón (Eds), Homem, Ambiente e Ecologia no Estado de Roraima. INPA, Manaus, Brasil: 445-462. 
Moles A.T. \& Westoby M. (2003) Latitude, seed predation and seed mass. Journal of Biogeography, 30, 105-128.

Moles A.T. \& Westoby M. (2004) What do seedlings die from, and what are the implications for evolution of seed size? Oikos, 106, 193-199.

Moles A.T., Ackerly D.D., Webb C.O., Tweddle J.C., Dickie J.B. \& Westoby M. (2005) A brief history of seed size. Science, $\mathbf{3 0 7}, 576-580$.

Moles A.T., Ackerly D.D., Tweddle J.C. et al. (2007) Global patterns in seed size. Global Ecology and Biogeography, 16, 109-116.

Moles A.T., Perkins S.E., Laffan S.W. et al. (2014) Which is a better predictor of plant traits: temperature or precipitation? Journal of Vegetation Science, 25, 1167-1180.

Moore R.P. (1973) Tetrazolium staining for assessing seed quality. In: Heydecker W. (Ed), Seed Ecology. Butterworths, London, UK: 347-366.

Moreira A.G. (2000) Effects of fire protection on savanna structure in Central Brazil. Journal of Biogeography, 27, 1021-1029.

Muller-Landau H.C. (2010) The tolerance-fecundity trade-off and the maintenance of diversity in seed size. Proceedings of the National Academy of Sciences of the USA, 107, 4242-4247.

Murray B.R., Brown A.H.D., Dickman C.R. \& Crowther M.S. (2004) Geographical gradients in seed mass in relation to climate. Journal of Biogeography, 31, 379-388.

Nardoto G.B., Souza M.P. \& Franco A.C. (1998) Estabelecimento e padrões sazonais de produtividade de Kielmeyera coriacea (Spr) Mart. nos cerrados do Planalto Central: efeitos do estresse hídrico e sombreamento. Revista Brasileira de Botânica, 98, 313-319.

Neves B.M.C. \& Miranda H.S. (1996) Efeitos do fogo no regime térmico do solo de um campo sujo de Cerrado. In: Miranda H.S., Saito C.H. \& Dias B.F.S. (Orgs), Impactos de 
Queimadas em Áreas de Cerrado e Restinga. Universidade de Brasília, Brasília, Brasil: $20-30$.

Newton R.J., Bond W.J. \& Farrant J.M. (2006) Effects of seed storage and fire on germination in the nut-fruited Restionaceae species, Cannomois virgate. South African Journal of Botany, 72, 177-180.

Nicotra A.B., Atkin O.K., Bonser S.P. et al. (2010). Plant phenotypic plasticity in a changing climate. Trends in Plant Science, 15, 684-692.

Oliveira-Filho A.T. \& Ratter J.A. (2002) Vegetation physiognomies and woody flora of the Cerrado Biome. In: Oliveira P.S. \& Marquis R.J. (Eds), The Cerrados of Brazil: Ecology and Natural History of a Neotropical Savanna. Columbia University Press, New York, USA: $121-140$.

Ooi M.K., Auld T.D. \& Denham A.J. (2009) Climate change and bet-hedging: interactions between increased soil temperatures and seed bank persistence. Global Change Biology, 15, 2375-2386.

Pammenter N.W. \& Berjak P. (2000a) Aspects of recalcitrant seed physiology. Revista Brasileira de Fisiologia Vegetal, 12, 56-69.

Pammenter N.W. \& Berjak P. (2000b) Evolutionary and ecological aspects of recalcitrant seed biology. Seed Science Research, 10, 301-306.

Paz H., Mazer S.J. \& Martínez-Ramos M. (1999) Effects of seed mass and environmental factors on seedling emergence in seven species of Psychotria (Rubiaceae). Ecology, 80, $1594-1606$.

Paz H. \& Martínez-Ramos M. (2003) Seed mass and seedling performance within eight species of Psychotria (Rubiaceae). Ecology, 84, 439-450.

Peel M.C., Finlayson B.L. \& McMahon T.A. (2007) Updated world map of the KöppenGeiger climate classification. Hydrology and Earth System Science, 11, 1633-1644. 
Pérez-Harguindeguy N., Díaz S., Garnier E. et al. (2013) New handbook for standardised measurement of plant functional traits worldwide. Australian Journal of Botany, 61, 167234.

Pinheiro M.H.O. \& Monteiro R. (2010) Contribution to the discussions on the origin of the cerrado biome: Brazilian savanna. Brazilian Journal of Biology, 70, 95-102.

Pivello V.R. (2011) The use of fire in the Cerrado and Amazonian rainforests of Brazil: past and present. Fire Ecology, 7, 24-39.

Pritchard H.W. (2004) Classification of seed storage 'types' for ex situ conservation in relation to temperature and moisture. In: Guerrant Jr E.O., Havens K. \& Maunder M. (Eds), Ex situ plant conservation: supporting species survival in the wild. Island Press, Washington D.C., USA: 139-161.

Pritchard H.W., Daws M.I., Fletcher B.J., Gaméné C.S., Msanga H.P. \& Omondi W. (2004) Ecological correlates of seed desiccation tolerance in tropical African dryland trees. American Journal of Botany, 91, 863-870.

Probert R.J. (2000) The role of temperature in the regulation of seed dormancy and germination. In: Fenner M. (Ed), Seeds: The Ecology of Regeneration in Plant Communities, 2nd edn. CABI Publishing, Wallingford, UK: 261-292.

Punyasena S.W. (2008) Estimating Neotropical palaeotemperature and palaeoprecipitation using plant family climatic optima. Palaeogeography, Palaeoclimatology, Palaeoecology, 265, 226-237.

Ramos-Neto M.B. \& Pivello V.R. (2000) Lightning fires in a Brazilian savanna national park: rethinking management strategies. Environmental Management, 26, 675-684.

Ratter J.A., Bridgewater S. \& Ribeiro J.F. (2003) Analysis of Floristic composition of the Brazilian cerrado begetation III: comparison of the woody vegetation of 376 areas. Edinburgh Journal of Botany, 60, 57-109. 
Rees M. \& Westoby M. (1997) Game-theoretical evolution of seed mass in multi-species ecological models. Oikos, 78, 116-126.

Rees M. \& Venable D.L. (2007) Why do big plants make big seeds? Journal of Ecology, 95, 926-936.

Reich P.B., Wright I.J., Cavender-Bares J., Craine J.M., Oleksyn J., Westoby M. \& Walters M.B. (2003) The evolution of plant functional variation: traits, spectra, and strategies. International Journal of Plant Science, 164, S143-S164.

Reyes O. \& Trabaud L. (2009) Germination behavior of 14 Mediterranean species in relation to fire factors: smoke and heat. Plant Ecology, 202, 113-121.

Rezende A.V., Walter B.M.T., Fagg C.W. et al. (2008) Fanerógamas do Bioma Cerrado. In: Sano S.M., Almeida S.P., Ribeiro J.F. (Eds), Cerrado: Ecologia e Flora, Vol. 2. Embrapa Informação Tecnológica, Brasília, Brasil: 443-1181.

Ribeiro J.F. \& Walter B.M.T. (2008) As principais fitofisionomias do bioma Cerrado. In: Sano S.M., Almeida S.P., Ribeiro J.F. (Eds), Cerrado: Ecologia e Flora, Vol. 1. Embrapa Informação Tecnológica, Brasília, Brasil: 151-212.

Ribeiro L.C., Pedrosa M. \& Borghetti F. (2013) Heat shock effects on seed germination of five Brazilian savanna species. Plant Biology, 15, 152-157.

Ribeiro L.C. \& Borghetti F. (2014) Comparative effects of desiccation, heat shock and high temperatures on seed germination of savanna and forest tree species. Austral Ecology, 39, $267-278$.

Ruggiero P.G.C., Batalha M.A., Pivello V.R. \& Meirelles S.T. (2002) Soil-vegetation relationships in cerrado (Brazilian savanna) and semideciduous forest, Southeastern Brazil. Plant Ecology, 160, 1-16.

Salazar A. (2010) Seed dynamics and seedling establishment of woody species in the tropical savannas of Central Brazil (cerrado). PhD thesis, University of Miami, Florida, USA. 
Salazar A., Goldstein G., Franco A.C. \& Miralles-Wilhelm F. (2011) Timing of seed dispersal and dormancy, rather than persistent soil seed-banks, control seedling recruitment of woody plants in Neotropical savannas. Seed Science Research, 21, 103116.

Salgado-Labouriau M.L. (1997) Late Quaternary paleoclimate in the savannas of South America. Journal of Quaternary Science, 12, 371-379.

Salgado-Labouriau M.L., Barberi M., Ferraz-Vicentini K.R. \& Parizzi M.G. (1998) A dry climatic event during the late Quaternary of tropical Brazil. Review of Paleobotany and Palynology, 99, 115-129.

Salomão A.N., Sousa-Silva J.C., Davide A.C., Gonzáles S., Torres R.A.A., Wetzel M.M.V.S., Firetti F. \& Caldas L.S. (2003) Germinação de sementes e produção de mudas de plantas do cerrado. Rede de Sementes do Cerrado, Brasília, Brasil.

Sarmiento G. (1992) A conceptual model relating environmental factors and vegetation formations in the lowlands of tropical South America. In: Furley P.A., Proctor J. \& Ratter J.A. (Eds), Nature and dynamics of forest-savanna boundaries. Chapman and Hall, London, UK: 583-603.

Schmidt I.B., Sampaio A.B. \& Borghetti F. (2005) Efeitos da época de queima sobre a reprodução sexuada e estrutura populacional de Heteropterys pteropetala (Adr. Juss.), Malpighiaceae, em áreas de Cerrado sensu stricto submetidas a queimas bienais. Acta Botanica Brasilica, 19, 927-934.

Scholes R.J. \& Archer S.R. (1997) Tree-grass interactions in savannas. Annual Review of Ecology and Systematics, 28, 517-544.

Schütz W., Milberg P. \& Lamont B.B. (2002) Germination requirements and seedling responses to water availability and soil type in four eucalypt species. Acta Oecologica, 23, 23-30. 
Scott K., Setterfield S., Douglas M. \& Andersen A. (2010) Soil seed banks confer resilience to savanna grass-layer plants during seasonal disturbance. Acta Oecologica, 36, 202-210.

Silva L.M.M., Aguiar I.B. \& Rodrigues T.J.D. (2001) Seed germination of Bowdichia virgilioides Kunth, under water stress. Revista Brasileira de Engenharia Agrícola e Ambiental, 5, 115-118.

Silva-Junior M.C. (2005) 100 árvores do cerrado - guia de campo, $1^{\text {a }}$ edição. Rede de Sementes do Cerrado, Brasília, Brasil.

Socolowski F. \& Takaki M. (2004) Germination of Jacaranda mimosifolia (D. Don Bignoniaceae) seeds: effects of light, temperature and water stress. Brazilian Archives of Biology and Technology, 47, 785-792.

Stark K.E., Arsenault A. \& Bradfield G.E. (2008) Variation in soil seed bank species composition of a dry coniferous forest: spatial scale and sampling considerations. Plant Ecology, 197, 173-181.

Staver A.C., Archibald S. \& Levin S.A. (2011a) The global extent and determinants of savanna and forest as alternative biome states. Science, 334, 230-232.

Staver, A.C., Archibald, S. \& Levin, S.A. (2011b) Tree cover in sub-Saharan Africa: rainfall and fire constrain forest and savanna as alternative stable states. Ecology, 92, 1063-1072.

Sy A., Grouzis M. \& Danthu P. (2001) Seed germination of seven Sahelian legume species. Journal of Arid Environments, 49, 875-882.

Tambelini M. \& Perez S.C.J.G.A. (1999) Temperature limits on germination of Stryphnodendron polyphyllum Mart. Journal of Tropical Forestry Science, 11, 630-636.

Teketay D. (1998) Germination of Acacia origena, A. pilispina and Pterolobium stellatum in response to different pre-sowing seed treatments, temperature and light. Journal of Arid Environments, 38, 551-560. 
Toledo M.B. \& Bush M.B. (2007) A mid-Holocene environmental change in Amazonian savannas. Journal of Biogeography, 34, 1313-1326.

Tweddle J.C., Dickie J.B., Baskin C.C. \& Baskin J.M. (2003) Ecological aspects of seed desiccation sensitivity. Journal of Ecology, 91, 294-304.

Venable D.L. \& Brown J.S. (1988) The selective interactions of dispersal, dormancy, and seed size as adaptations for reducing risk in variable environments. American Naturalist, $131,360-384$.

Venable D.L. (2007) Bet hedging in a guild of annual deserts. Ecology, 88, 1086-1090.

Verslues P.E., Agarwal M., Katiyar-Agarwal S., Zhu J. \& Zhu J.K. (2006) Methods and concepts in quantifying resistance to drought, salt and freezing, abiotic stress that affect plant water status. The Plant Journal, 45, 523-539.

Villela F.A., Doni-Filho L. \& Siqueira E.L. (1991) Tabela de potencial osmótico em função da concentração de polietilenoglicol 6000 e da temperatura. Pesquisa Agropecuária Brasileira, 26, 1957-1968.

Walck J.L., Hidayati S.N., Dixon K.W., Thompson K. \& Poschlod P. (2011) Climate change and plant regeneration from seed. Global Change Biology, 17, 2145-2161.

Walter H. \& Breckle S.W. (2002) Walter's Vegetation of the earth: the ecological systems of the geo-biosphere. Springer-Berlin, New York, USA.

Werneck F.P., Nogueira C., Colli G.R., Sites J.W. \& Costa G.C. (2012) Climatic stability in the Brazilian Cerrado: implications for biogeographical connections of South American savannas, species richness and conservation in a biodiversity hotspot. Journal of Biogeography, 39, 1695-1706.

Westoby M., Jurado E. \& Leishman M. (1992) Comparative evolutionary ecology of seed size. Trends in Ecology and Evolution, 7, 368-372. 
Westoby M., Falster D.S., Moles A.T., Vesk P.A. \& Wright I.J. (2002) Plant ecological strategies: some leading dimensions of variation between species. Annual Review of Ecology and Systematics, 33, 125-159.

Whelan R.J. (1995) The Ecology of Fire. Cambridge University Press, Cambridge, UK.

Whelan R.J., Rogers R.W., Dickman C.R. \& Sutherland E.F. (2002) Critical life cycles of plants and animals: developing a process-based understanding of population changes in fireprone landscapes. In: Bradstock R.A., Williams J. \& Gill A.M. (Eds), Flammable Australia: the Fire Regimes and Biodiversity of a Continent. Cambridge University Press, Cambridge, UK: 94-124.

Wiegand K., Ward D. \& Saltz D. (2005) Multi-scale patterns and bush encroachment in an arid savanna with a shallow soil layer. Journal of Vegetation Science, 16, 311-320.

Williams P.R., Congdon R.A., Grice A.C. \& Clarke P.J. (2005) Germinable soil seed banks in a tropical savanna: seasonal dynamics and effects of fire. Austral Ecology, 30, 79-90.

Woodward F.I. (1987) Climate and plant distribution: Cambridge studies in ecology. Cambridge University Press, New York, USA.

Wulff R.D. (1995) Environmental maternal effects on seed quality and germination. In: Kigel J. \& Galili G. (Eds), Seed development and germination. Marcel Dekker, New York, USA: 491-505.

Zar J.H. (1999) Bioestatistical Analisys, $4^{\text {th }}$ edn. Prenctice-Hall, New Jersey, USA. 


\section{APÊNDICE}

\section{Apêndice - Tabelas de descrição de efeitos de variáveis sobre a germinação comparativa de sementes de espécies ocorrentes em savanas do Brasil Central e de Roraima}

Tabela A1. Efeitos do ambiente de origem da população (A), do conteúdo de água (C) e da massa da semente (M) sobre a resposta germinativa de sementes de pares conespecíficos dos cerrados de Roraima e do Brasil Central submetidas à dessecação. Os valores de significância estatística foram obtidos através do teste da razão de verossimilhança, em que os desvios com e sem cada termo do modelo foram comparados. O símbolo “ - " representa as variáveis não incluídas no modelo.

\begin{tabular}{ccccccccc}
\hline Espécie & \multicolumn{7}{c}{ Variáveis } \\
& A & $\mathbf{C}$ & $\mathbf{M}$ & $\mathbf{A} * \mathbf{C}$ & $\mathbf{A} * \mathbf{M}$ & $\mathbf{C A} * \mathbf{M}$ & $\mathbf{A} * \mathbf{C A} * \mathbf{M}$ \\
Bowdichia virgilioides & - & $<0,001$ & - & 0,001 & - & - & - \\
Curatella americana & - & 0,007 & - & - & - & - & - \\
Anadenanthera peregrina & 0,003 & 0,028 & - & - & - & - & - \\
\hline
\end{tabular}


Tabela A2. Efeitos do ambiente de origem da população (A), do potencial osmótico (P) e da massa da semente (M) sobre a resposta germinativa de sementes de pares conespecíficos dos cerrados de Roraima e do Brasil Central submetidas ao déficit hídrico. Os valores de significância estatística foram obtidos através do teste da razão de verossimilhança, em que os desvios com e sem cada termo do modelo foram comparados. O símbolo “ - " representa as variáveis não incluídas no modelo.

\begin{tabular}{cccccccc}
\hline Espécies & \multicolumn{7}{c}{ Variáveis } \\
& $\mathbf{A}$ & $\mathbf{P}$ & $\mathbf{M}$ & $\mathbf{A} * \mathbf{P}$ & $\mathbf{A} * \mathbf{M}$ & $\mathbf{P} * \mathbf{M}$ & $\mathbf{A} * \mathbf{P} * \mathbf{M}$ \\
Bowdichia virgilioides & - & $<0,001$ & - & - & - & - & - \\
Curatella americana & $<0,001$ & $<0,001$ & - & - & - & - & - \\
Anadenanthera peregrina & - & $<0,001$ & - & - & - & - & - \\
\hline
\end{tabular}


Tabela A3. Efeitos do ambiente de origem da população (A), da temperatura (Tp), do tempo de exposição (T) e da massa da semente (M) sobre a resposta germinativa de sementes de pares conespecíficos dos cerrados de Roraima e do Brasil Central submetidas a choques térmicos. Os valores de significância estatística foram obtidos através do teste da razão de verossimilhança, em que os desvios com e sem cada termo do modelo foram comparados. O símbolo “ - " representa as variáveis não incluídas no modelo.

Espécies

Variáveis

\begin{tabular}{|c|c|c|c|c|c|c|c|c|c|c|c|c|c|c|c|}
\hline & $\mathbf{A}$ & $\mathbf{T p}$ & $\mathbf{T}$ & $\mathbf{M}$ & $\mathbf{A} * \mathbf{T p}$ & $\mathbf{A} * \mathbf{T}$ & $\mathbf{A} * \mathbf{M}$ & $\mathbf{T} \mathbf{p}^{* \mathbf{T}}$ & Tp*M & $\mathbf{T} * \mathbf{M}$ & $\mathbf{A} * \mathbf{T} \mathbf{p} * \mathbf{T}$ & $\mathbf{A} * \mathbf{T p} * \mathbf{M}$ & $\mathbf{A} * \mathbf{T} * \mathbf{M}$ & $\mathbf{T p} * \mathbf{T} * \mathbf{M}$ & $\mathbf{A} * \mathbf{T} \mathbf{p} * \mathbf{T} * \mathbf{M}$ \\
\hline Bowdichia virgilioides & - & $<0,001$ & - & - & $<0,001$ & - & - & - & - & - & - & - & - & - & - \\
\hline Curatella americana & 0,005 & - & - & - & - & - & - & $<0,001$ & - & - & - & - & - & - & - \\
\hline Anadenanthera peregrina & - & 0,001 & 0,18 & - & $<0,001$ & 0,001 & - & 0,003 & - & - & $<0,001$ & - & - & - & - \\
\hline
\end{tabular}


Tabela A4. Efeitos do ambiente de origem da população (A), da temperatura (Tp) e da massa da semente (M) sobre a resposta germinativa, em temperaturas crescentes, de sementes de pares conespecíficos dos cerrados de Roraima e do Brasil Central. Os valores de significância estatística foram obtidos através do teste da razão de verossimilhança, em que os desvios com e sem cada termo do modelo foram comparados. O símbolo “- " representa as variáveis não incluídas no modelo.

\begin{tabular}{ccccccccc}
\hline Espécies & \multicolumn{7}{c}{ Variáveis } \\
\hline & $\mathbf{A}$ & $\mathbf{T p}$ & $\mathbf{M}$ & $\mathbf{A} * \mathbf{T p}$ & $\mathbf{A} * \mathbf{M}$ & $\mathbf{P} * \mathbf{M}$ & $\mathbf{A}^{* \mathbf{T} p * \mathbf{M}}$ \\
Bowdichia virgilioides & 0,001 & $<0,001$ & - & - & - & - & - \\
Curatella americana & 0,002 & $<0,001$ & - & - & - & - & - \\
A. falcatax A. peregrina & - & $<0,001$ & - & 0,001 & - & - & - \\
\hline
\end{tabular}

